\title{
NORTHWEST ATLANTIC FISHERIES ORGANIZATION
}

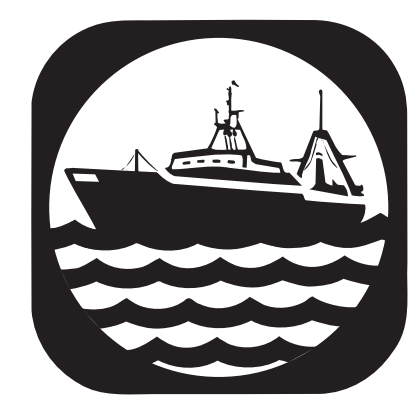

Scientific Council Studies

Number 45

NAFO Research Vessel Stock-by-Stock Surveys Summary 2000-2010 


\section{(c) creative \\ $\begin{array}{lllllllllll}C & O & M & M & O & N & S & D & E & E & D\end{array}$ \\ Attribution-NonCommercial 2.5 Canada}

You are free to copy and distribute the work and to make derivative works under the following conditions:

Attribution. You must attribute the work in the manner specified by the author or licensor.

Noncommercial. You may not use this work for commercial purposes.

Any of these conditions can be waived if you get permission from the copyright holder. Your fair dealing and other rights are in no way affected by the above.

http://creativecommons.org/licenses/by/2.5/ca/legalcode.en

ISSN-1682-9808

Northwest Atlantic Fisheries Organization

2 Morris Drive, Suite 100

Dartmouth, Nova Scotia, Canada B2B $1 \mathrm{~K} 8$

Tel.: (902) 468-5590 • Fax: (902) 468-5538

Email: info@nafo.int • Website: www.nafo.int 


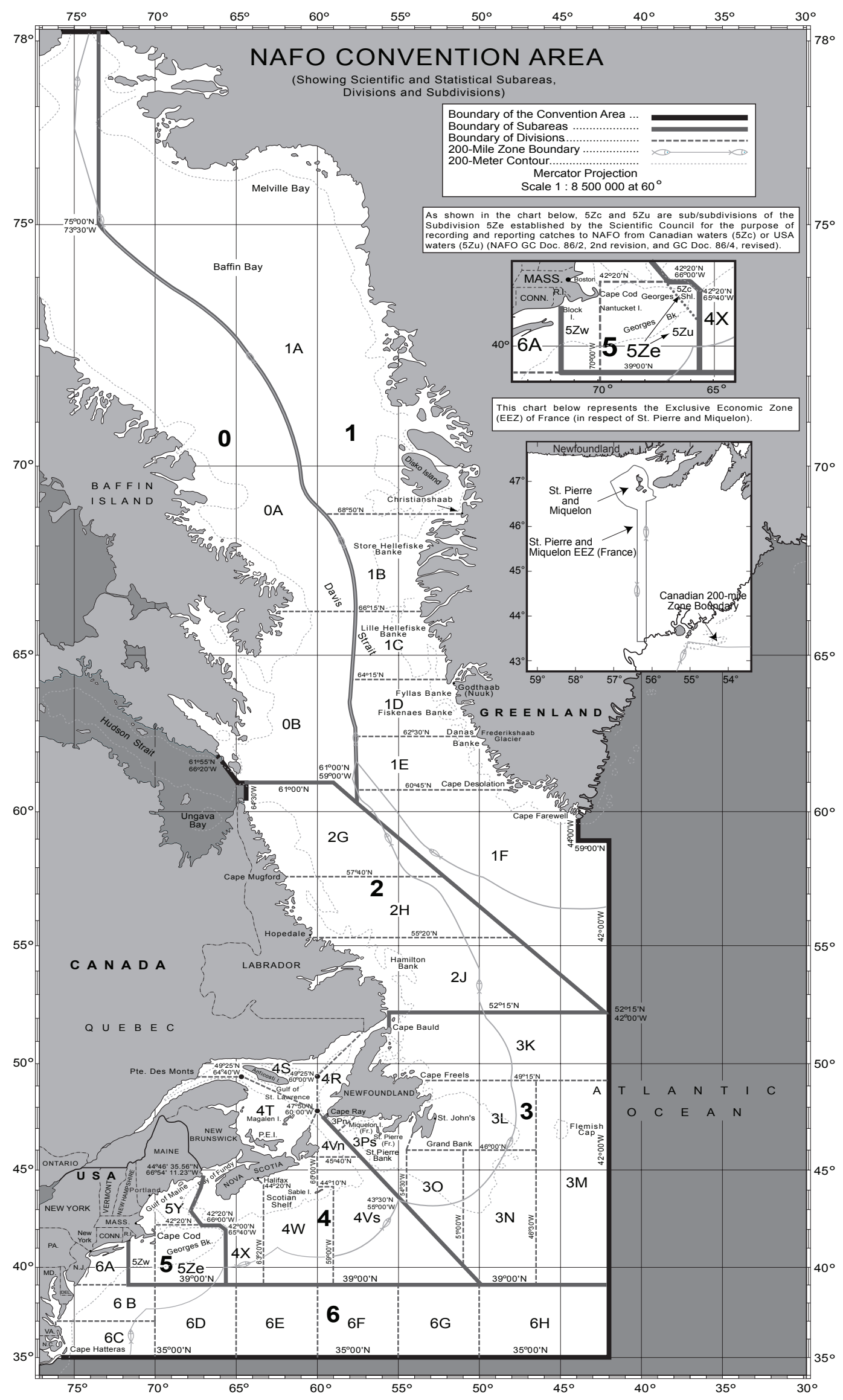





\title{
Stock-by-Stock Research Vessel Surveys Reported During 2001-2010
}

\author{
NAFO Secretariat
}

NAFO Secretariat. 2013. NAFO Research Vessel Stock-by-Stock Surveys Summary 2000-2010. Scientific Council Studies, 45: 1-91. doi:10.2960/S.v45.m1

\begin{abstract}
The Scientific Council at its meeting in June 1990 agreed to compile an inventory and information on research vessel surveys conducted with respect to stocks assessed by the Scientific Council (SCS Doc. 90/22). This inventory was judged to be a useful reference and very helpful for the establishment of other inventories. During its meeting in June 1991 the Council agreed that the Designated Experts for the stocks should update the information annually (NAFO Sci. Coun. Rep., 1991, p. 37) for review by STACFIS. Since 1991, the inventory has been compiled annually and presented to the Scientific Council in the form of Scientific Council Summary Documents. A collation of this information was published as part of the NAFO Scientific Council Studies series in 2001 (NAFO Sci. Coun. Studies, 34: 19-83).
\end{abstract}

A review of the annual inventories showed that there often were revisions and updates from one year to the next, and consequently readers of the SCS Document series may experience difficulties in interpreting the information. The Secretariat therefore took the initiative to compile a decadal publication. Noting this represented the best interpretation of the available information; Designated Experts responsible for stock assessments were requested to verify the accuracy of this compilation.

The following tabulations were compiled by the Secretariat in order to provide a comprehensive overview of surveys during the 2001-2010 decade used for stock assessments by the Scientific Council. Information supplied in the SCS Documents were collated and edited as needed, and the SCR Documents cited in them were checked and corrections made to the tables when necessary.

This paper is compiled in the format designed by the Scientific Council in 1990s. Stock-by-Stock tabulations are listed with the northernmost stock first and progressing southwards. The following is the sequence of presentation:

Greenland halibut in Subarea $0+$ Divisions $1 \mathrm{~B}-\mathrm{lF}$

Greenland halibut in Division 1A

Roundnose grenadier in Subareas 0 and 1

Northern shrimp in Subareas 0+1

Redfish in Subarea 1

Other Finfish in Subarea 1

Northern shrimp in ICES Subarea XIV (Denmark Strait)

Cod in Division 2J and 3KL

Greenland halibut in Divisions 2J and 3KLNMNO

Witch flounder in Divisions 2J and 3KL

Cod in Division 3M

Redfish in Division 3M

American plaice in Division 3M

Northern shrimp in Division 3M
Cod in Divisions $3 \mathrm{~N}$ and 30

Redfish in Divisions 3L and 3N

American plaice in Divisions 3LNO

Yellowtail flounder in Divisions 3LNO

Northern shrimp in Divisions 3LNO

Witch flounder in Divisions 3LNO

Capelin in Divisions 3NO

White hake in Divisions 3NOPs

Thorny skate in Divisions 3LNOPs

Redfish in Division 30

Elasmobranchs in Subareas 2-6

Roughhead grenadier in Subareas 2 and 3

Short-finned squid in Subareas 3 and 4

Short-finned squid in Subareas 5 and 6

References to pertinent documents are noted in the tables and a complete list of documents cited is listed at the end. 







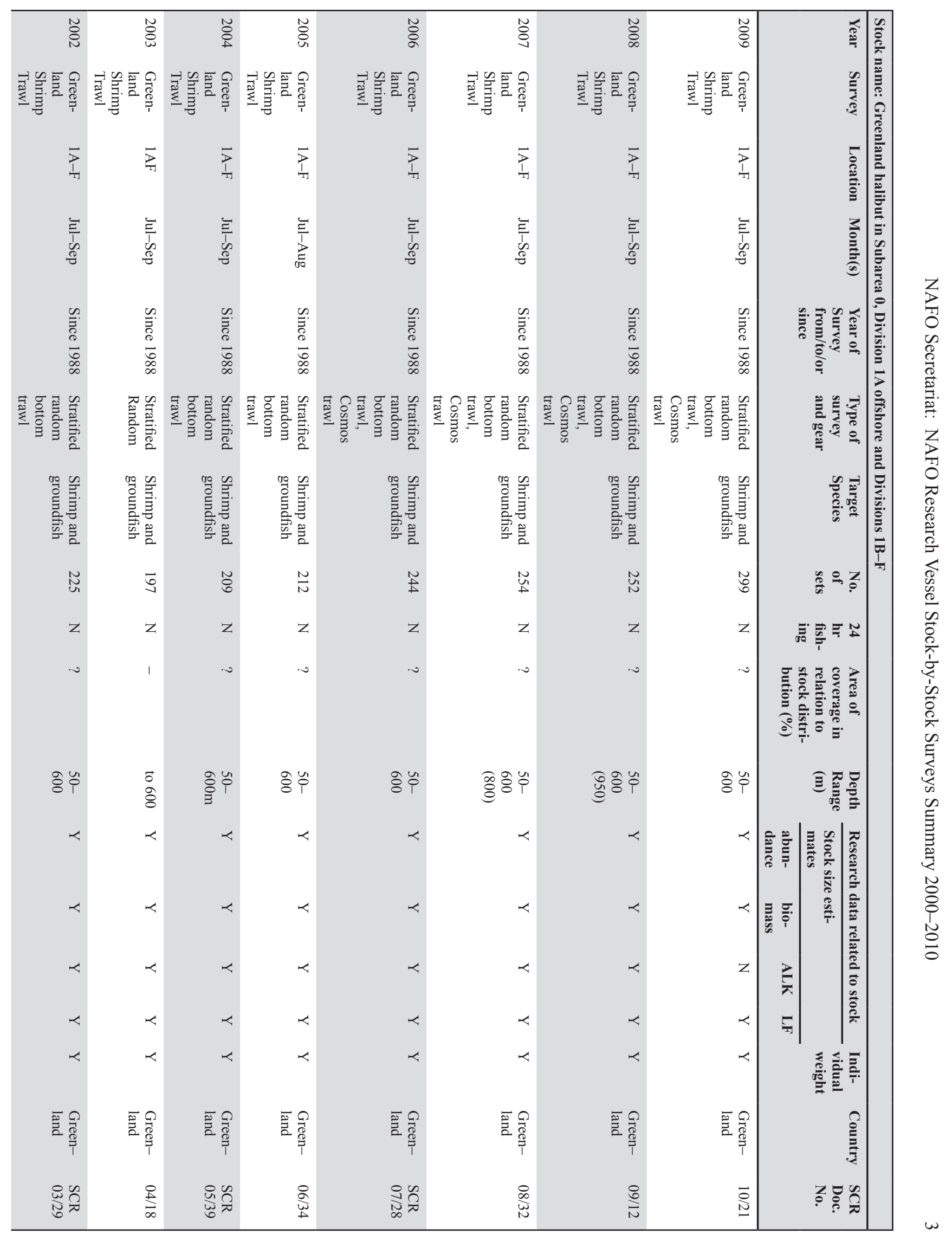




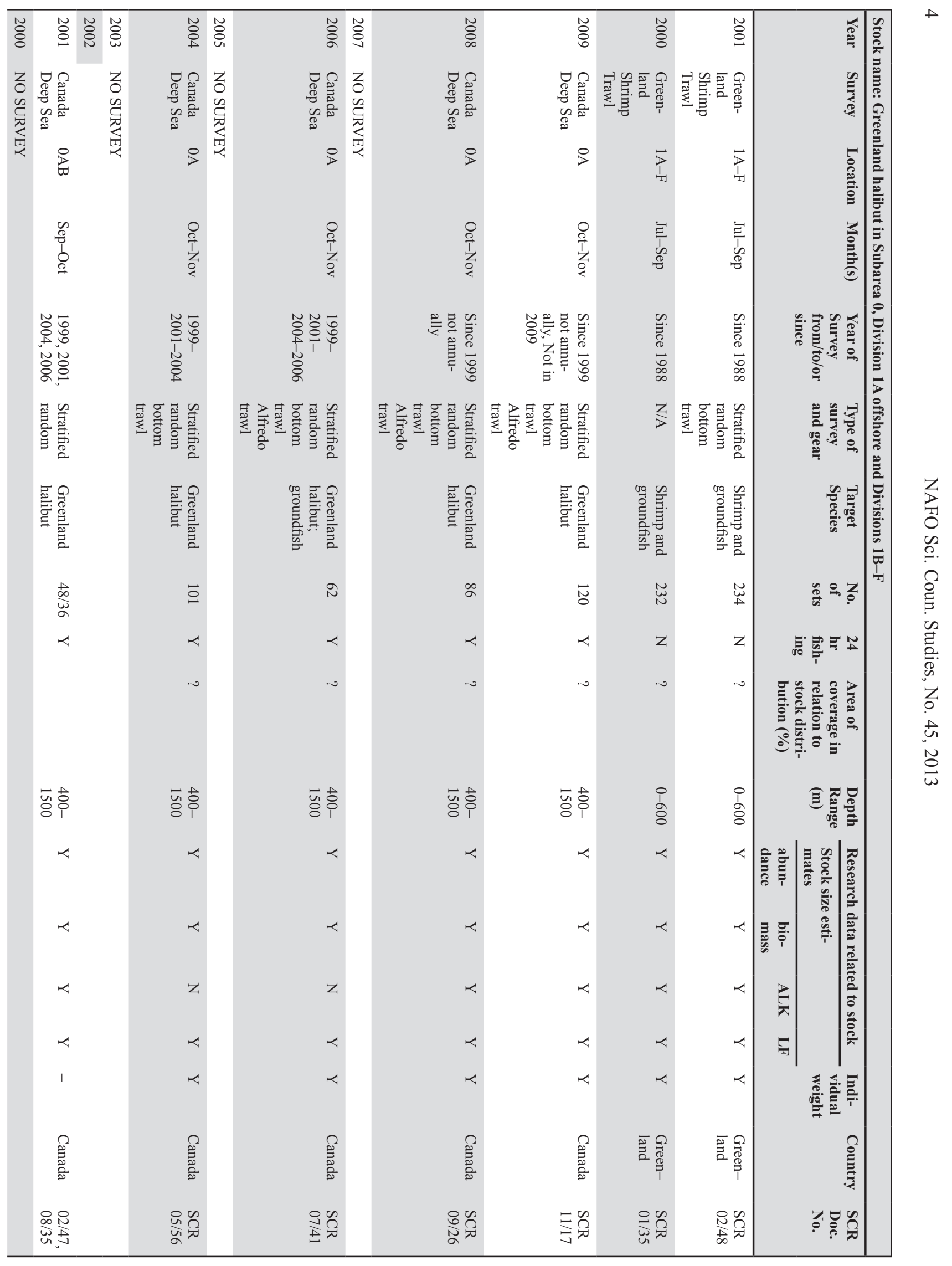




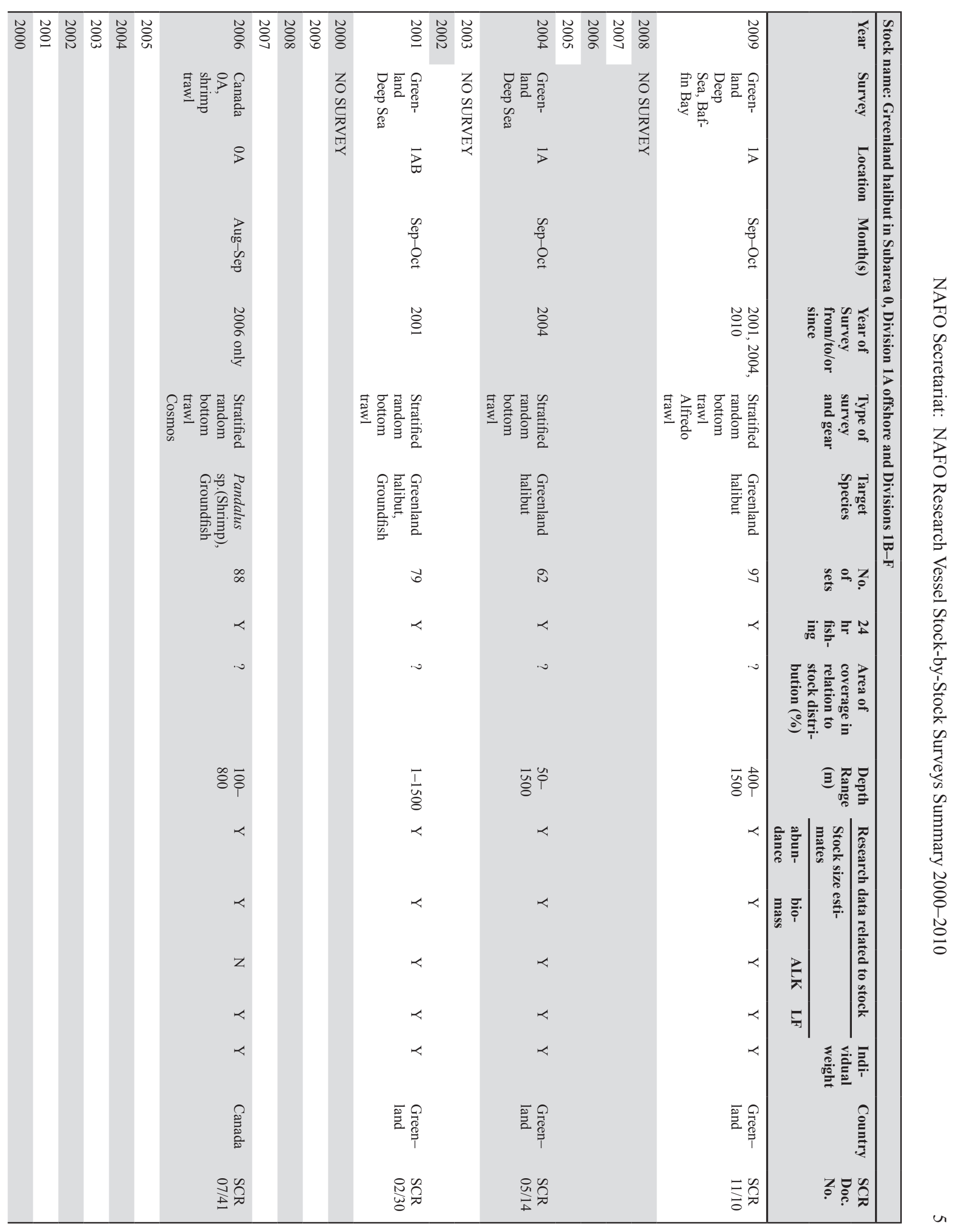




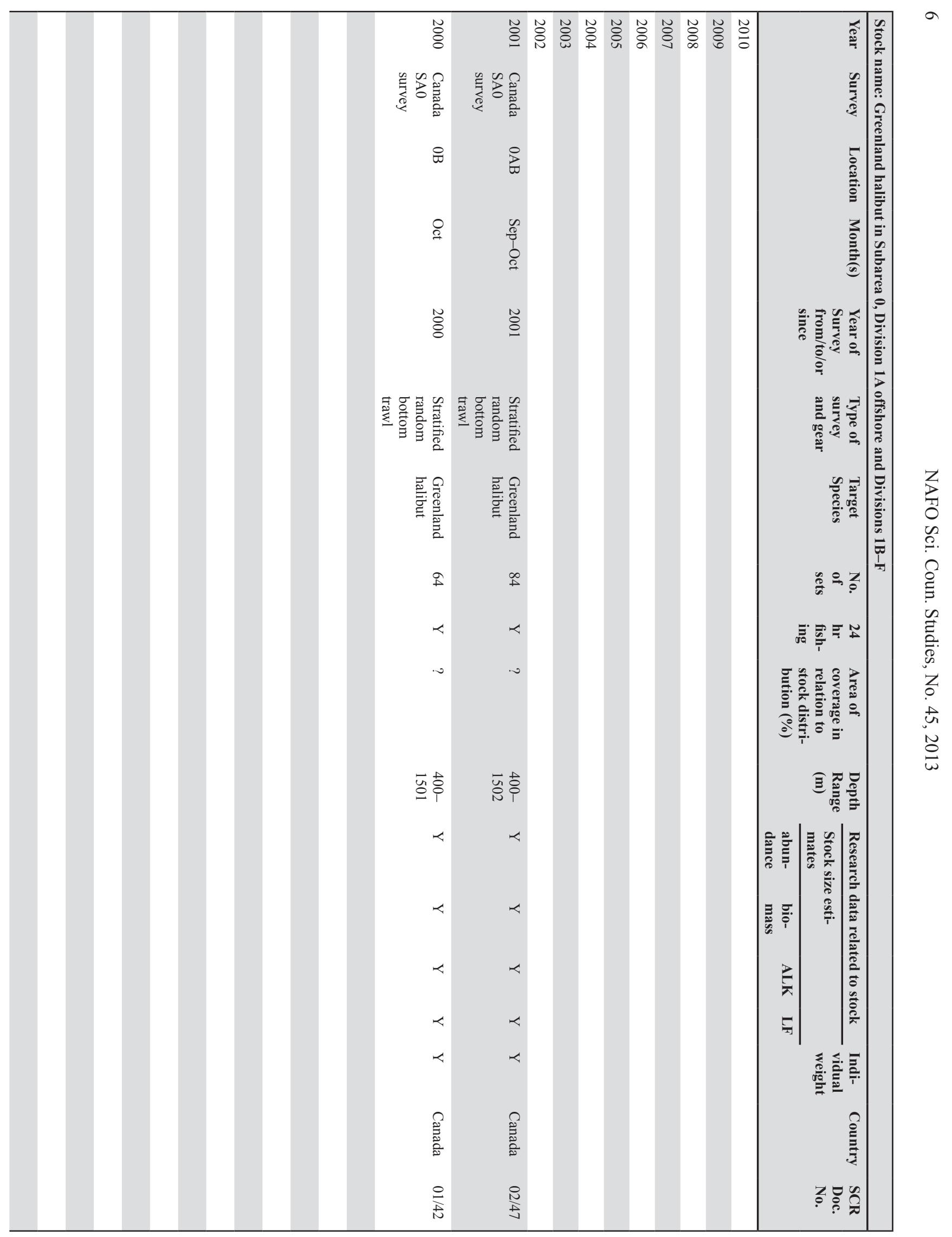




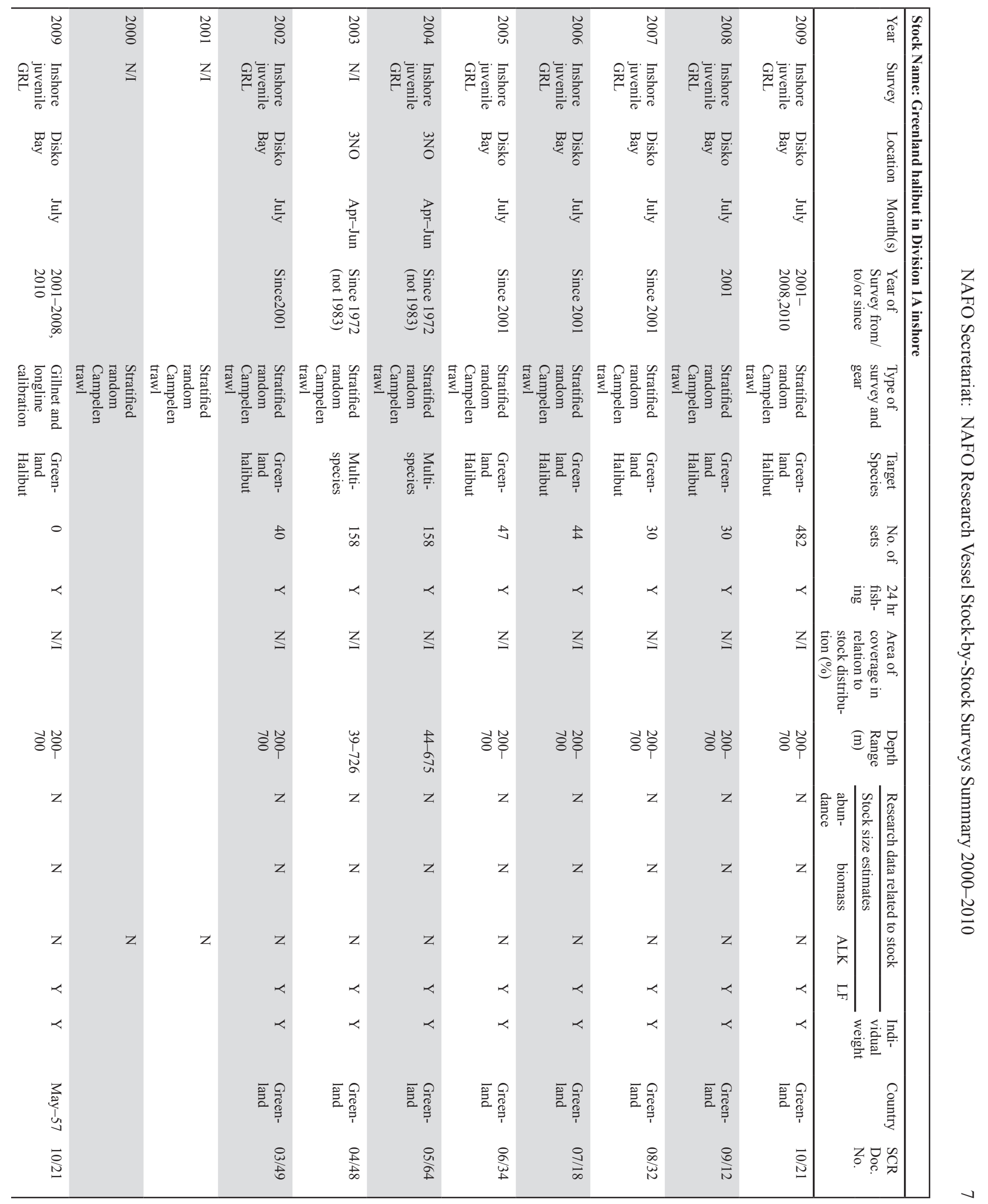




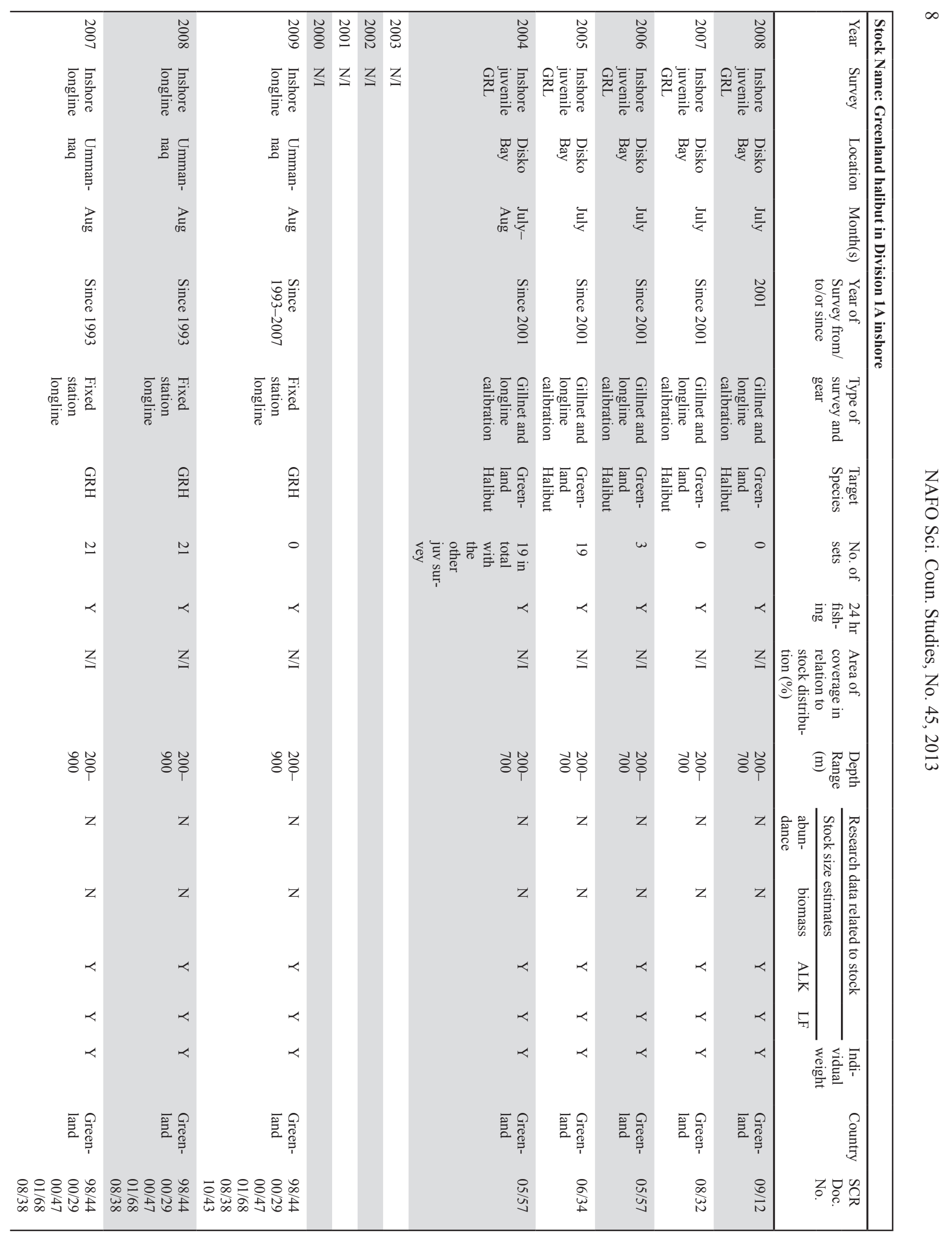




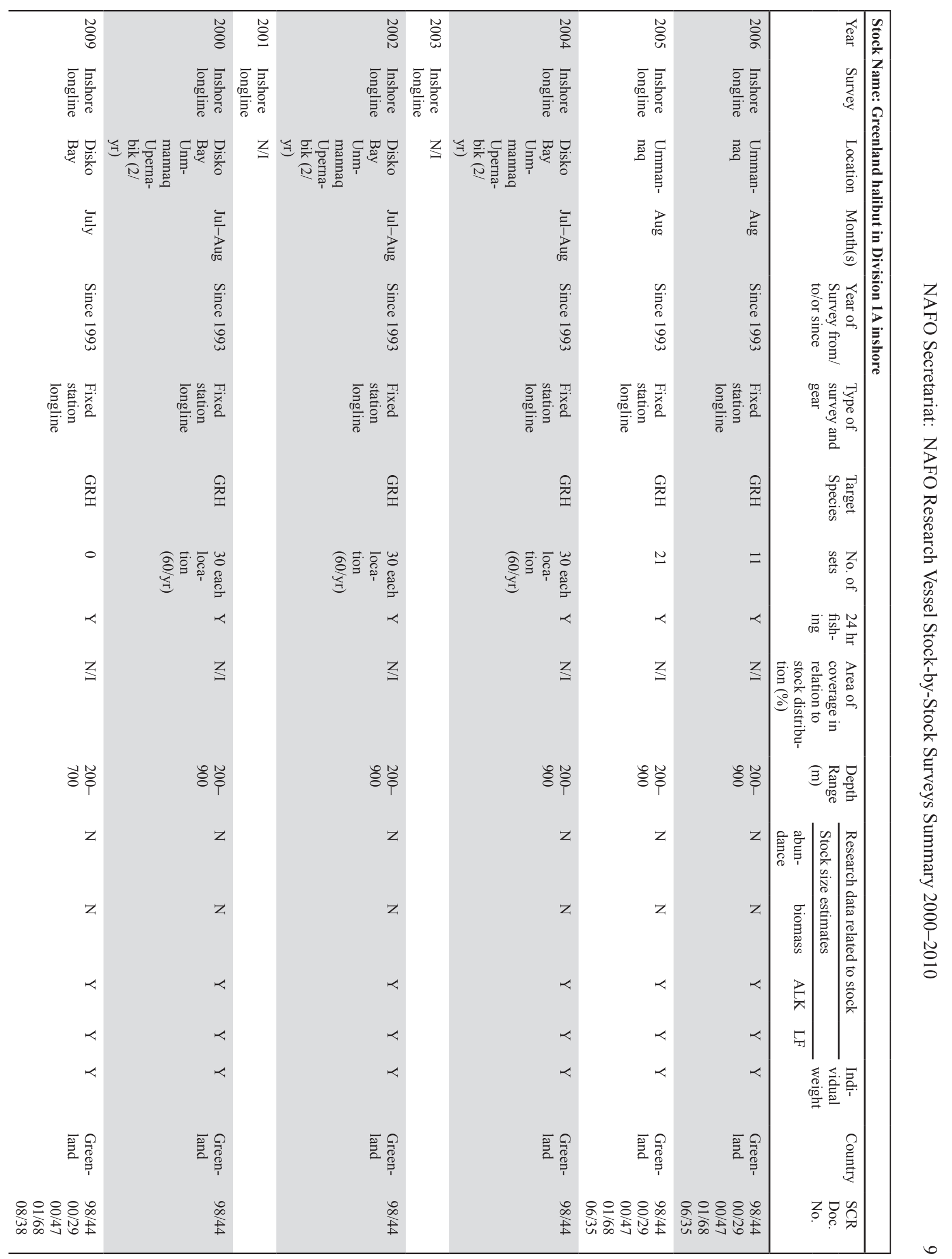




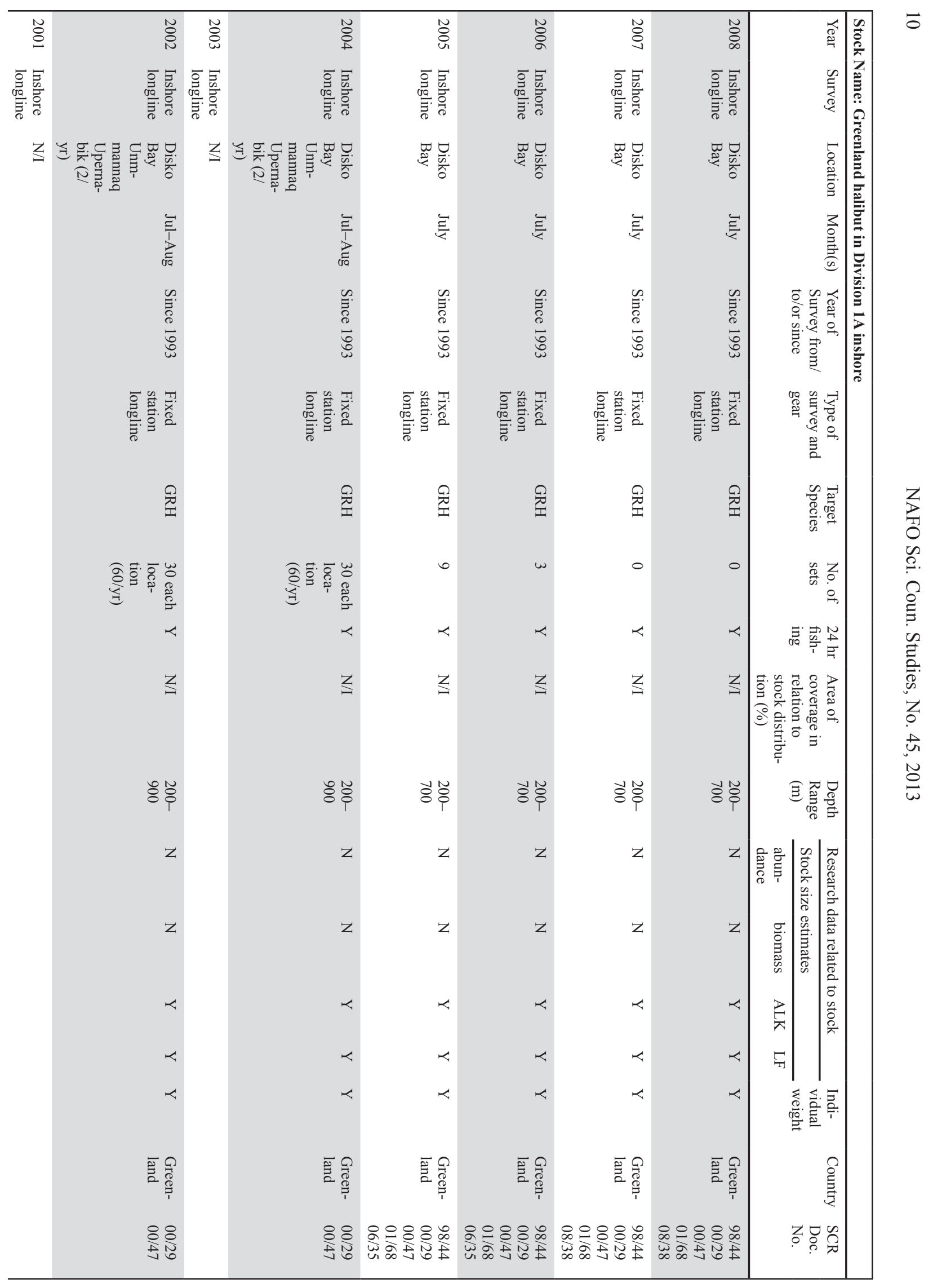




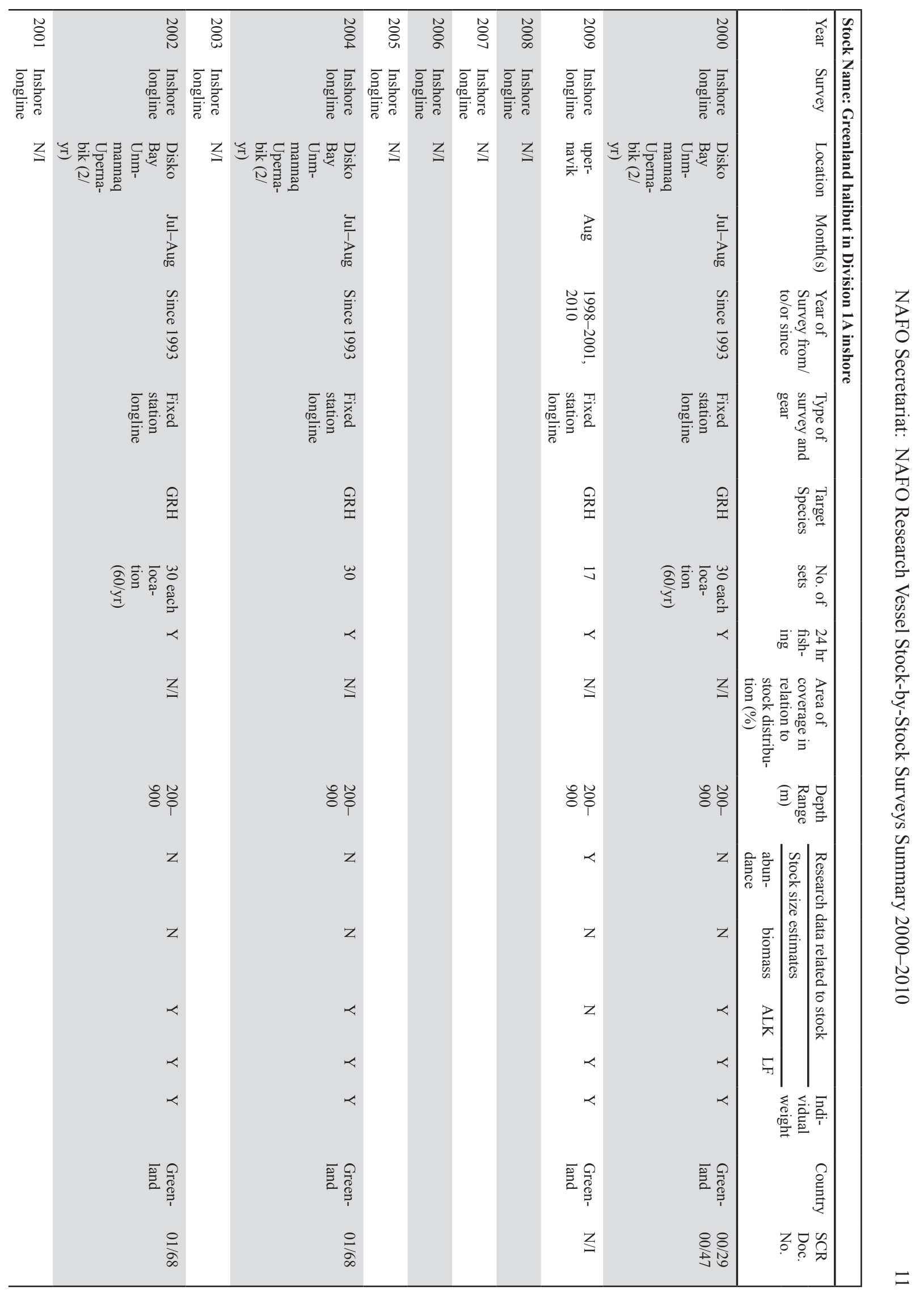




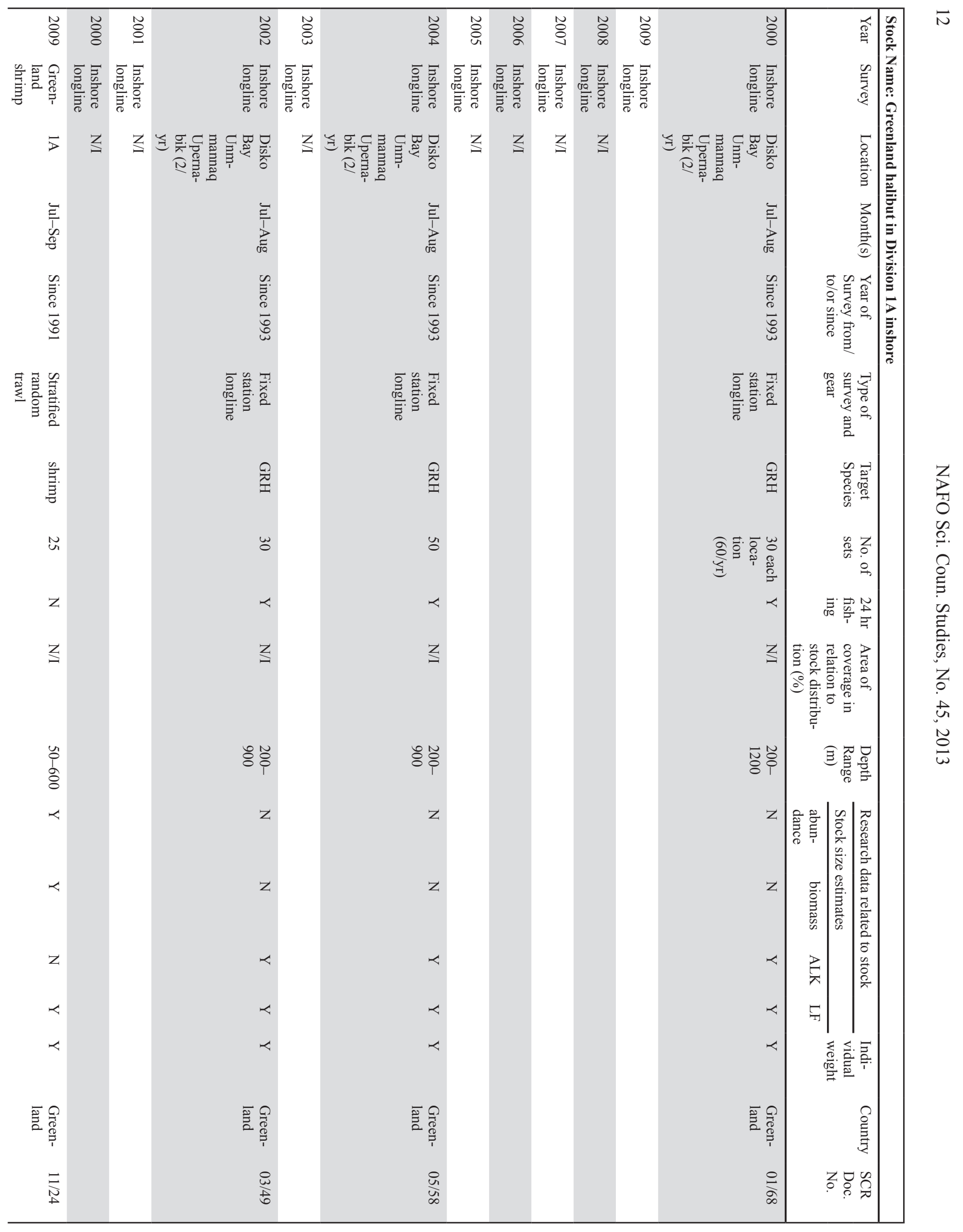




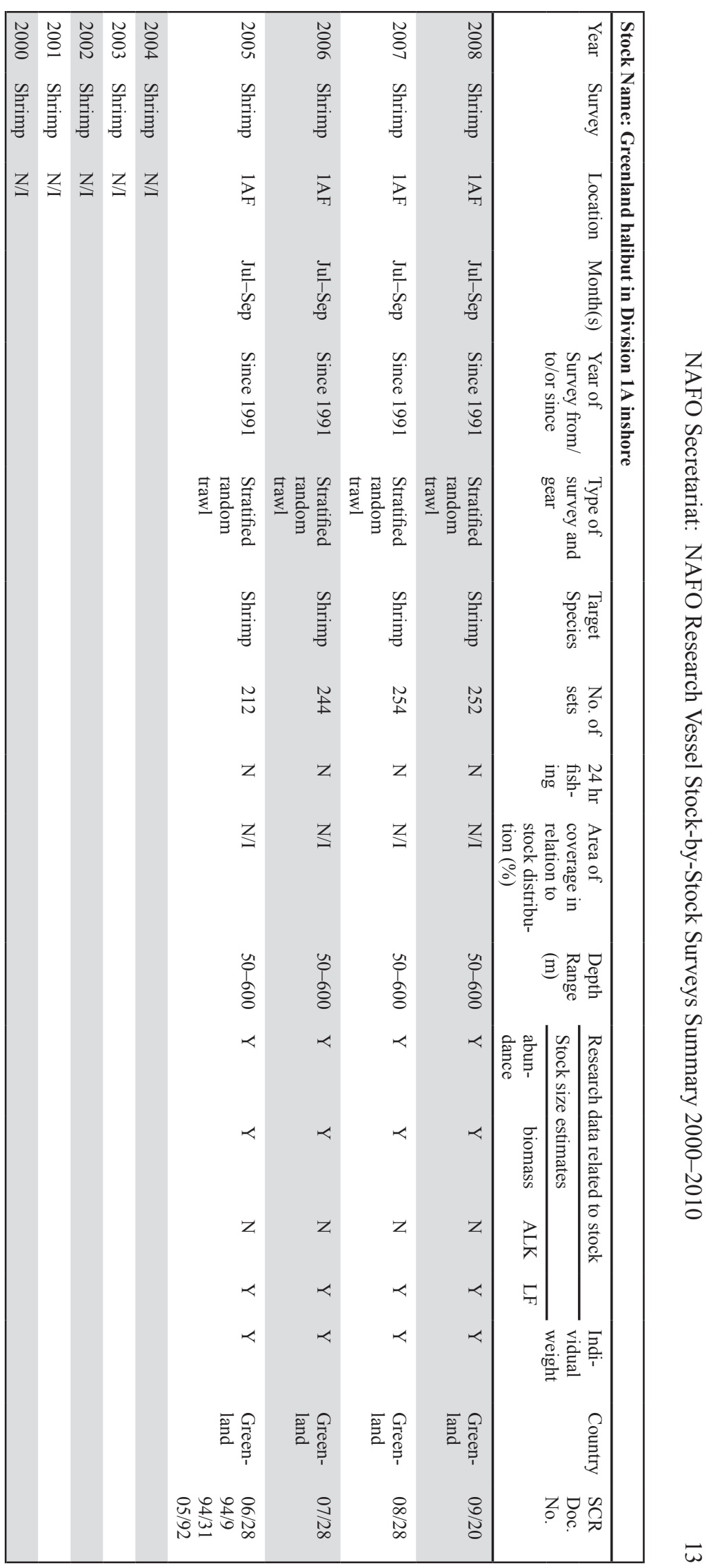




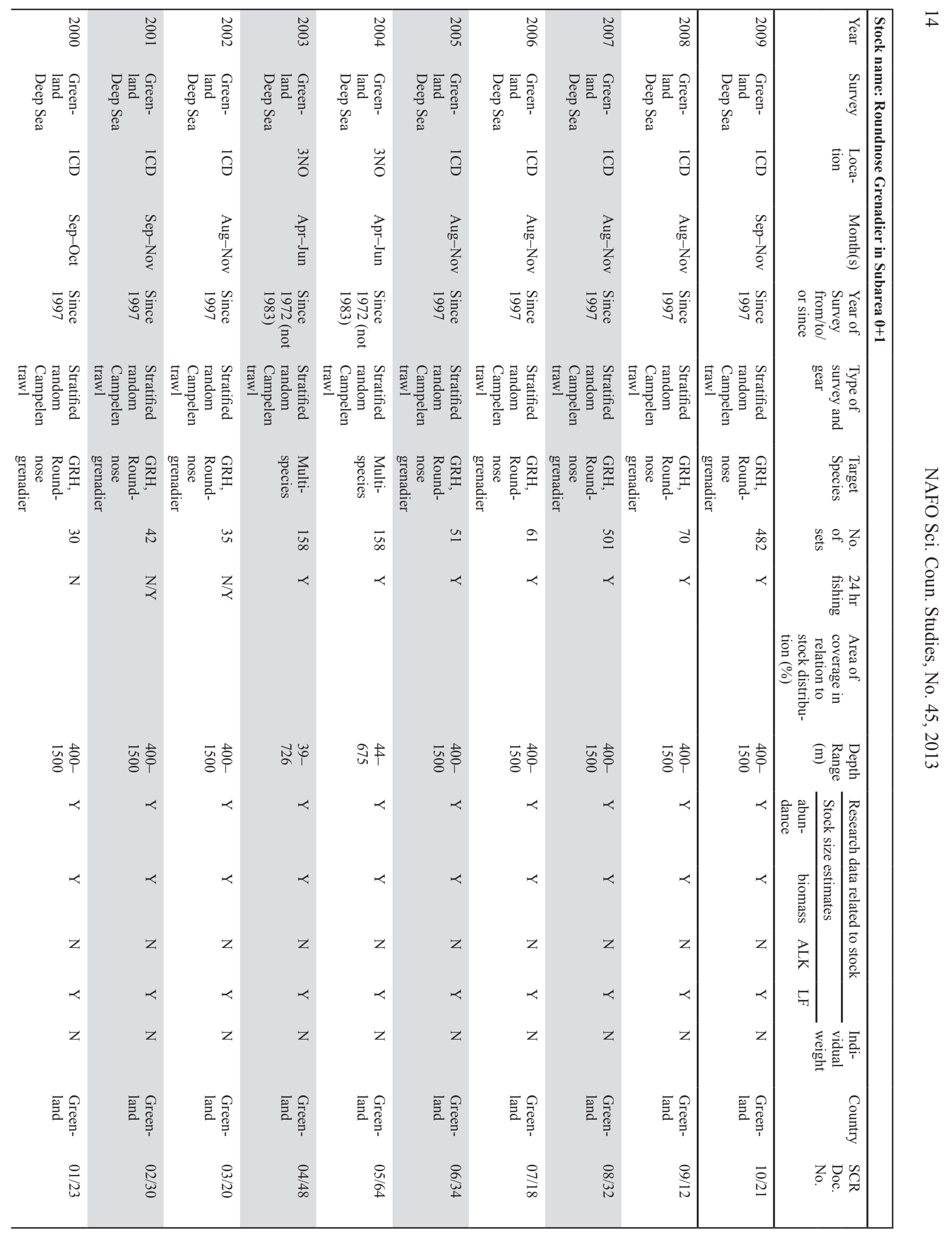




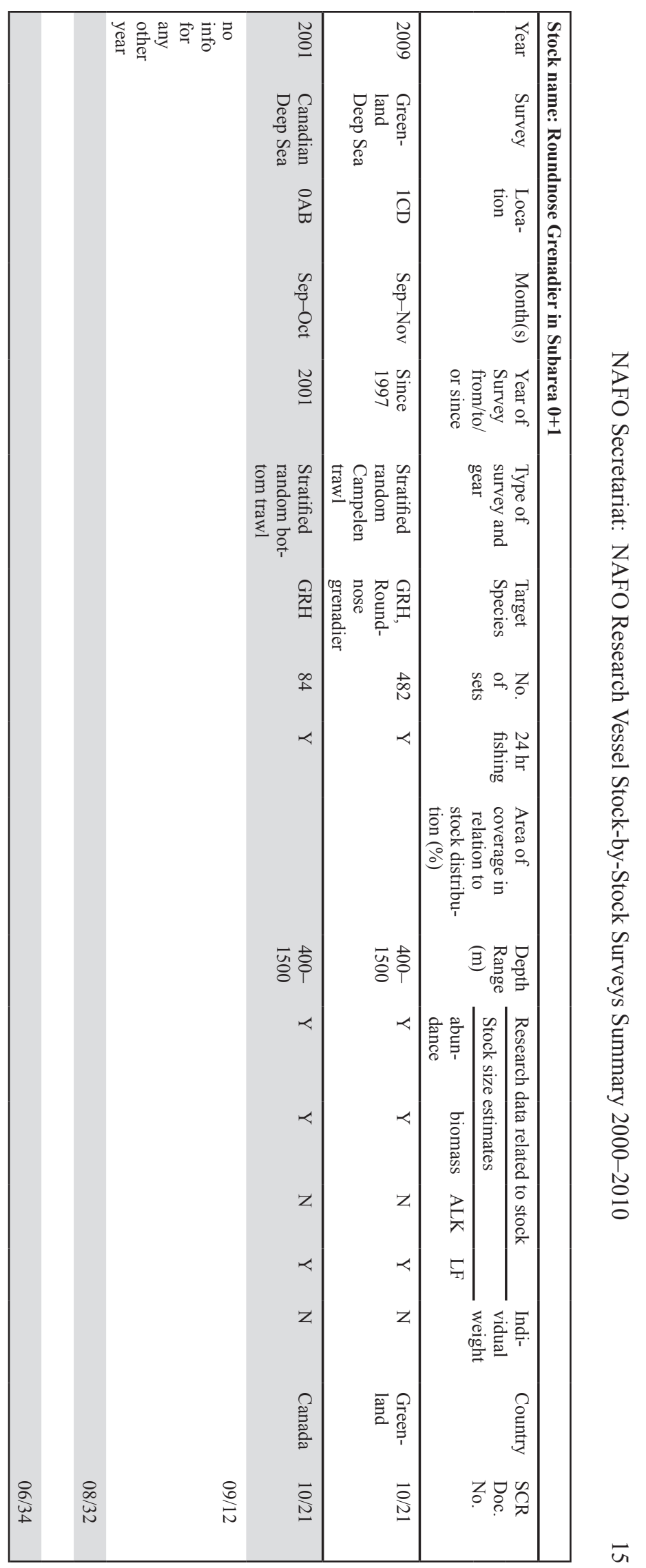




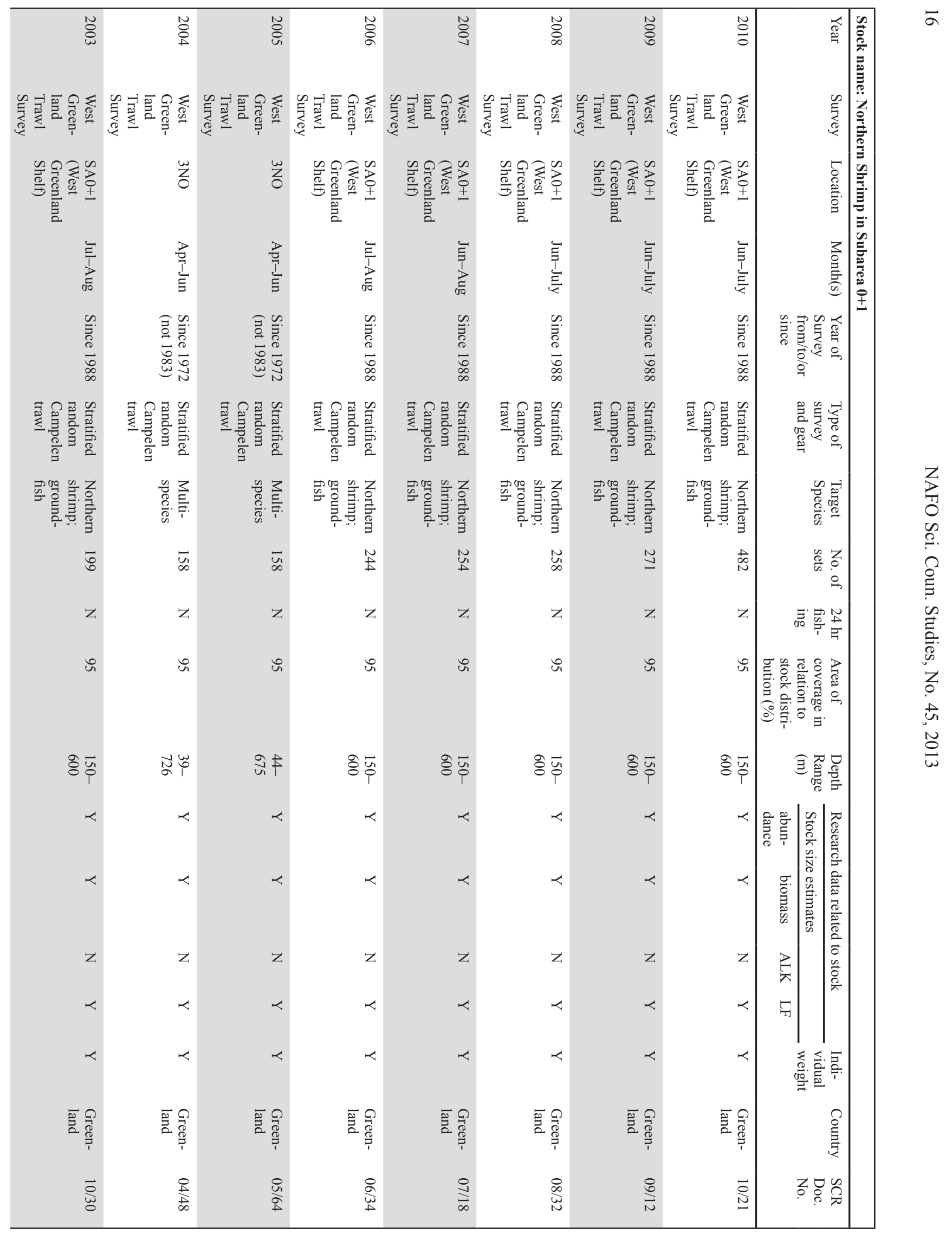




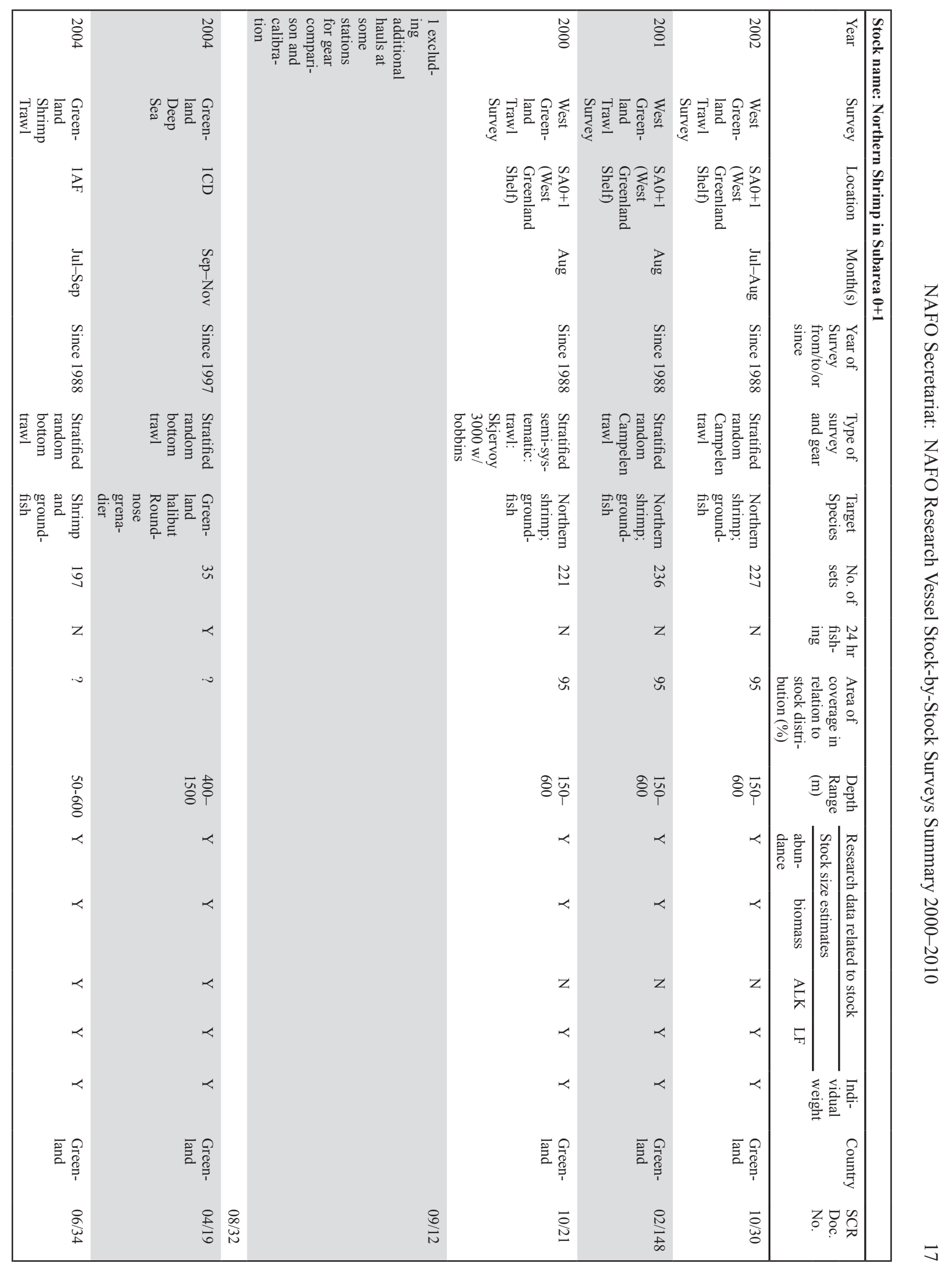




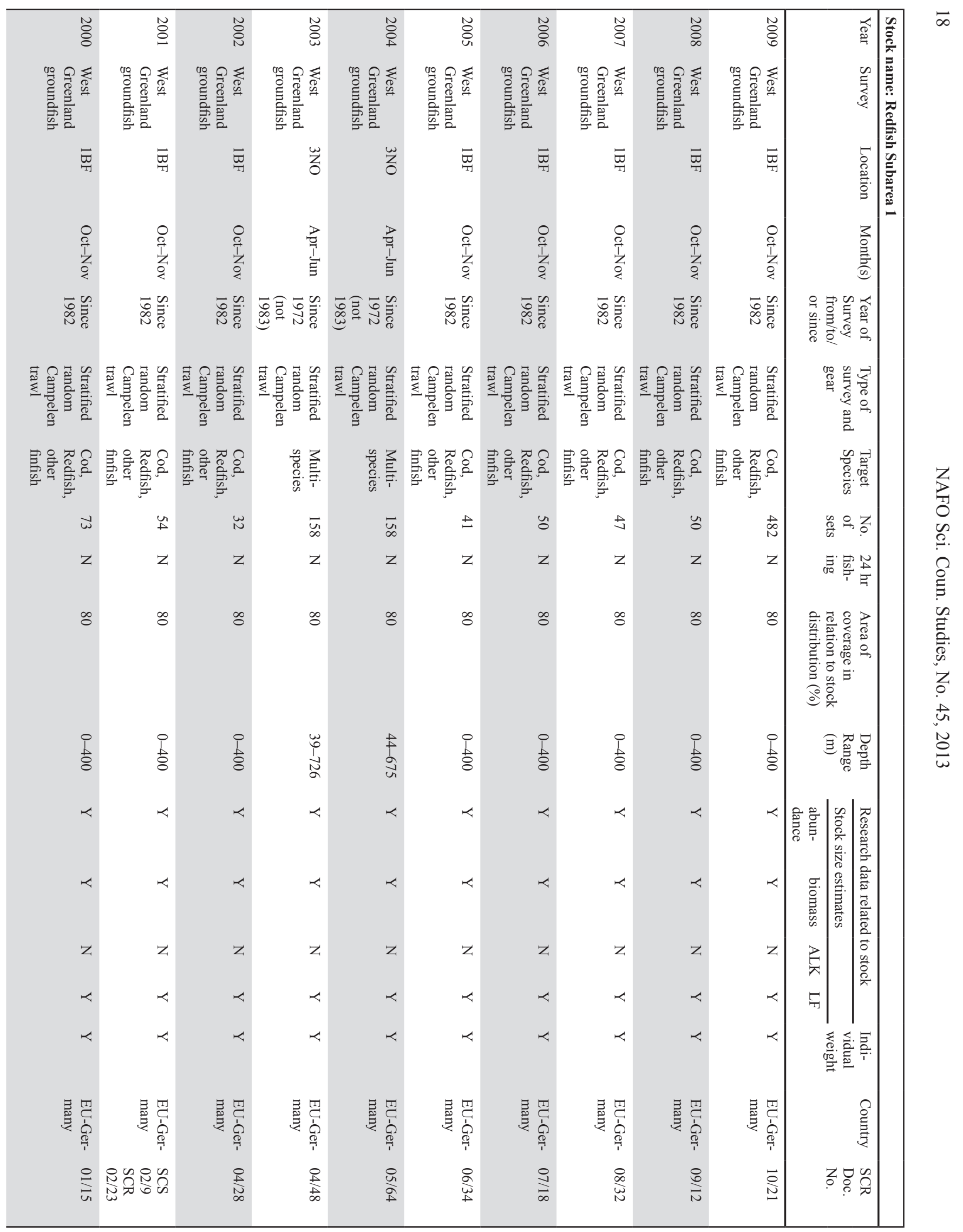




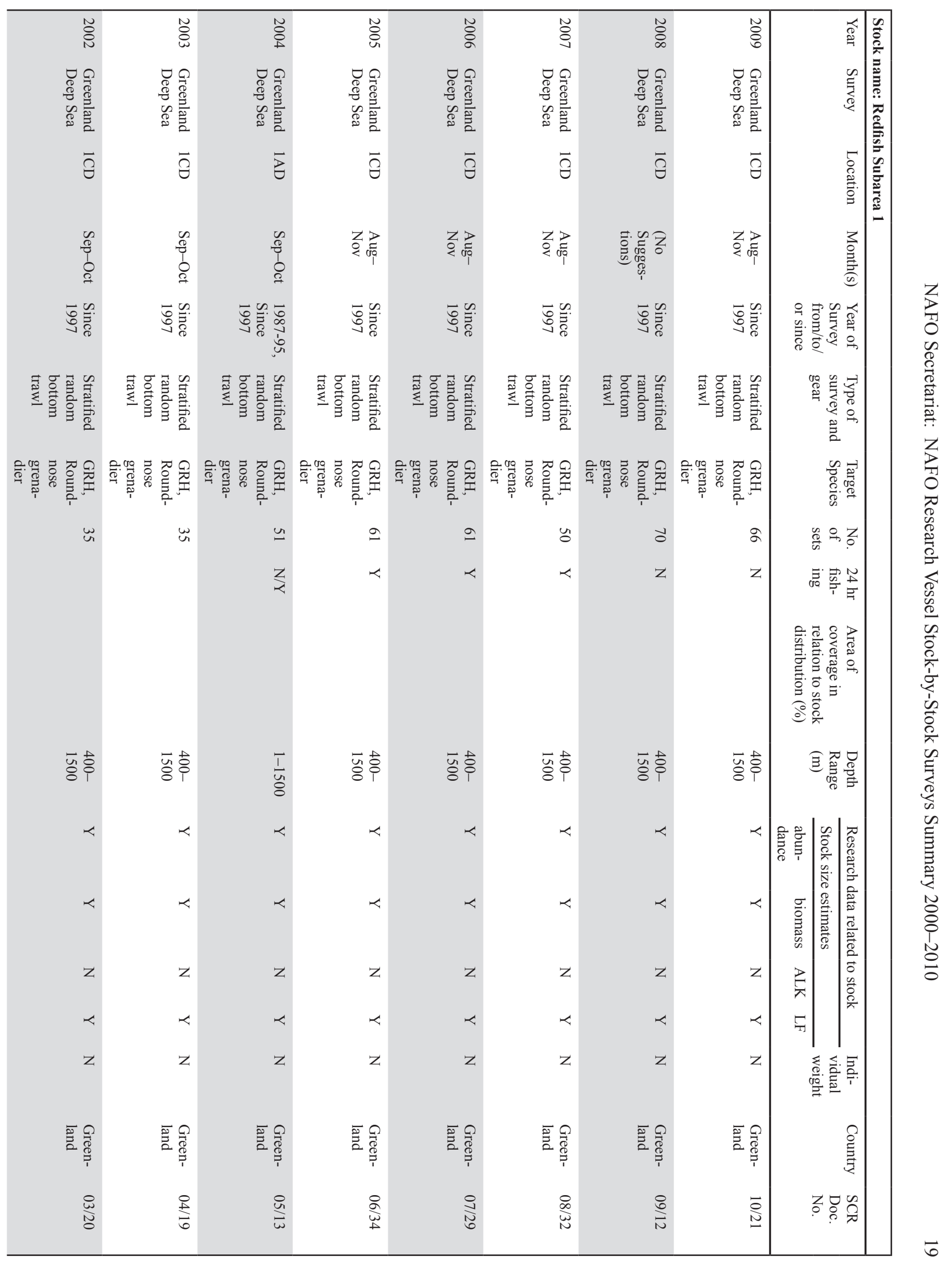




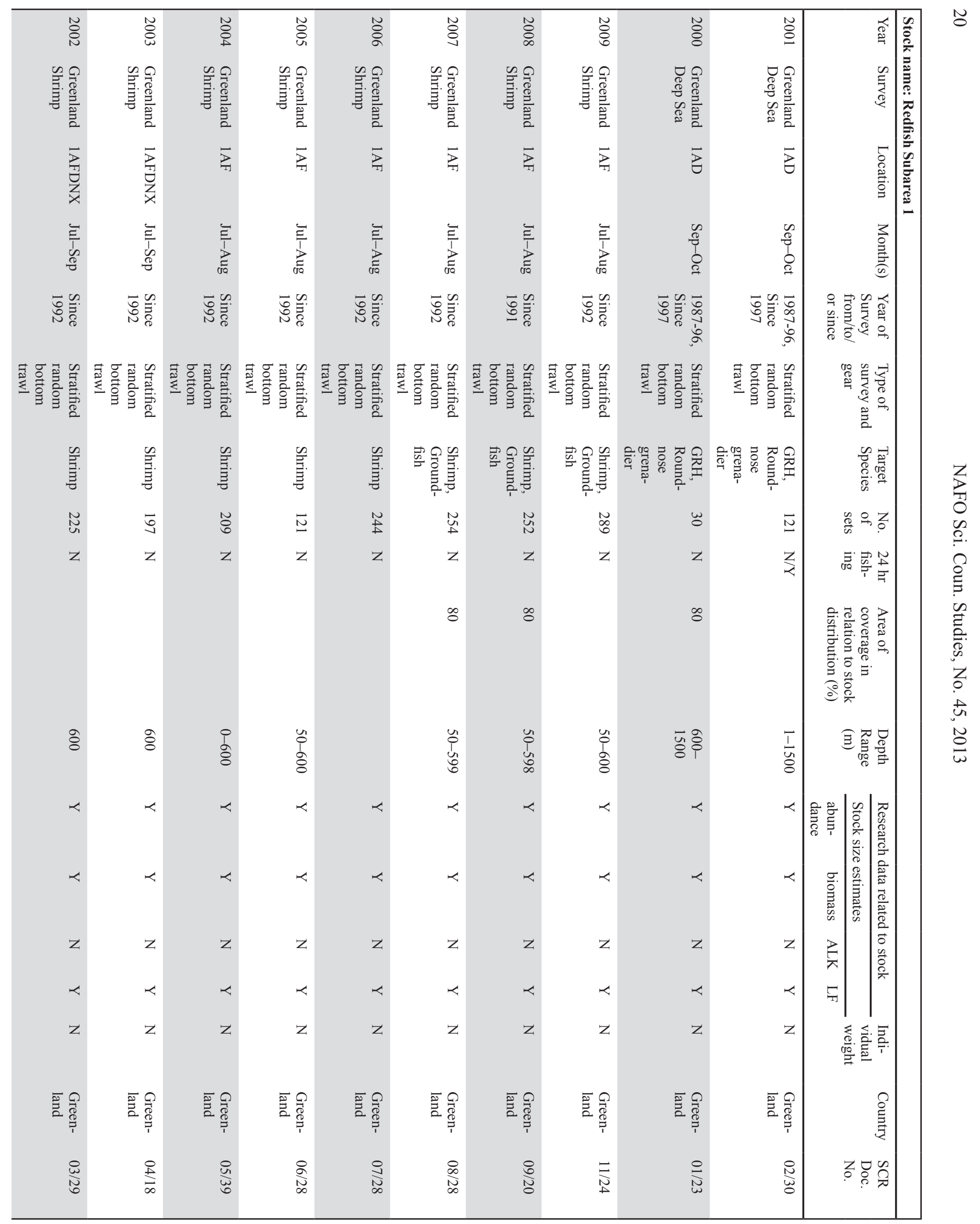




\begin{tabular}{|c|c|c|c|}
\hline$\tilde{8}$ & $\tilde{\Xi}$ & $\widehat{\oiint}$ & \\
\hline 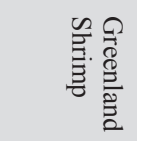 & 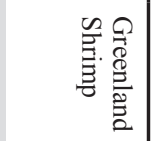 & 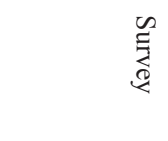 & \\
\hline$\vec{P}$ & $\vec{x}_{1}$ & 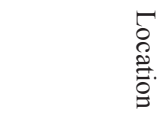 & 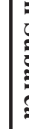 \\
\hline 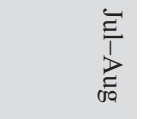 & $\begin{array}{l}\vec{\Xi} \\
\vec{\Xi} \\
\overrightarrow{v a}\end{array}$ & 该 & \\
\hline 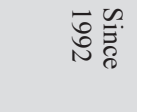 & 党: & 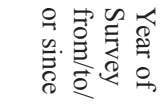 & \\
\hline 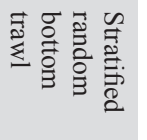 & 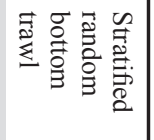 & 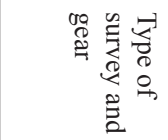 & \\
\hline$\frac{n}{E}$ & $\frac{\mathscr{N}}{E}$ & 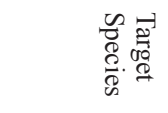 & \\
\hline$\underset{\sim}{\sim}$ & $\underset{+}{\sim}$ & 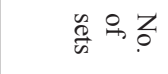 & \\
\hline z & $z$ & 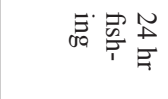 & \\
\hline$\stackrel{\infty}{\circ}$ & & 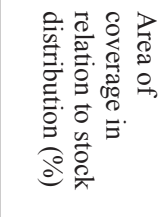 & \\
\hline $\begin{array}{l}0 \\
\text { के }\end{array}$ & $\begin{array}{l}0 \\
8\end{array}$ & 实冚曾 & \\
\hline$\prec$ & $\prec$ & 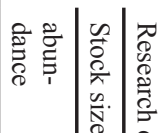 & \\
\hline$\prec$ & $\prec$ & 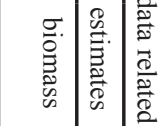 & \\
\hline$z$ & $z$ & 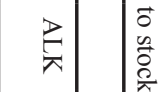 & \\
\hline$\prec$ & $\prec$ & 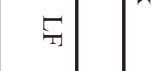 & \\
\hline z & $z$ & 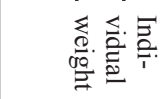 & \\
\hline 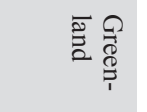 & 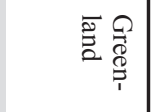 & 尺 & \\
\hline 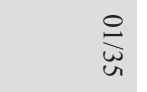 & $\underset{\substack{N \\
\frac{1}{\infty}}}{\mid}$ & 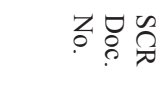 & \\
\hline
\end{tabular}




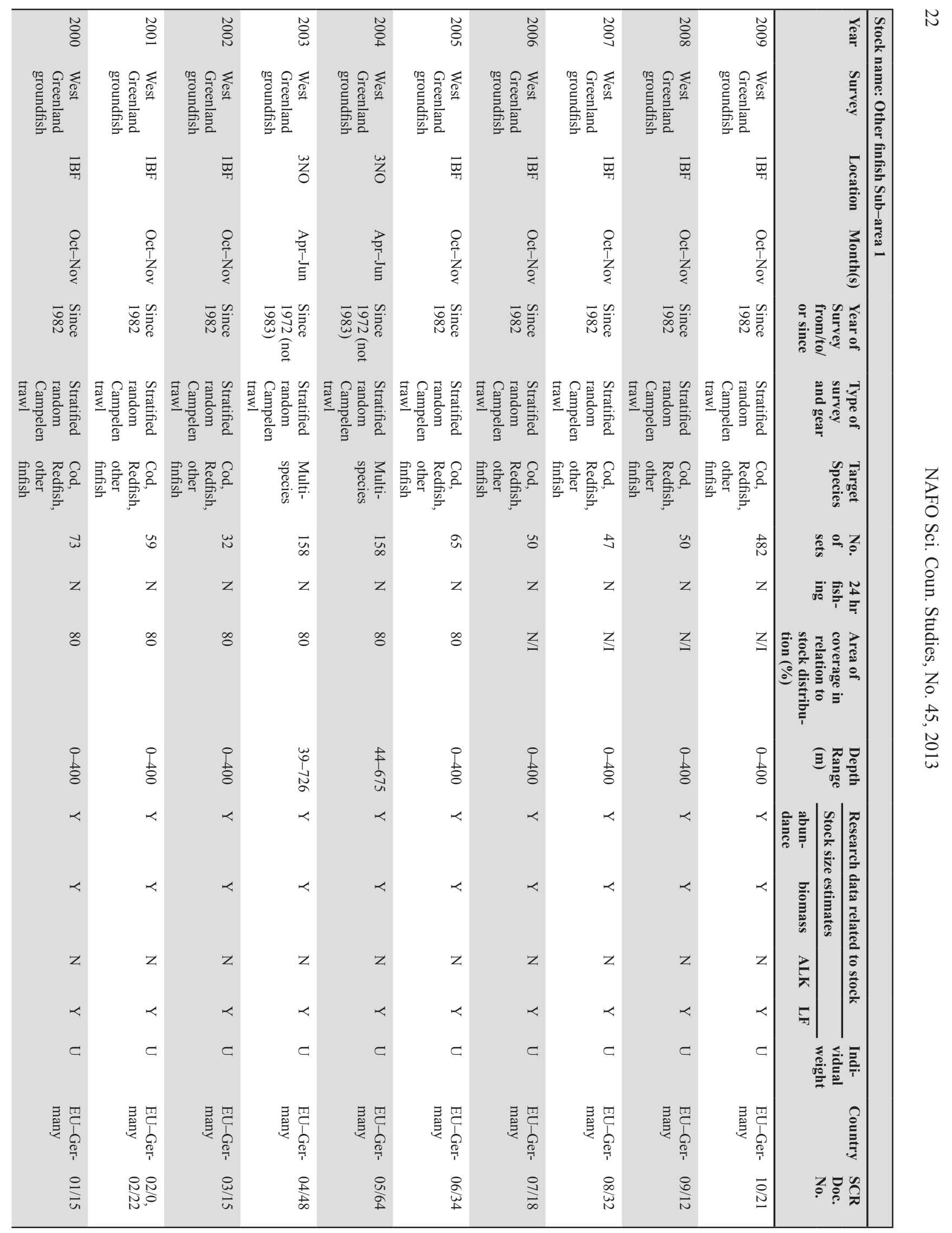




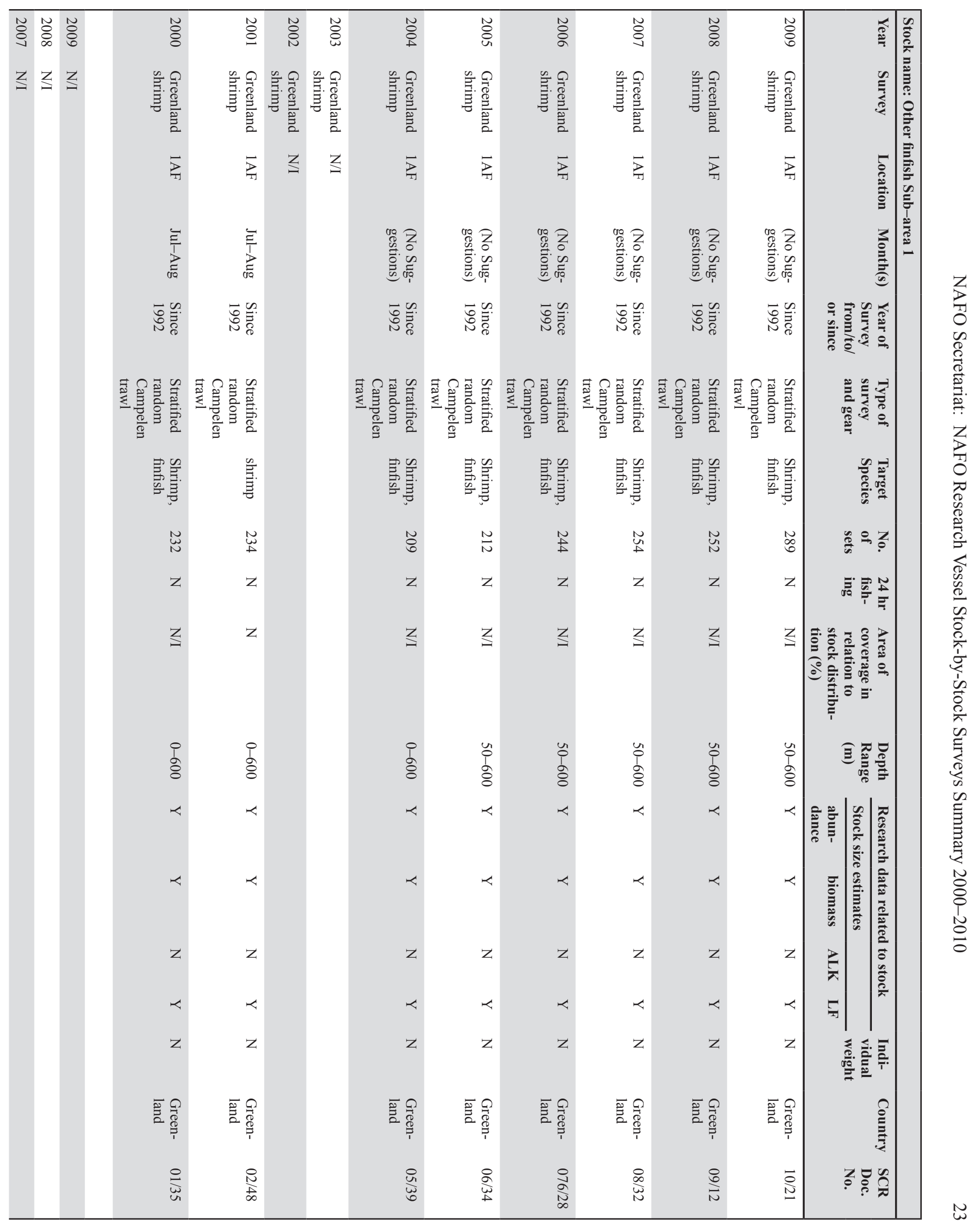




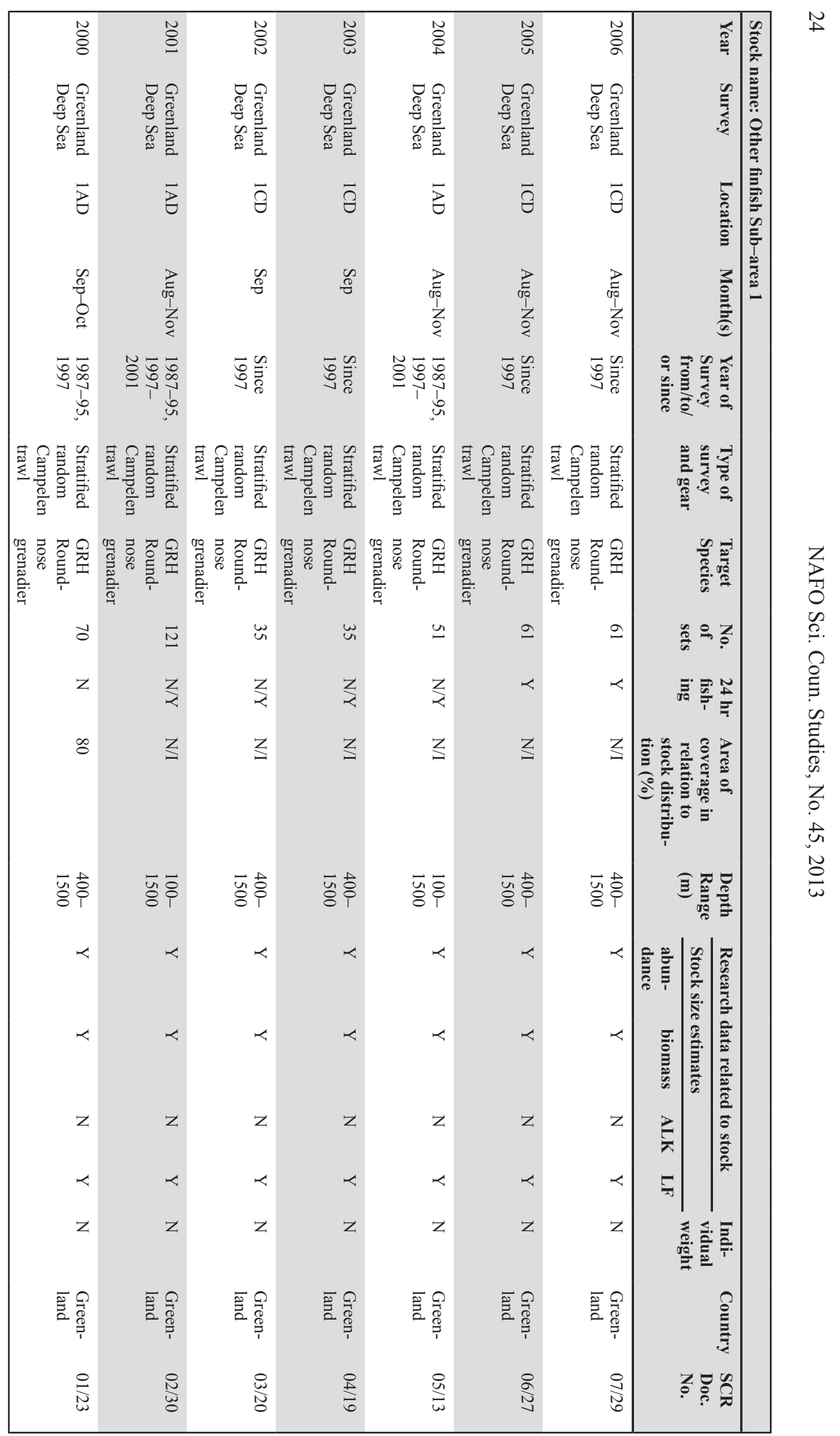




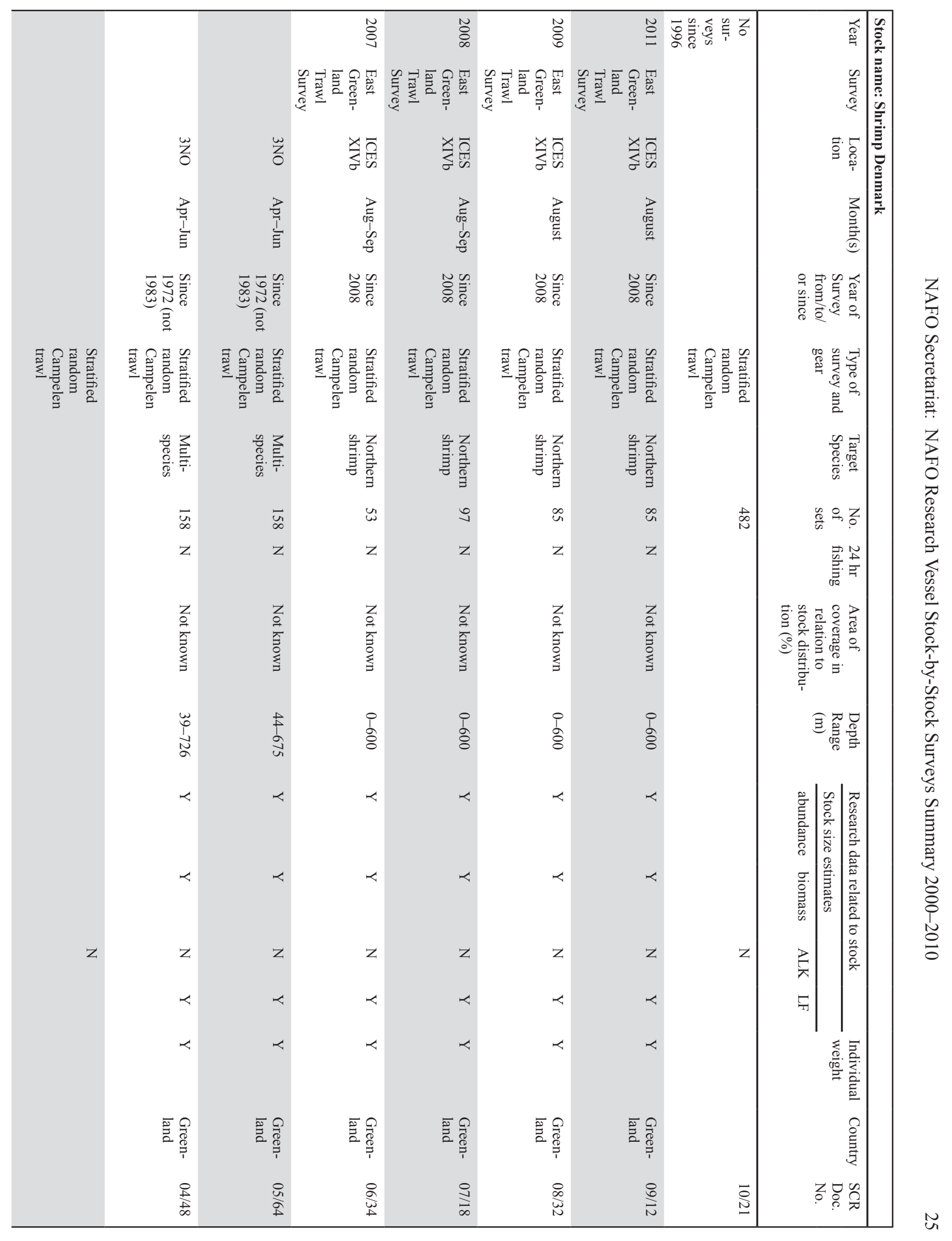




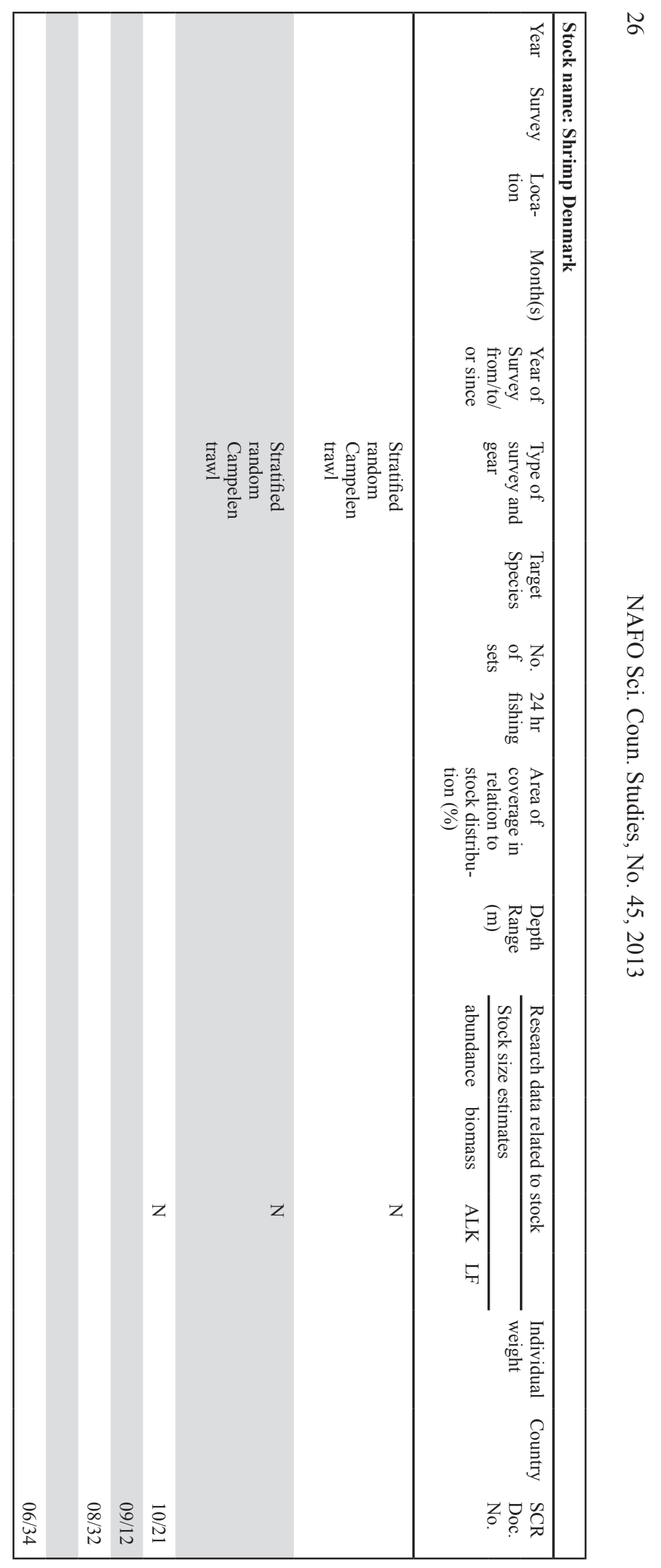




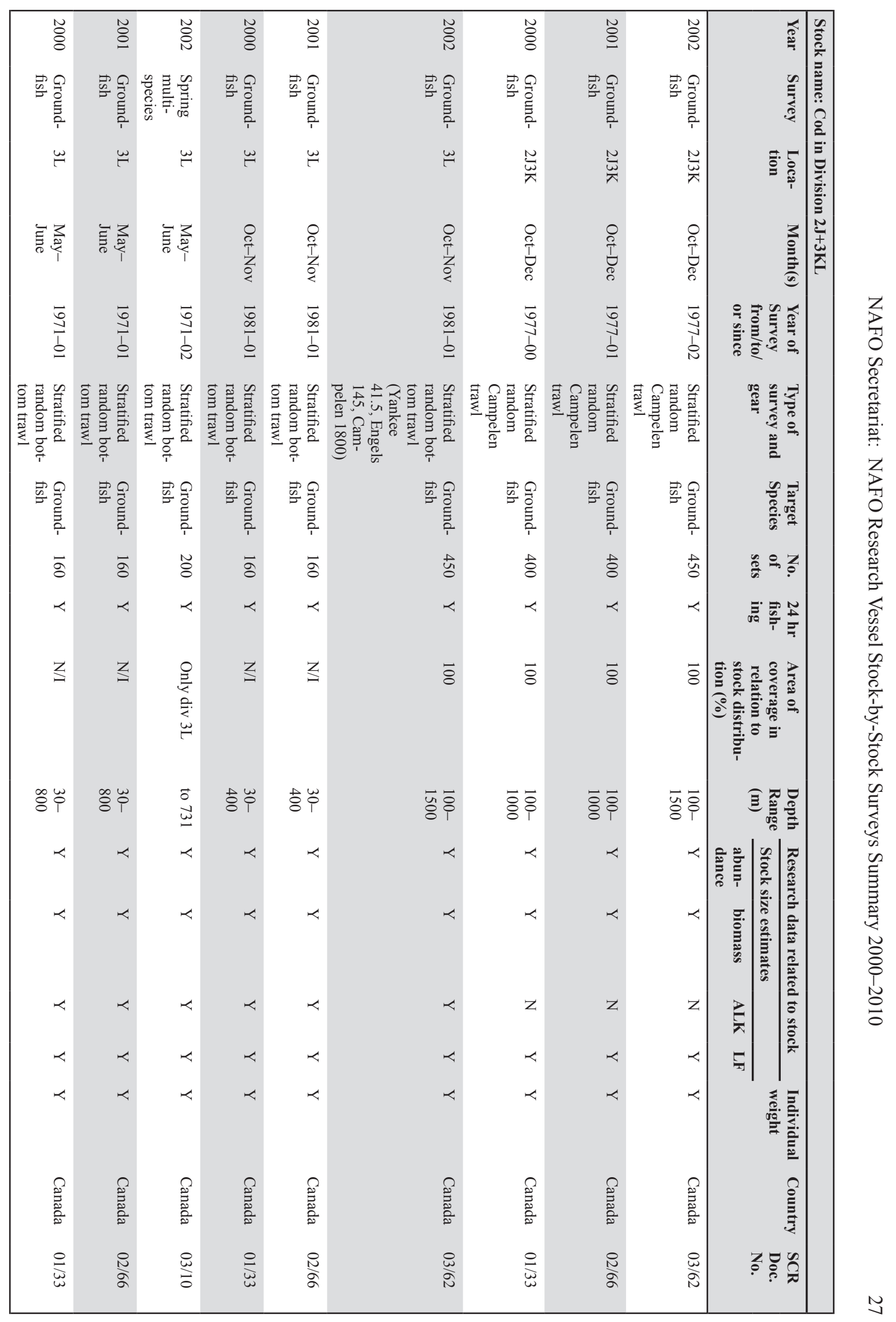




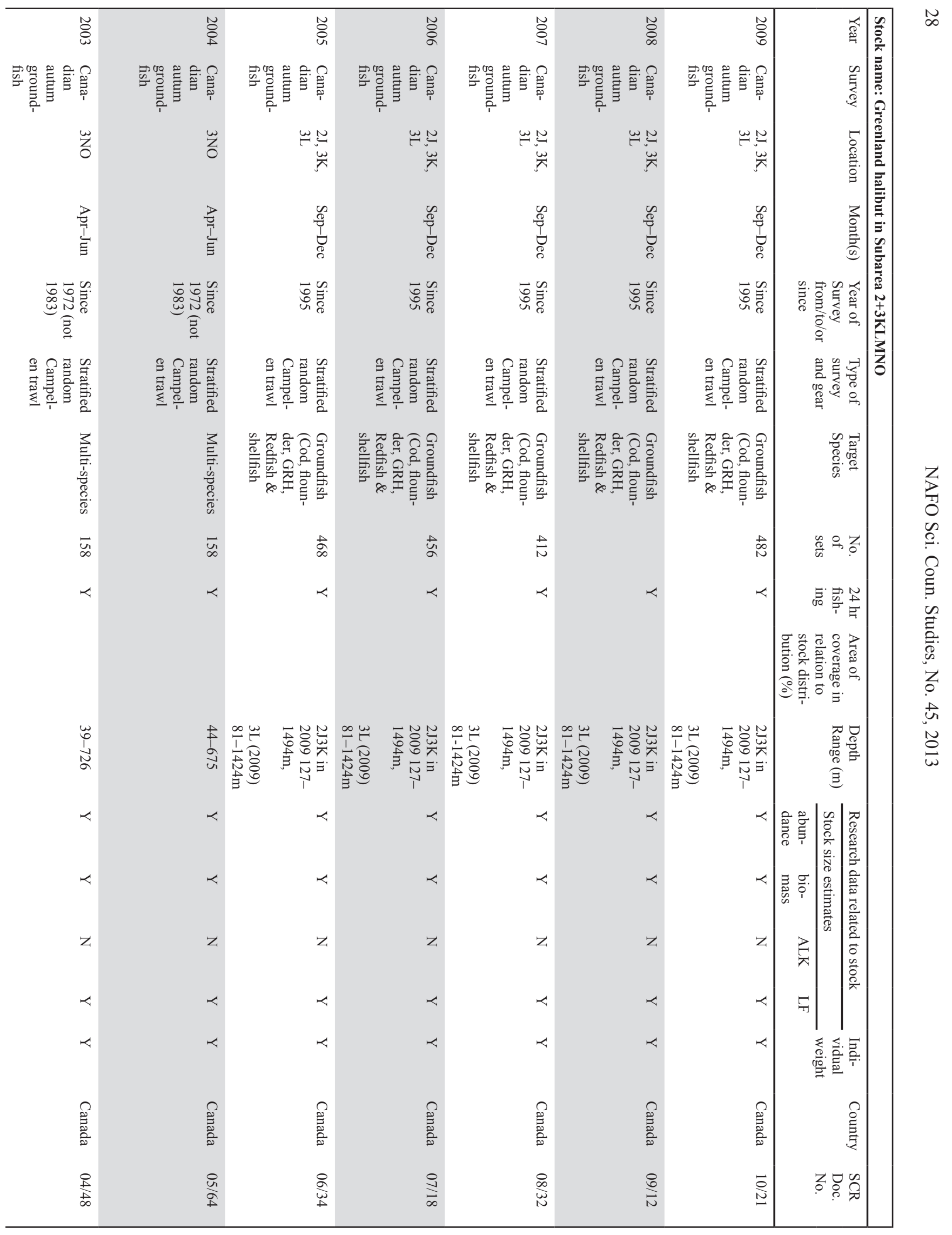




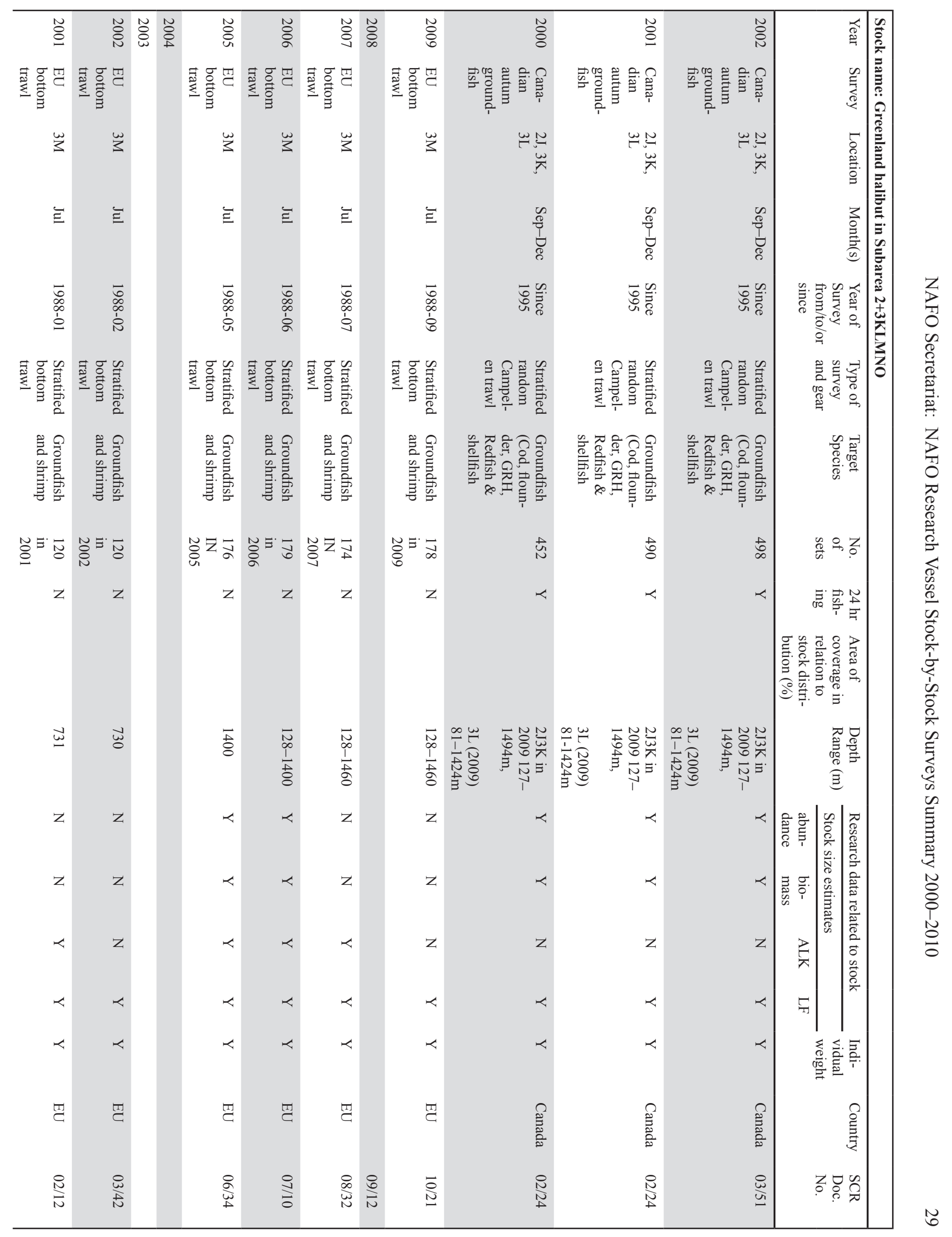




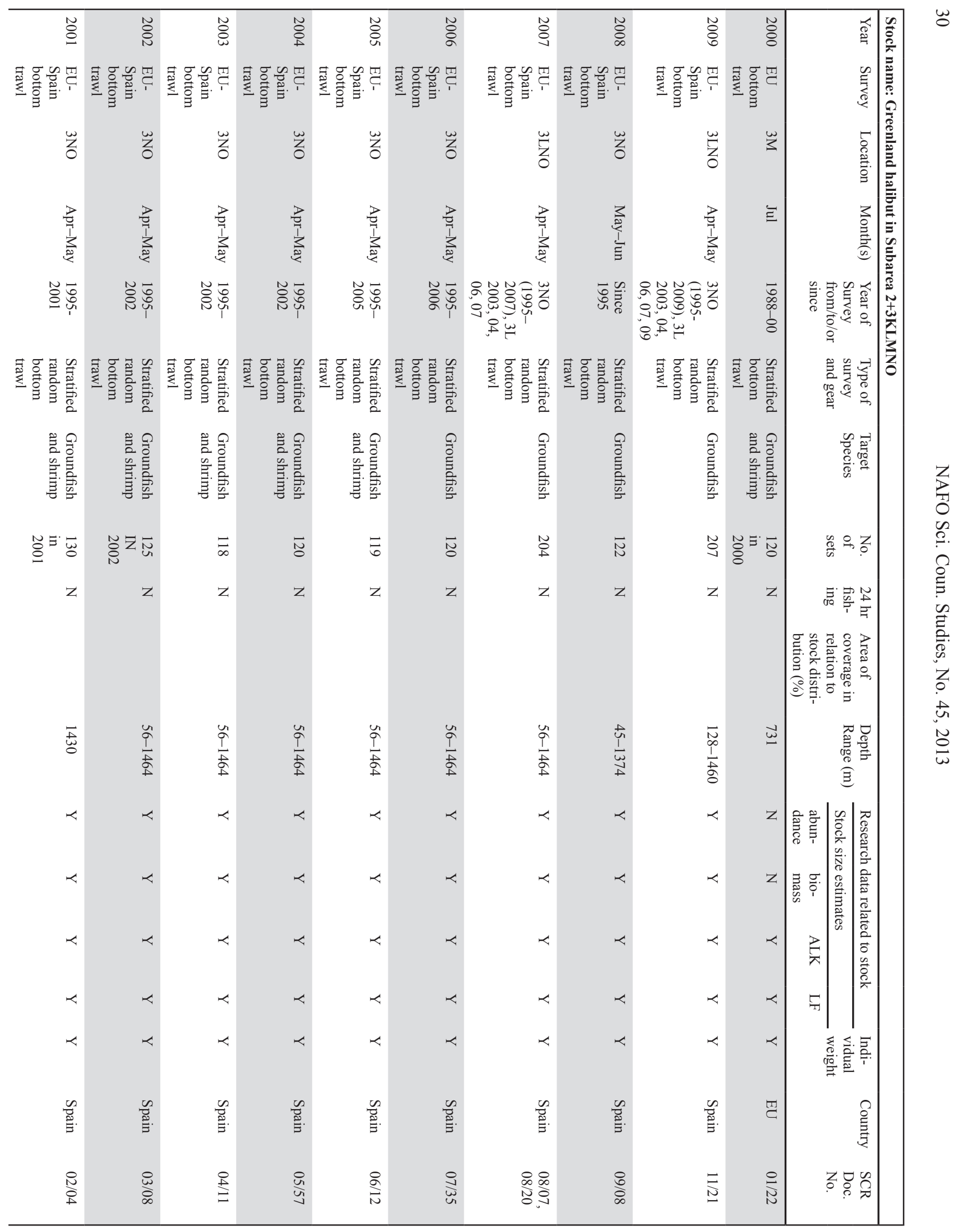




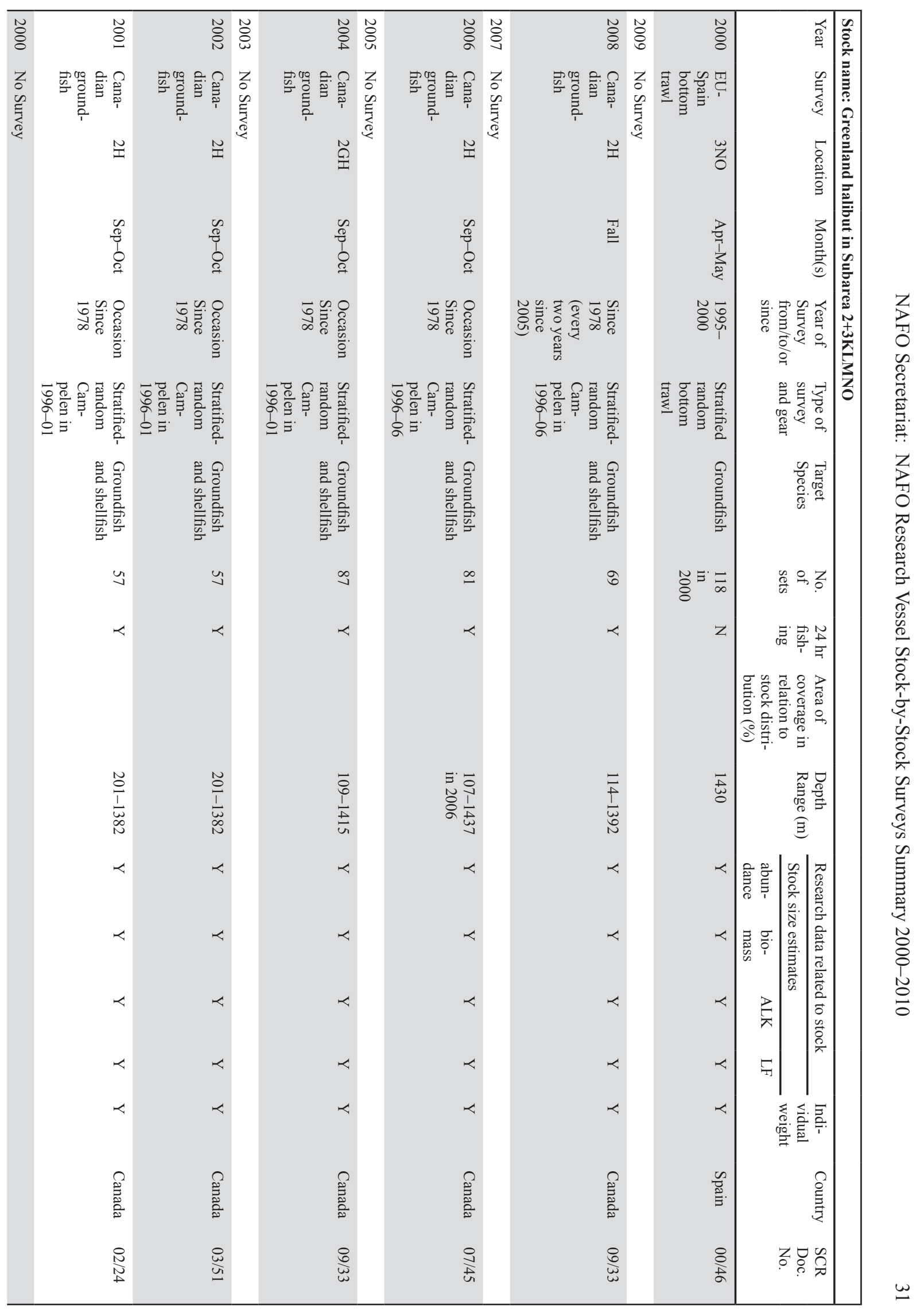




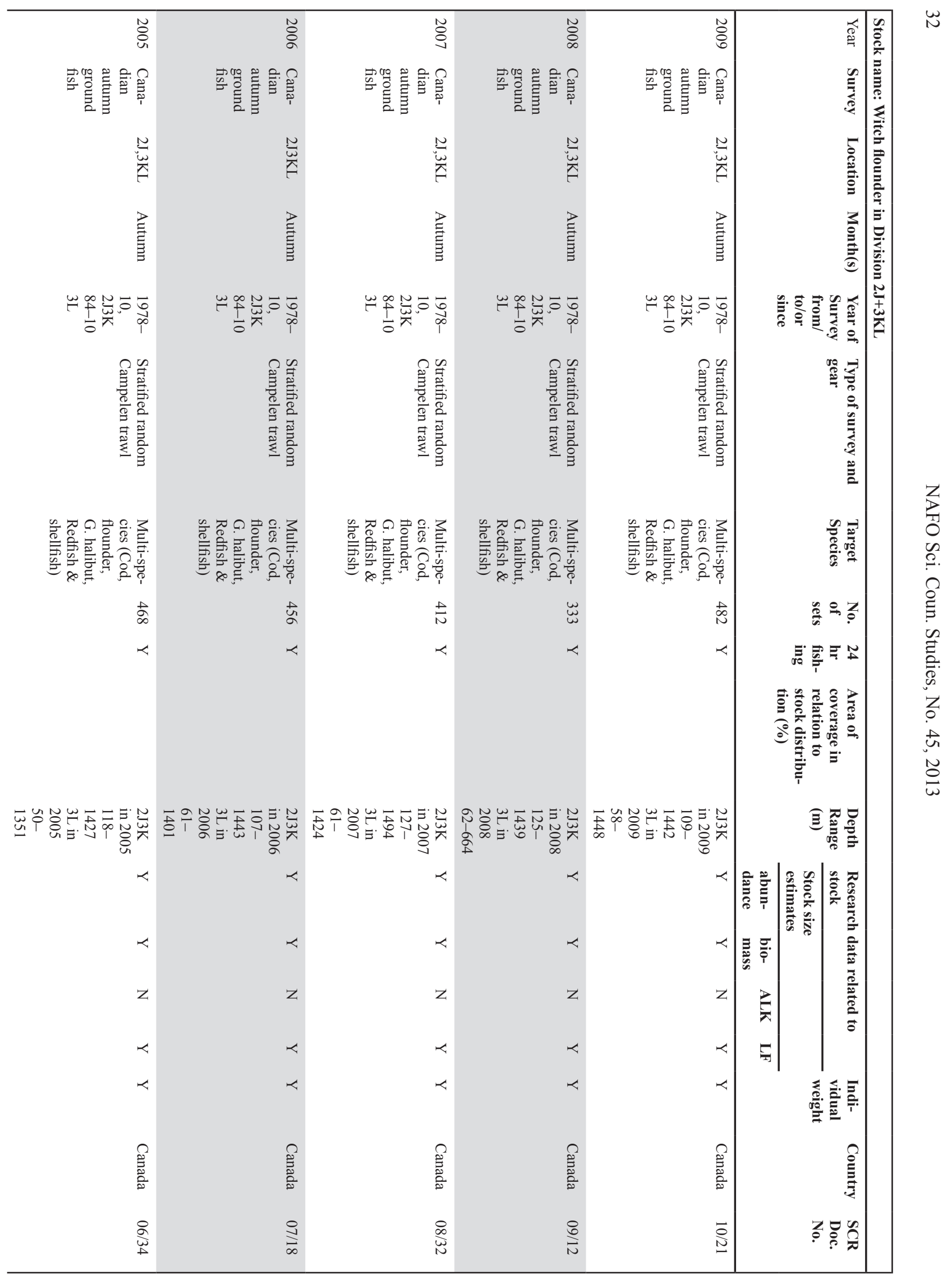




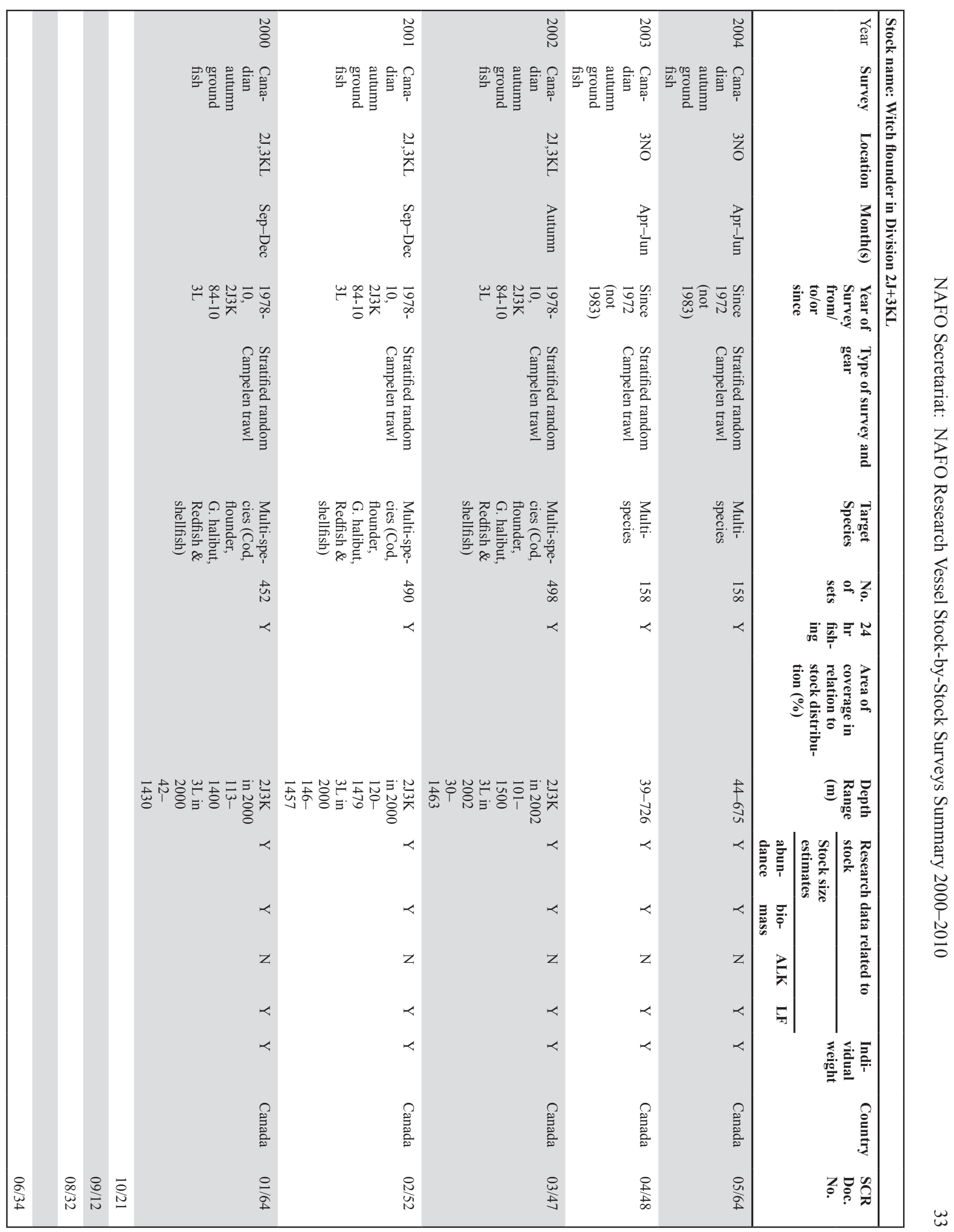




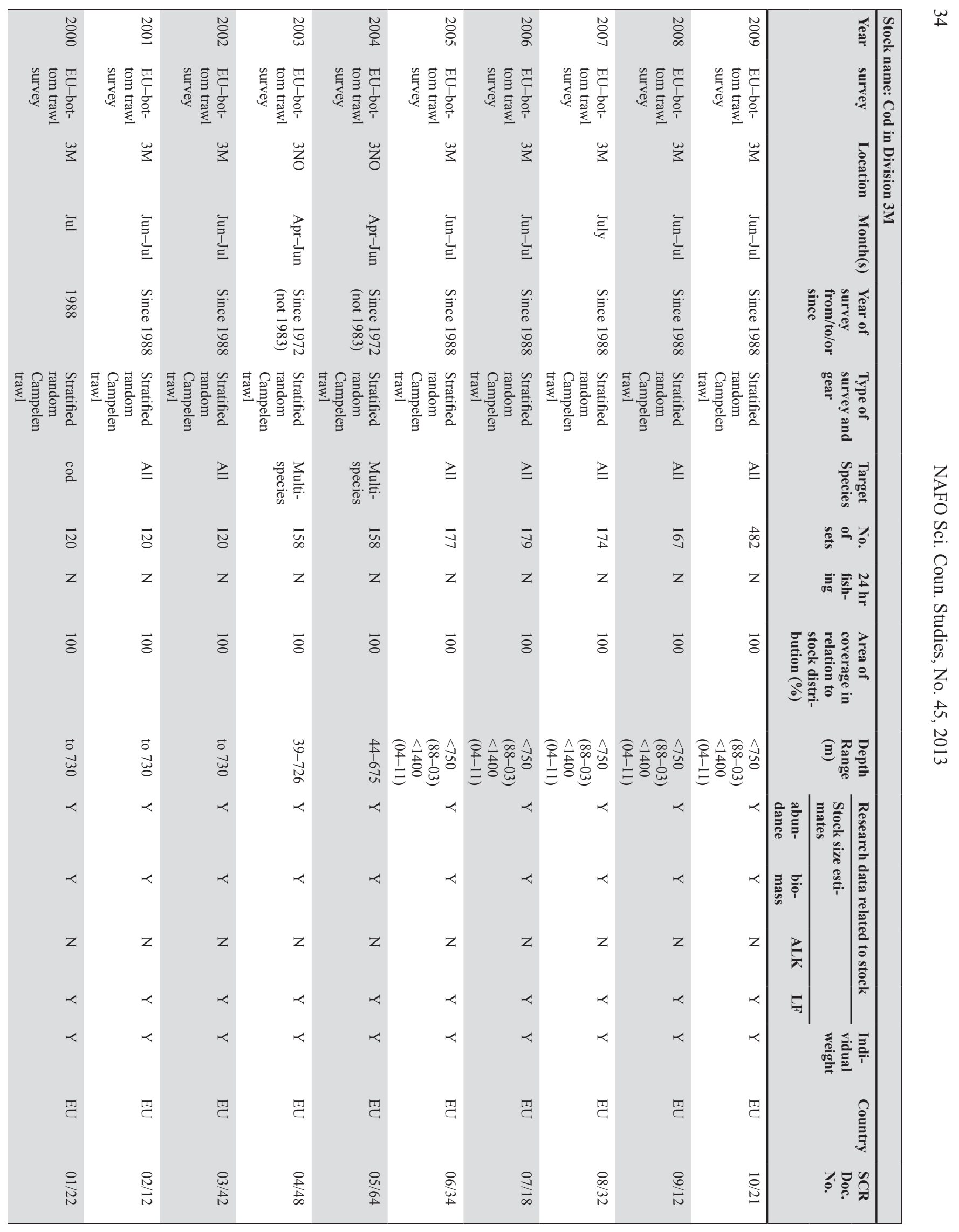




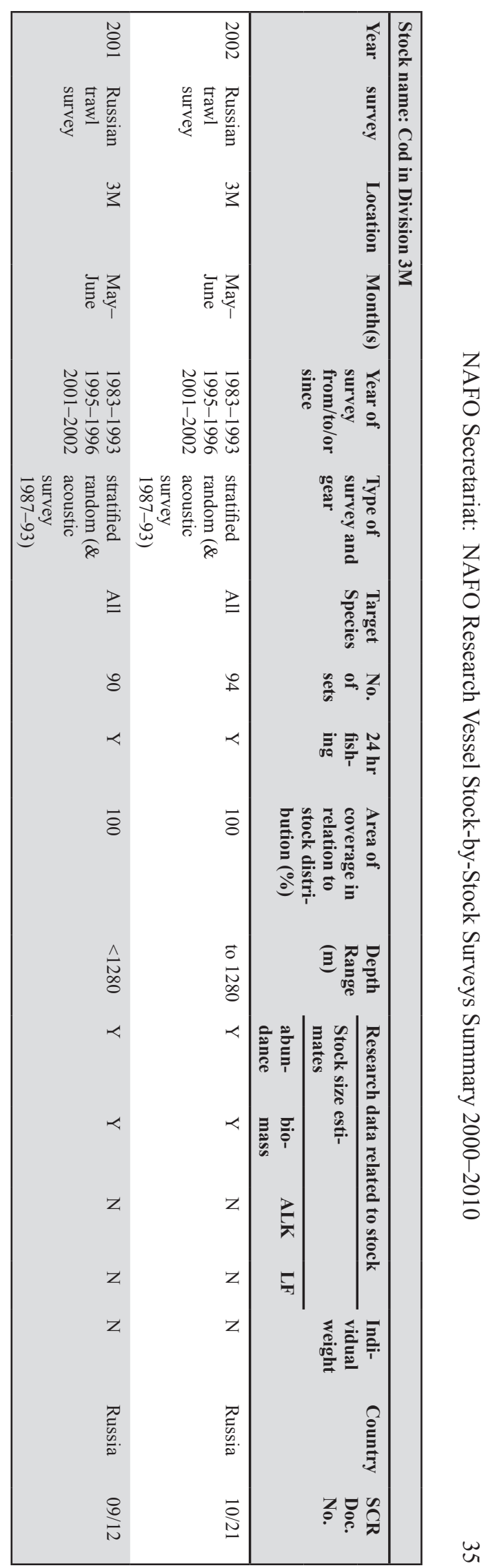




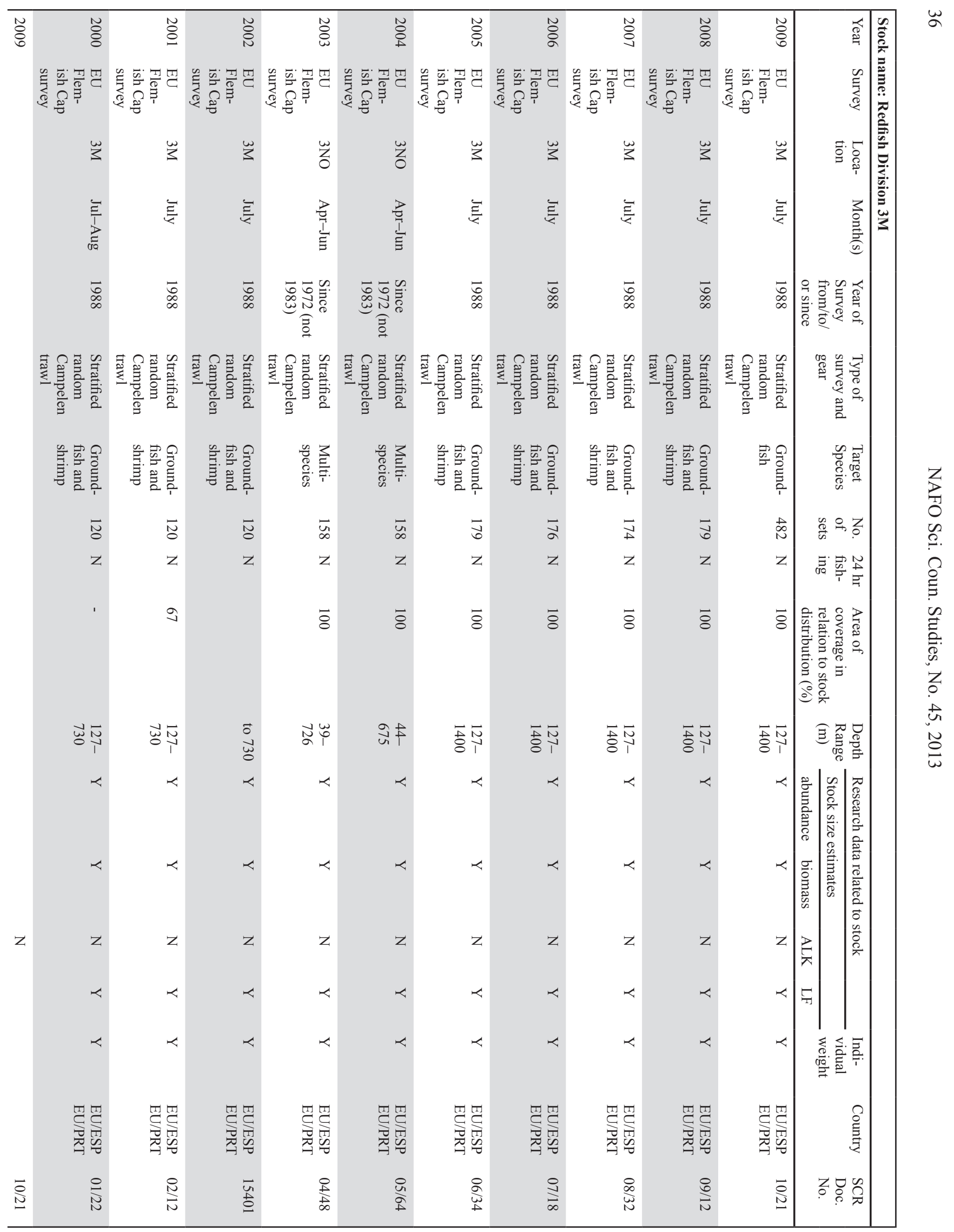




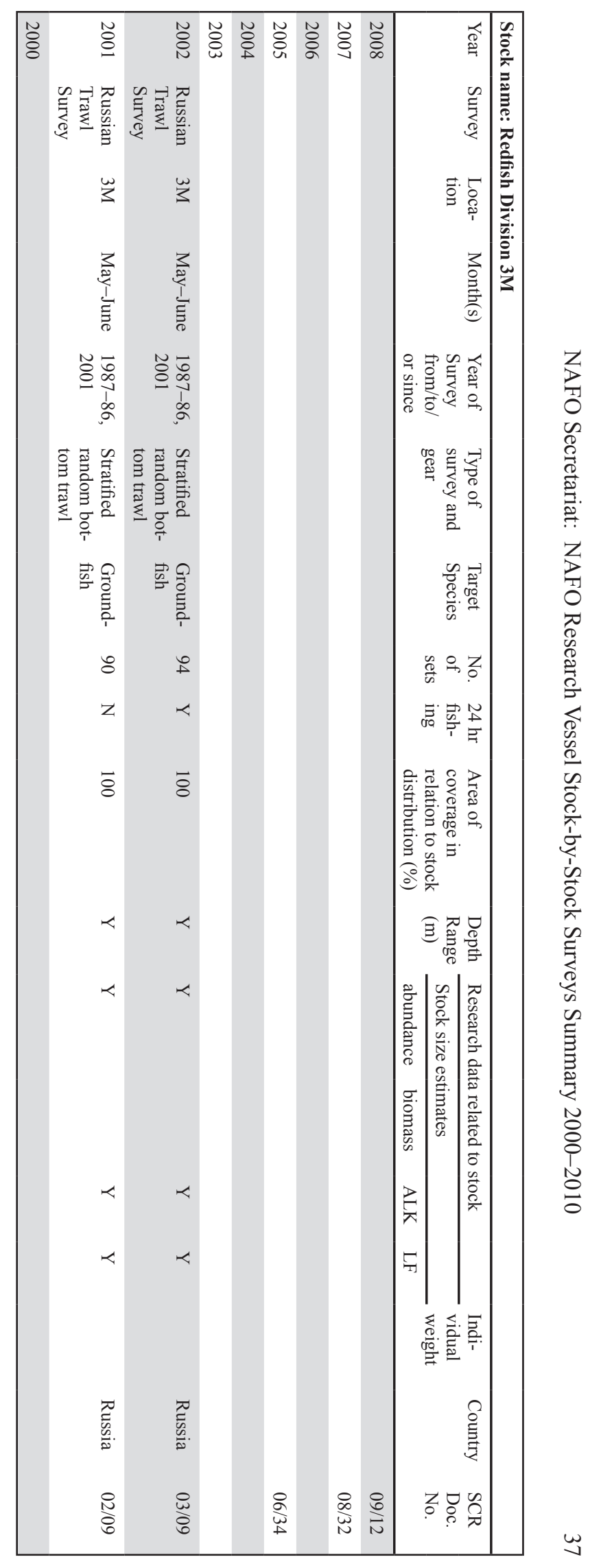




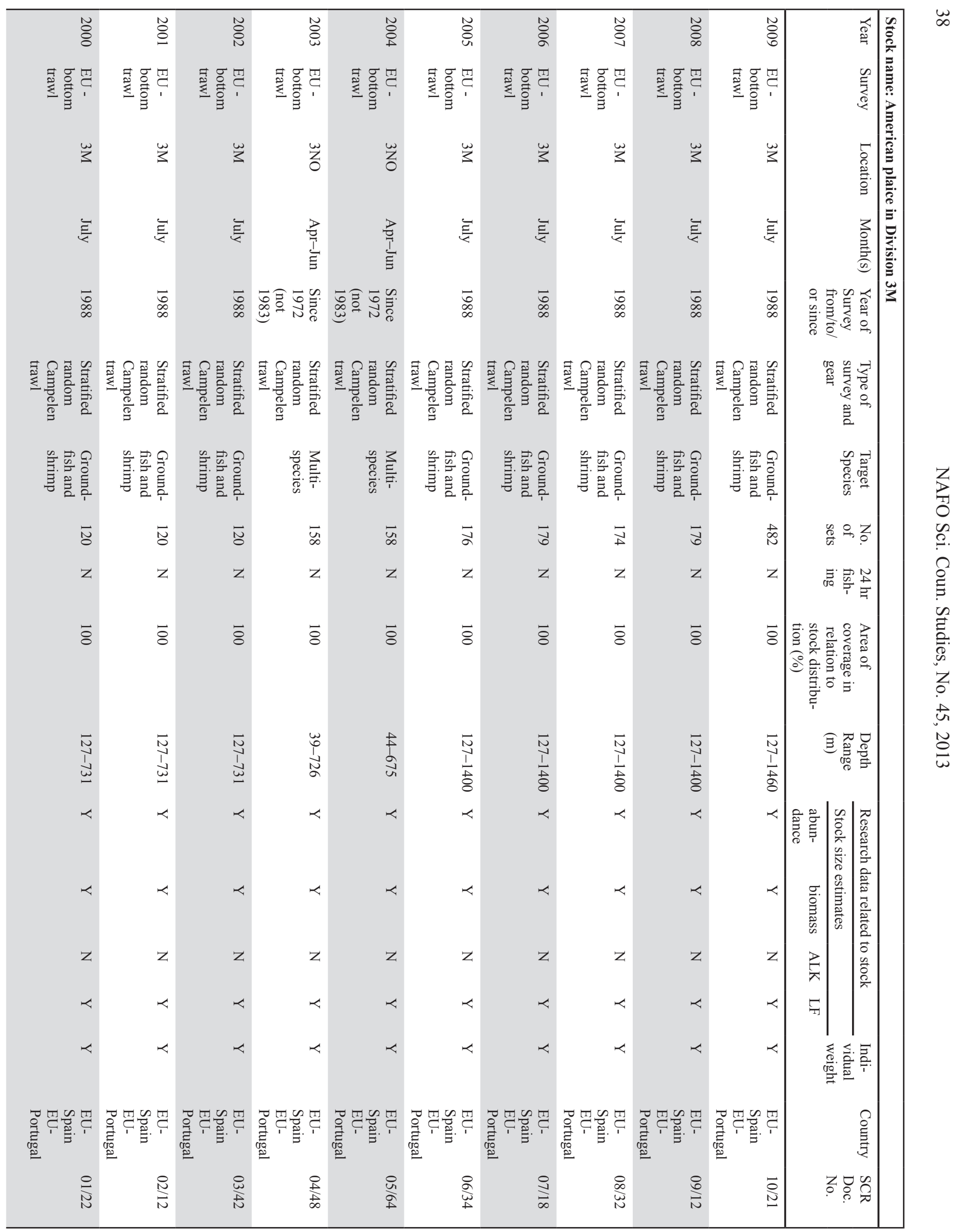




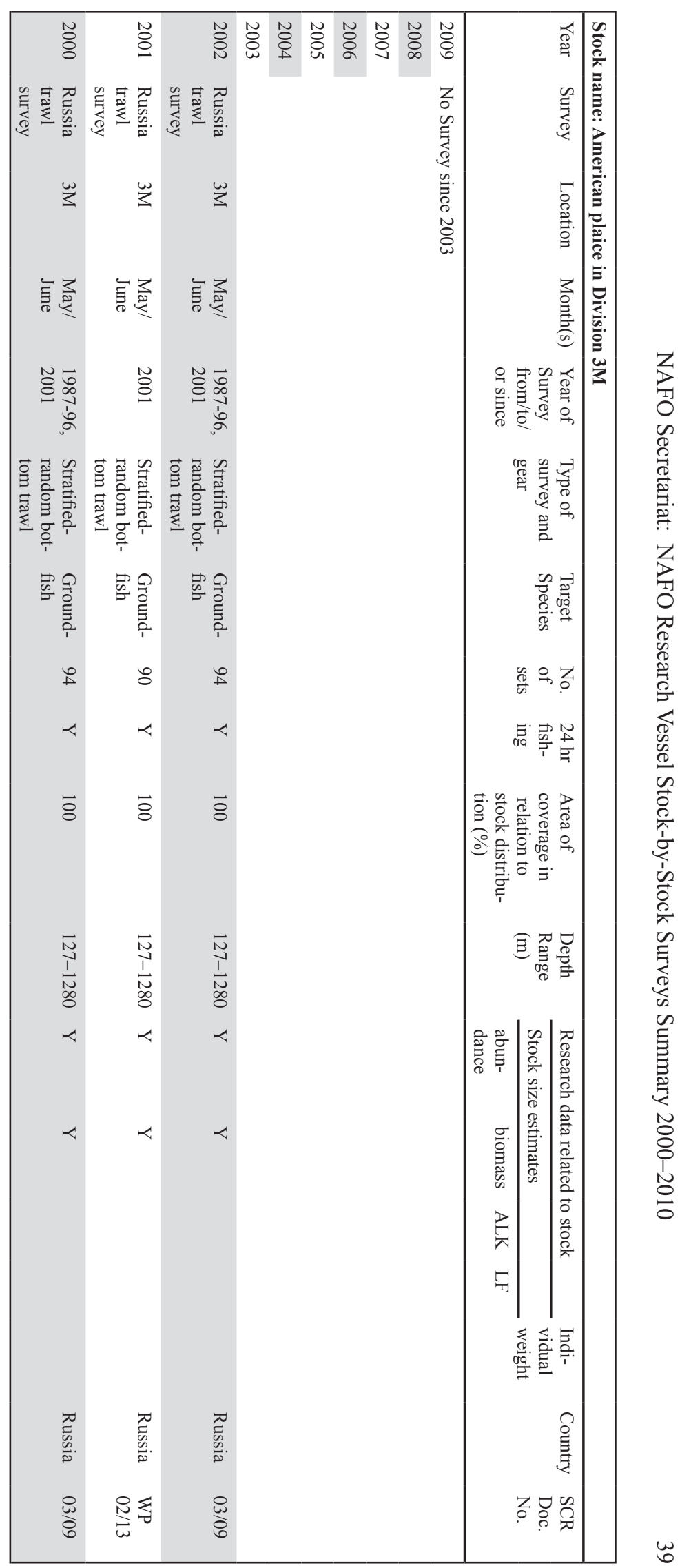




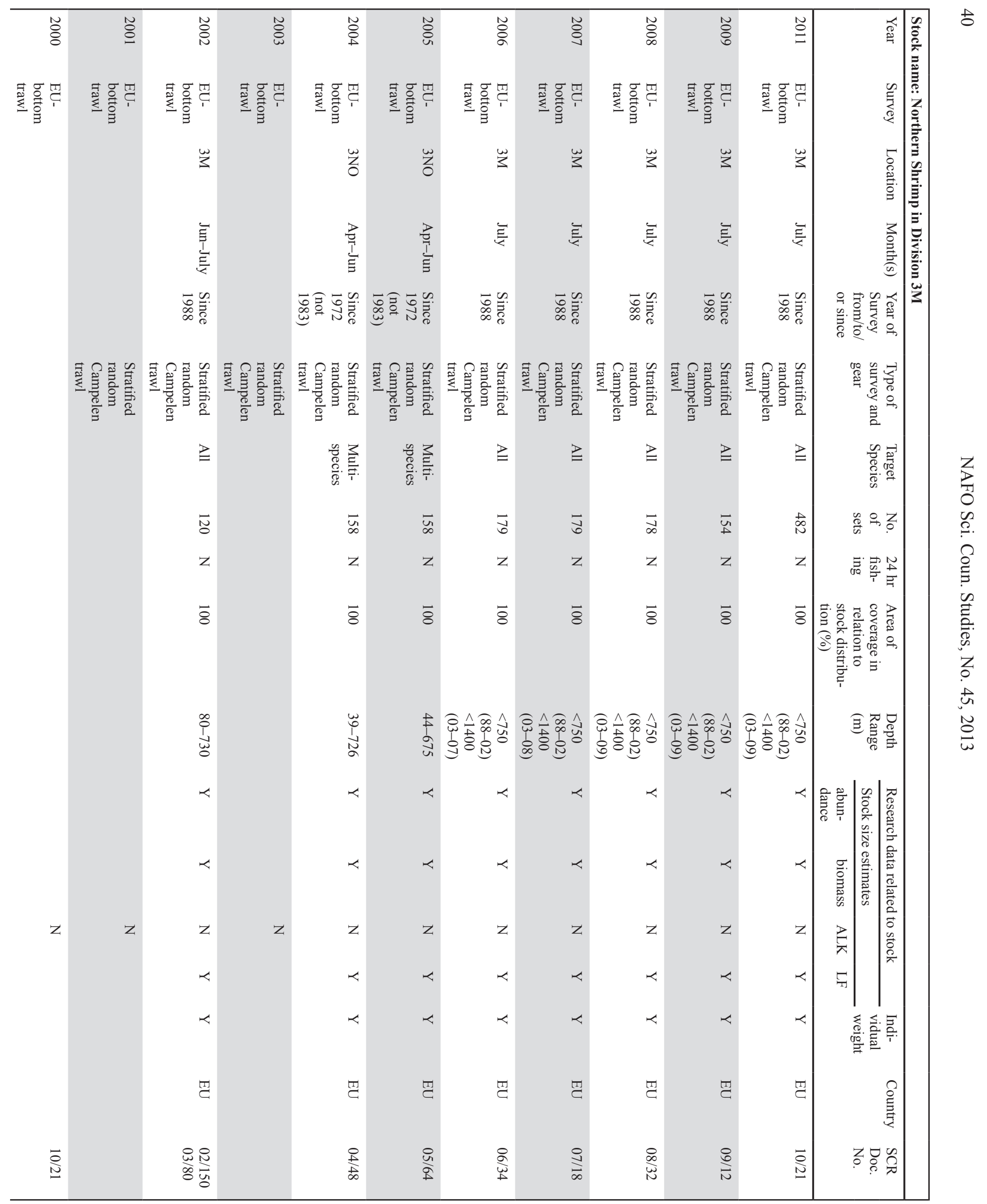




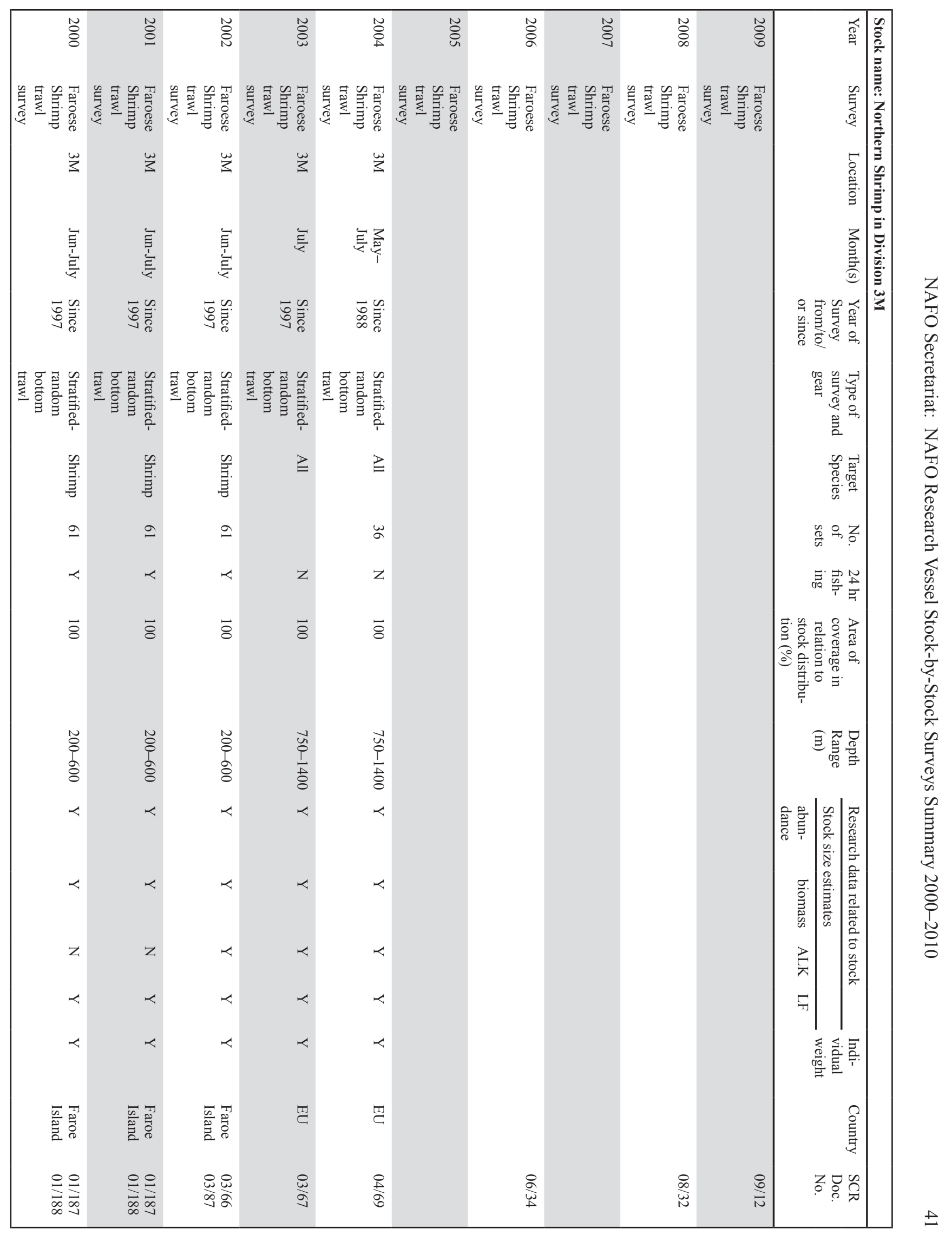




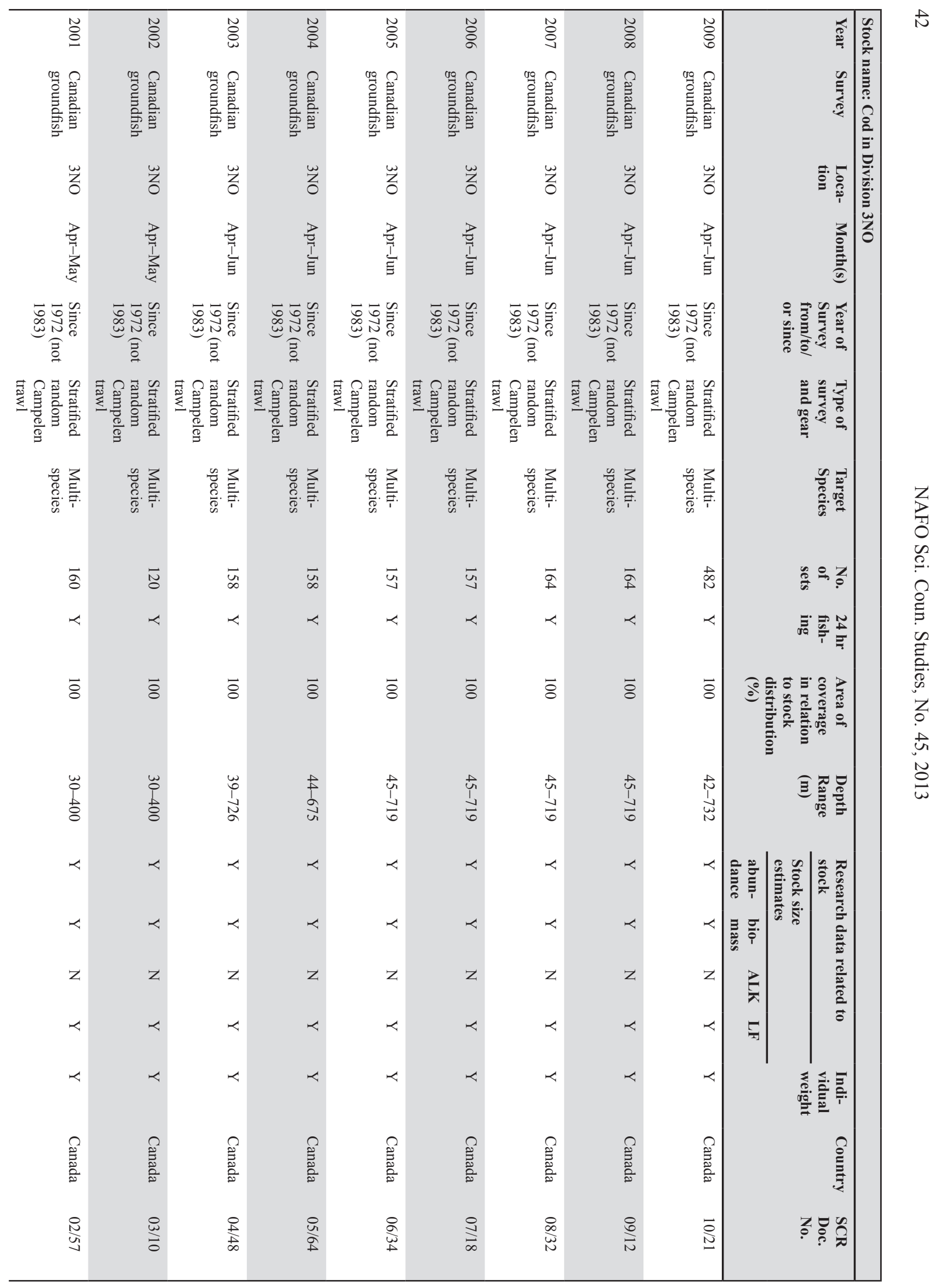




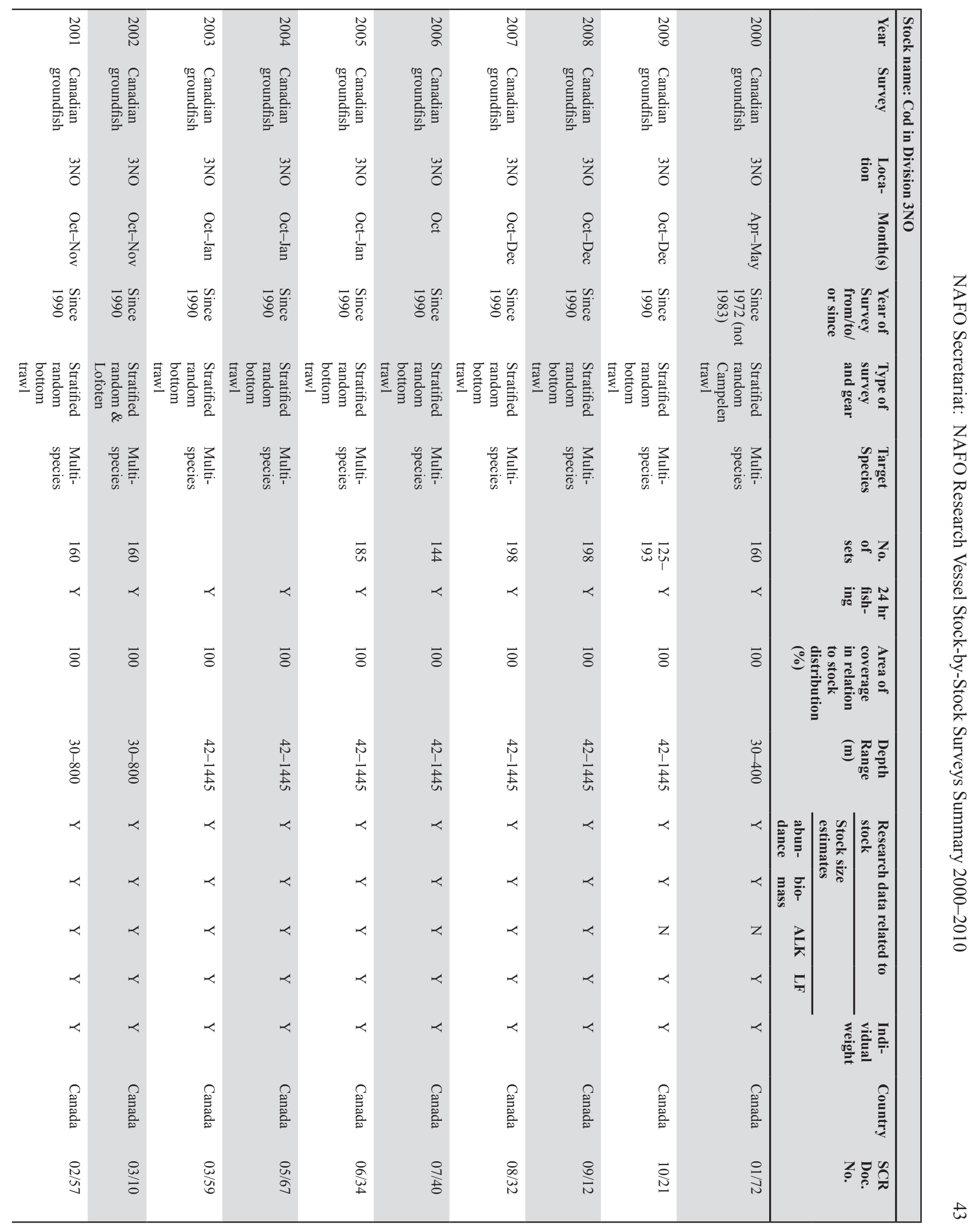




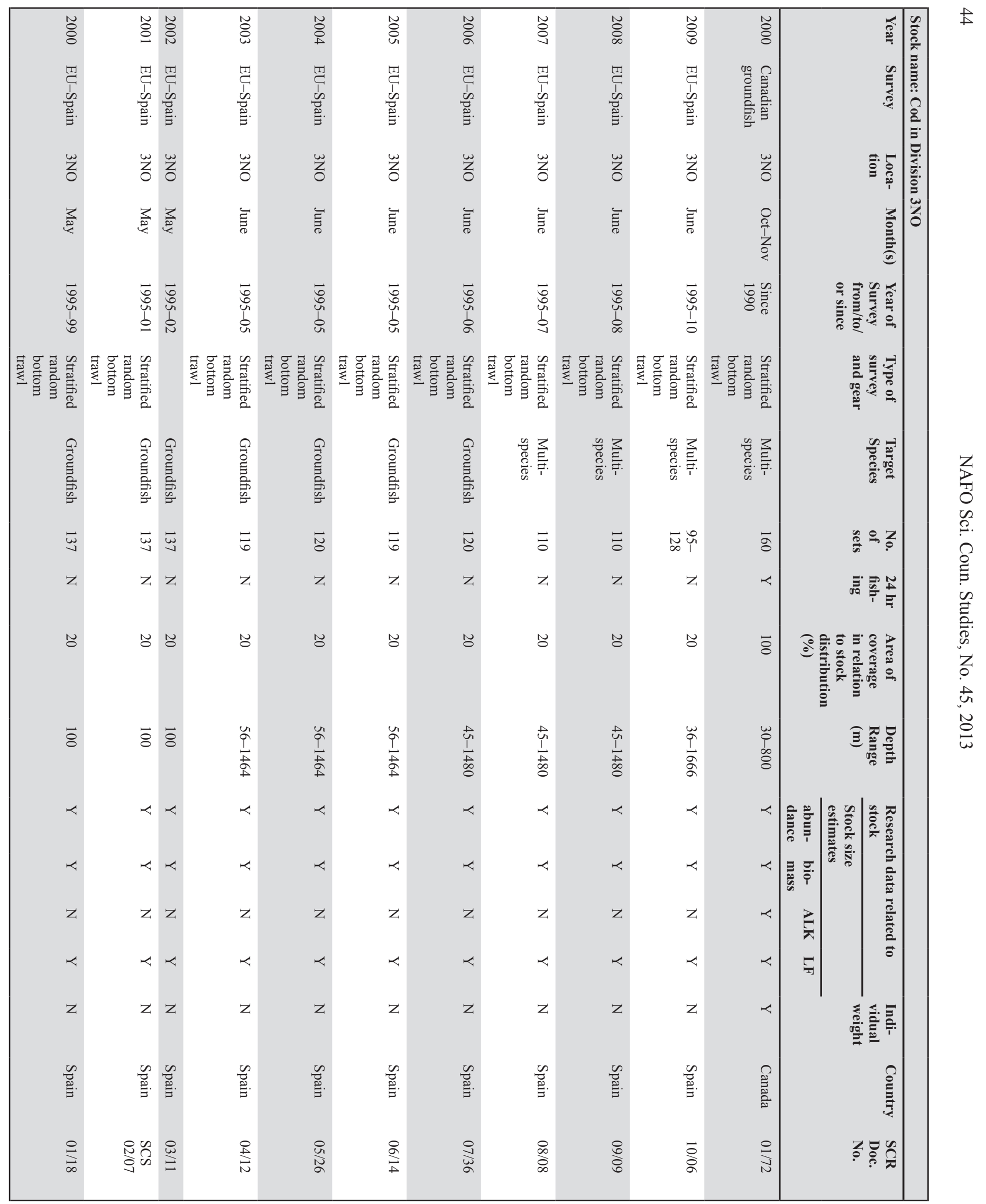




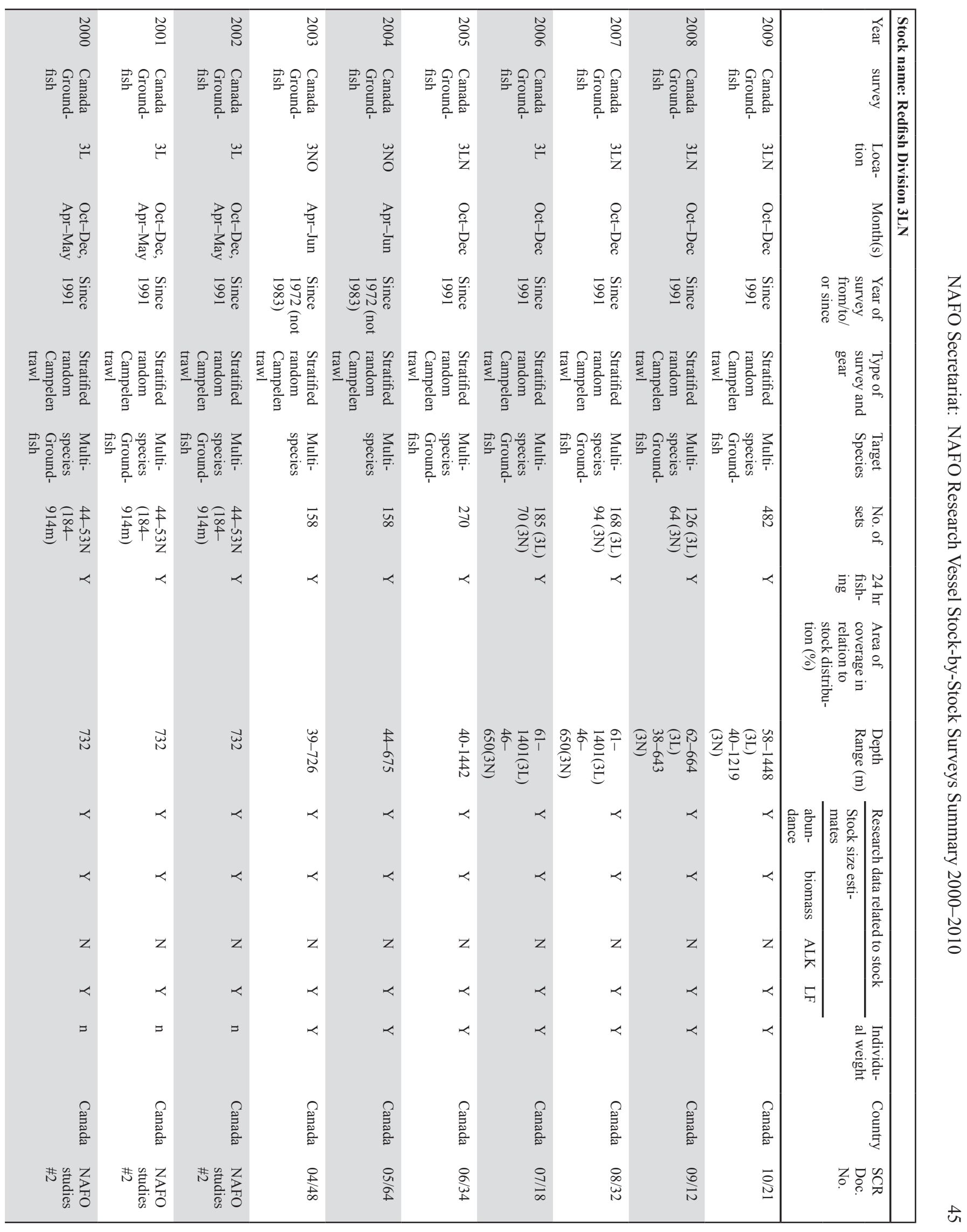




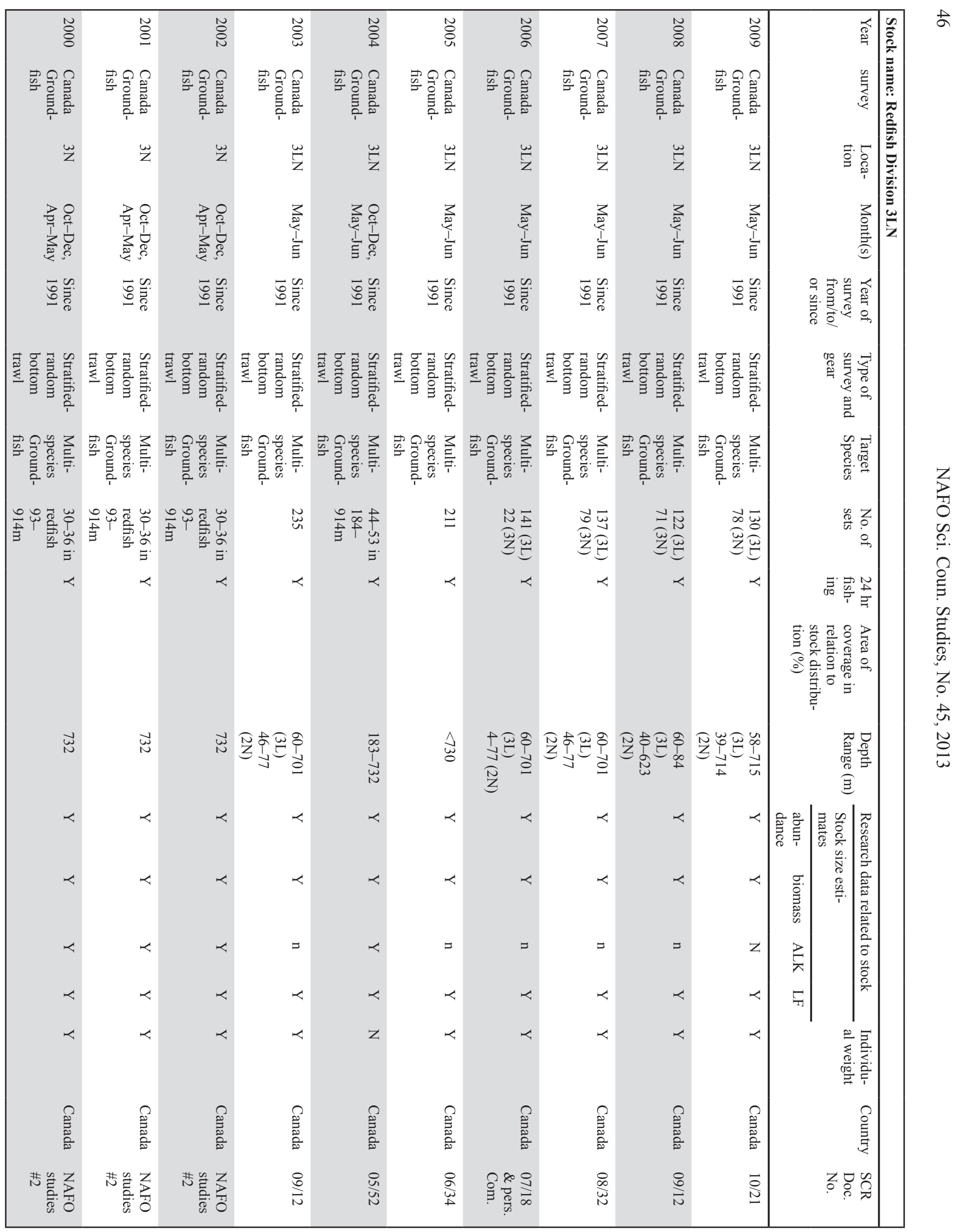




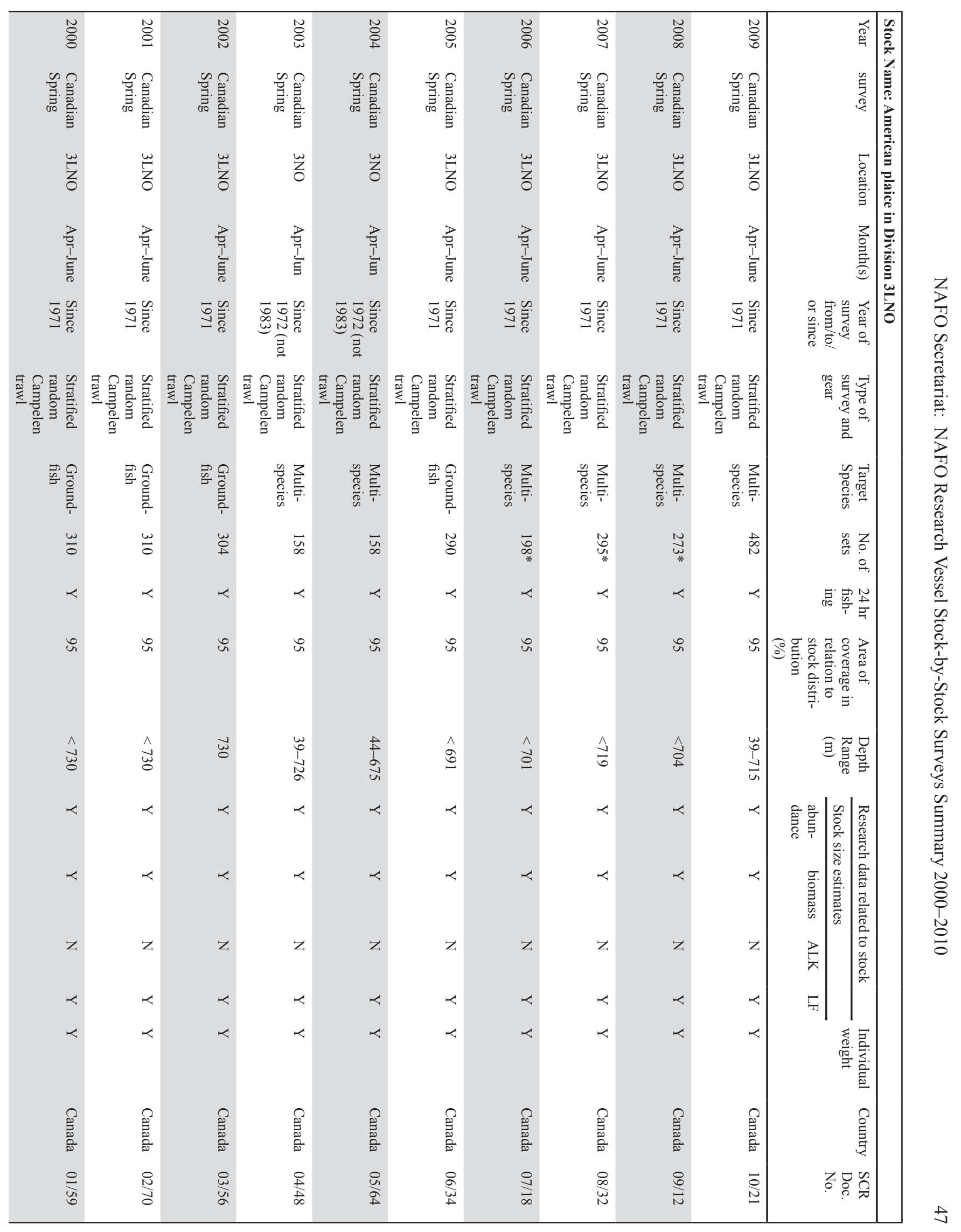




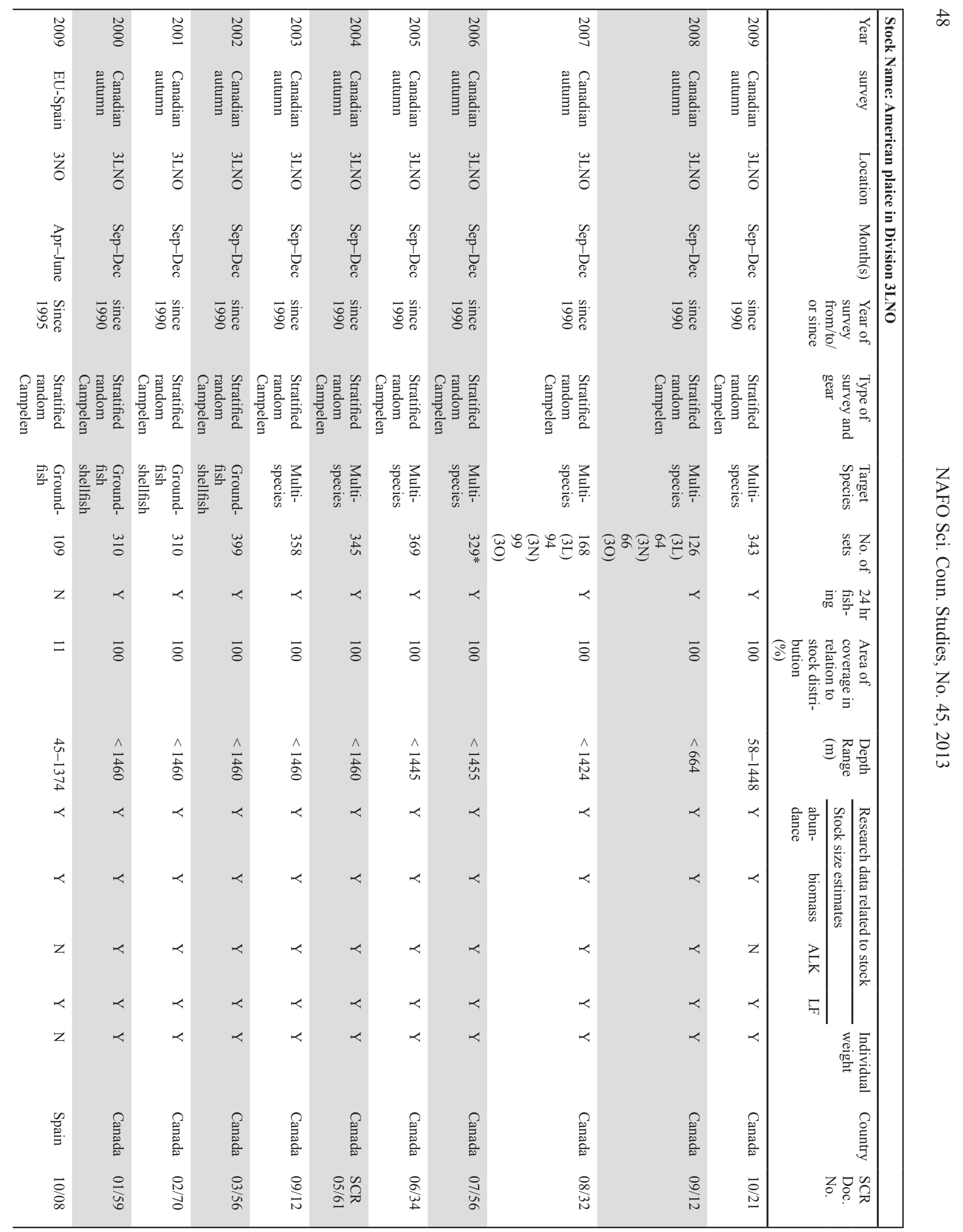




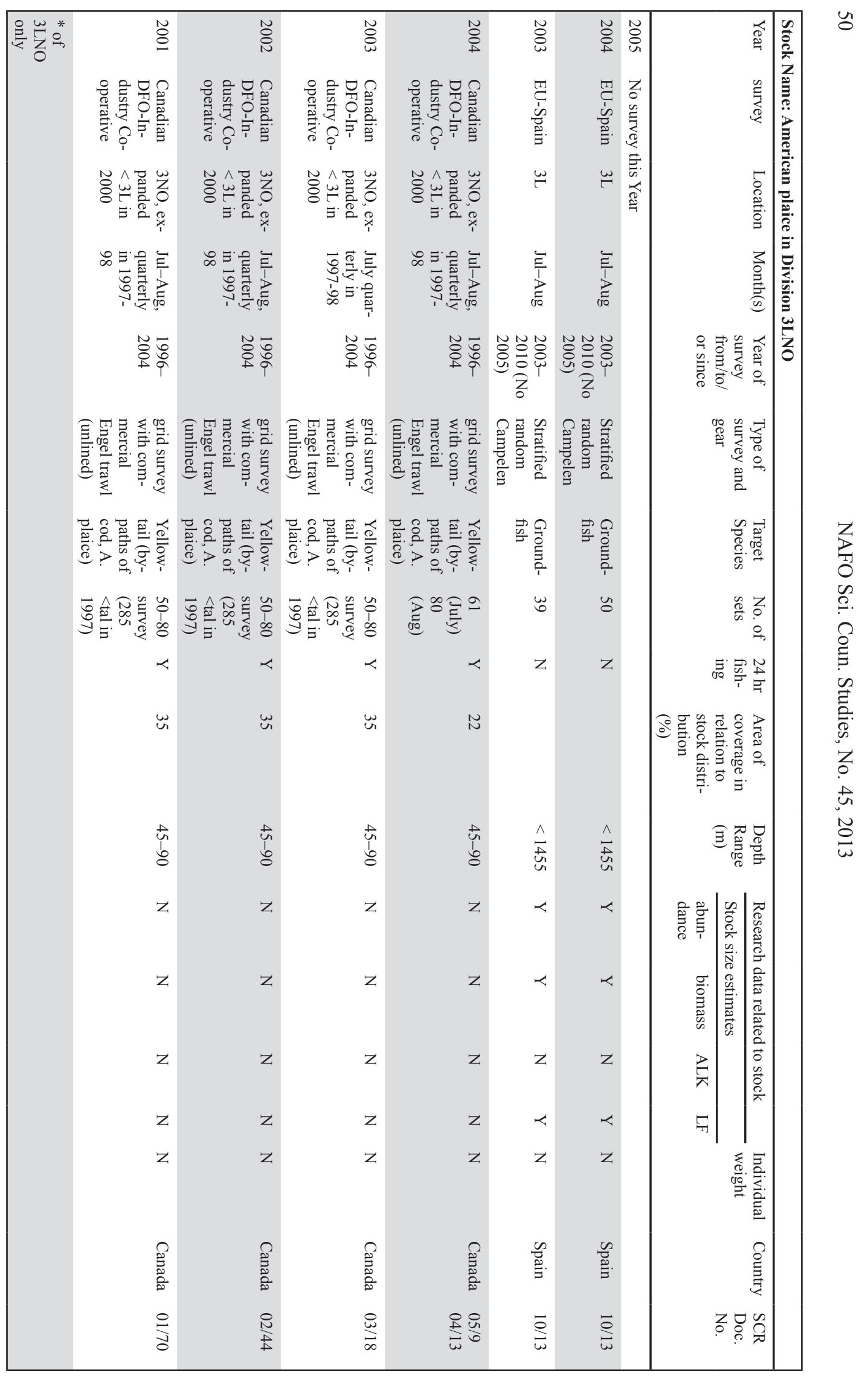




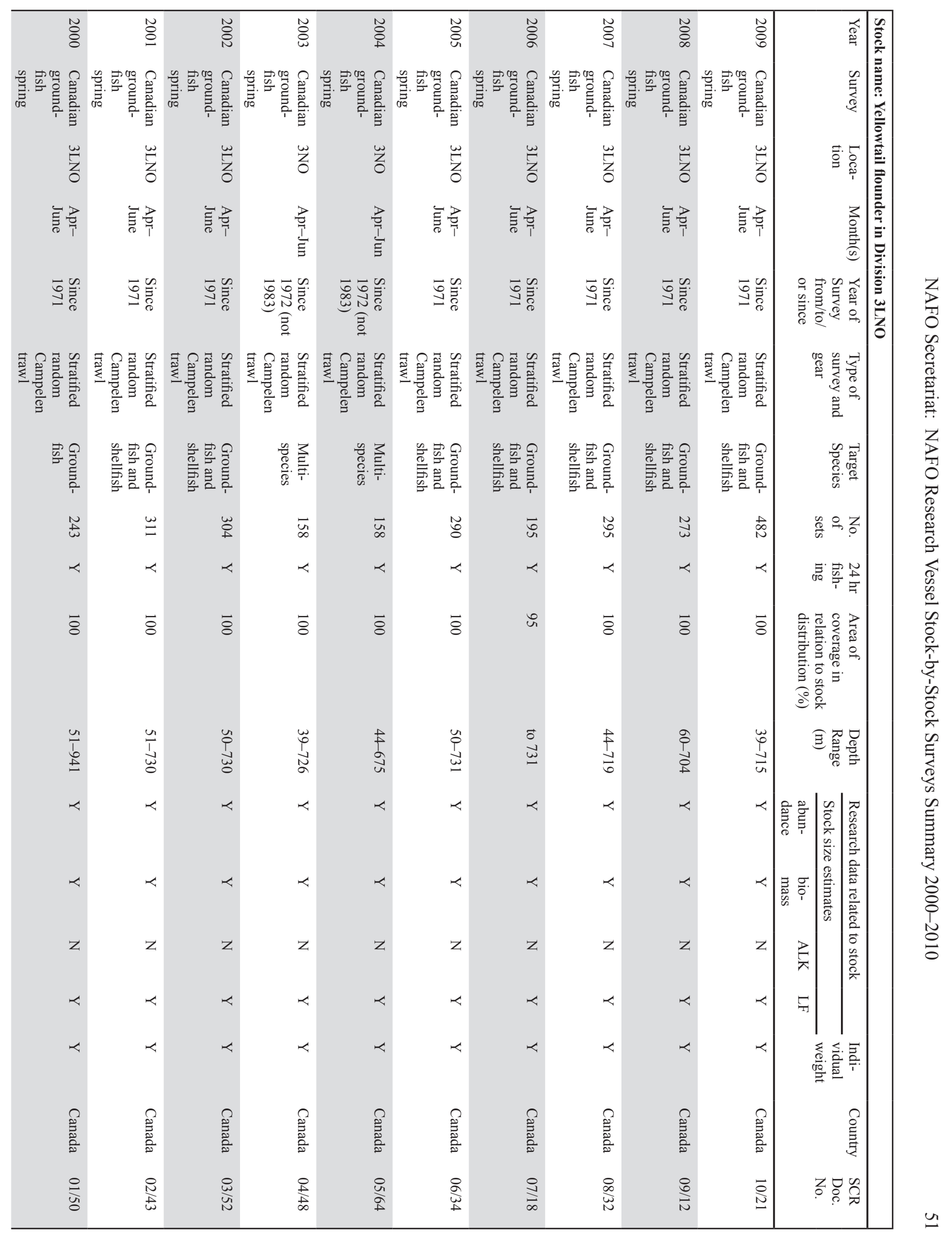




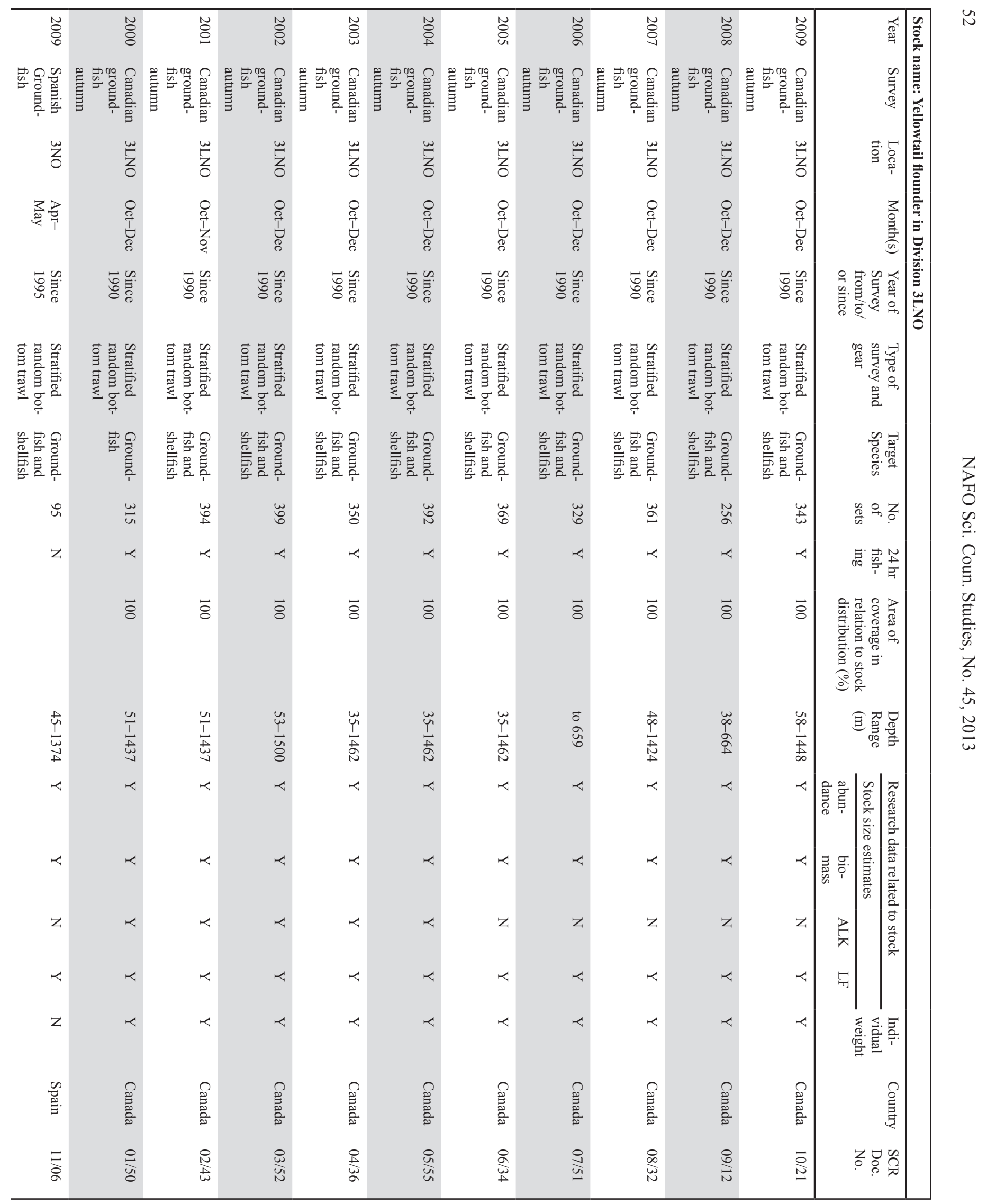




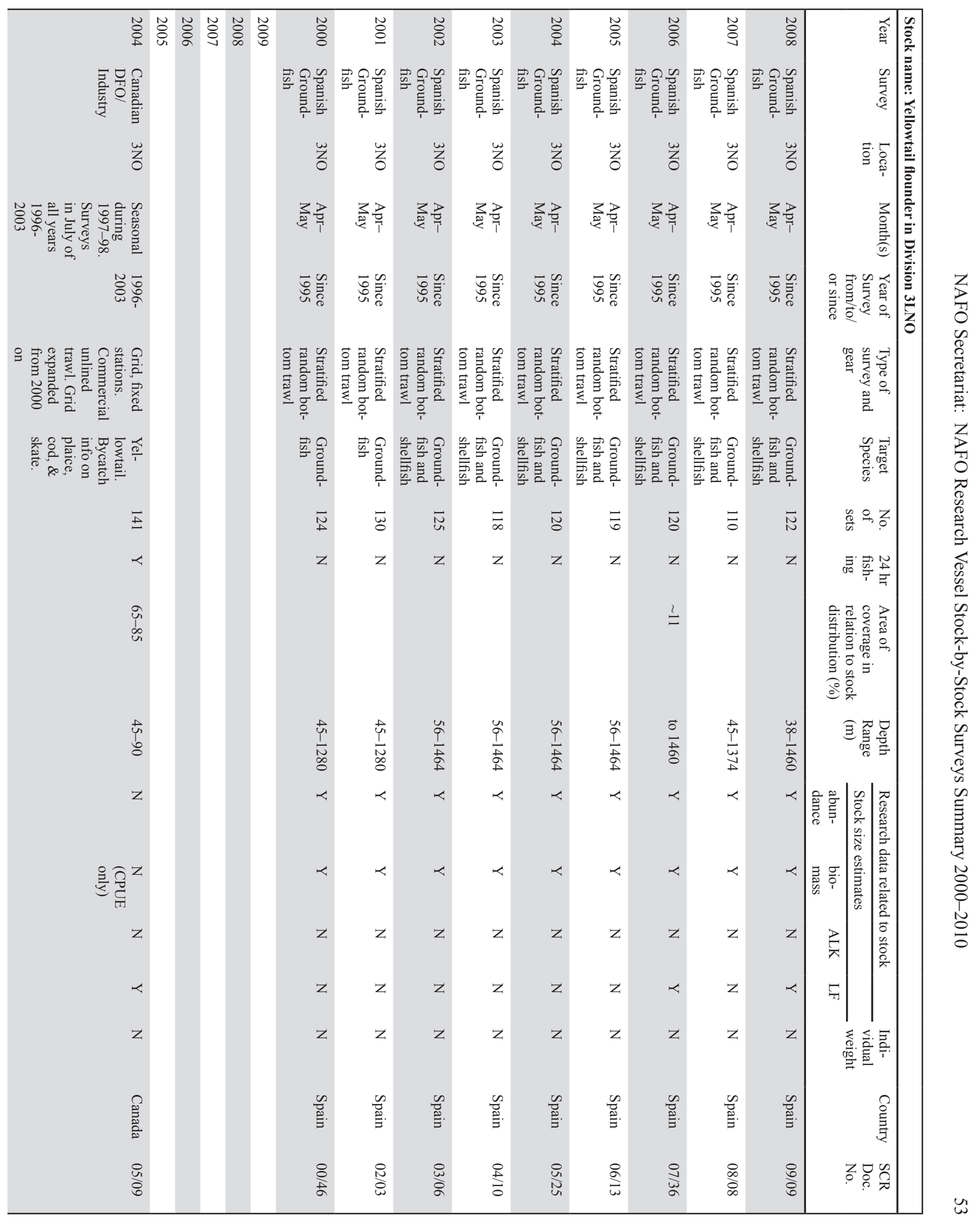




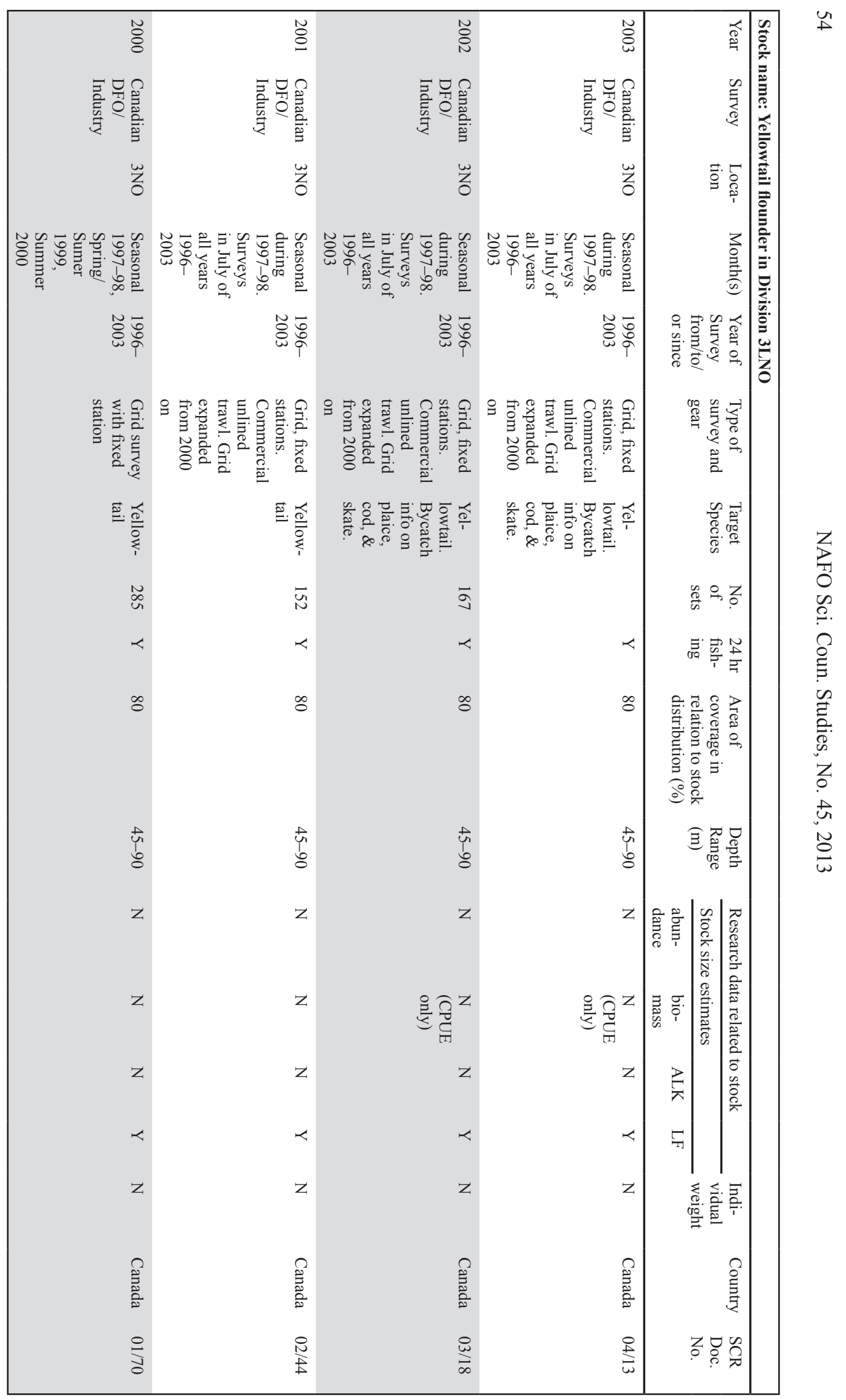




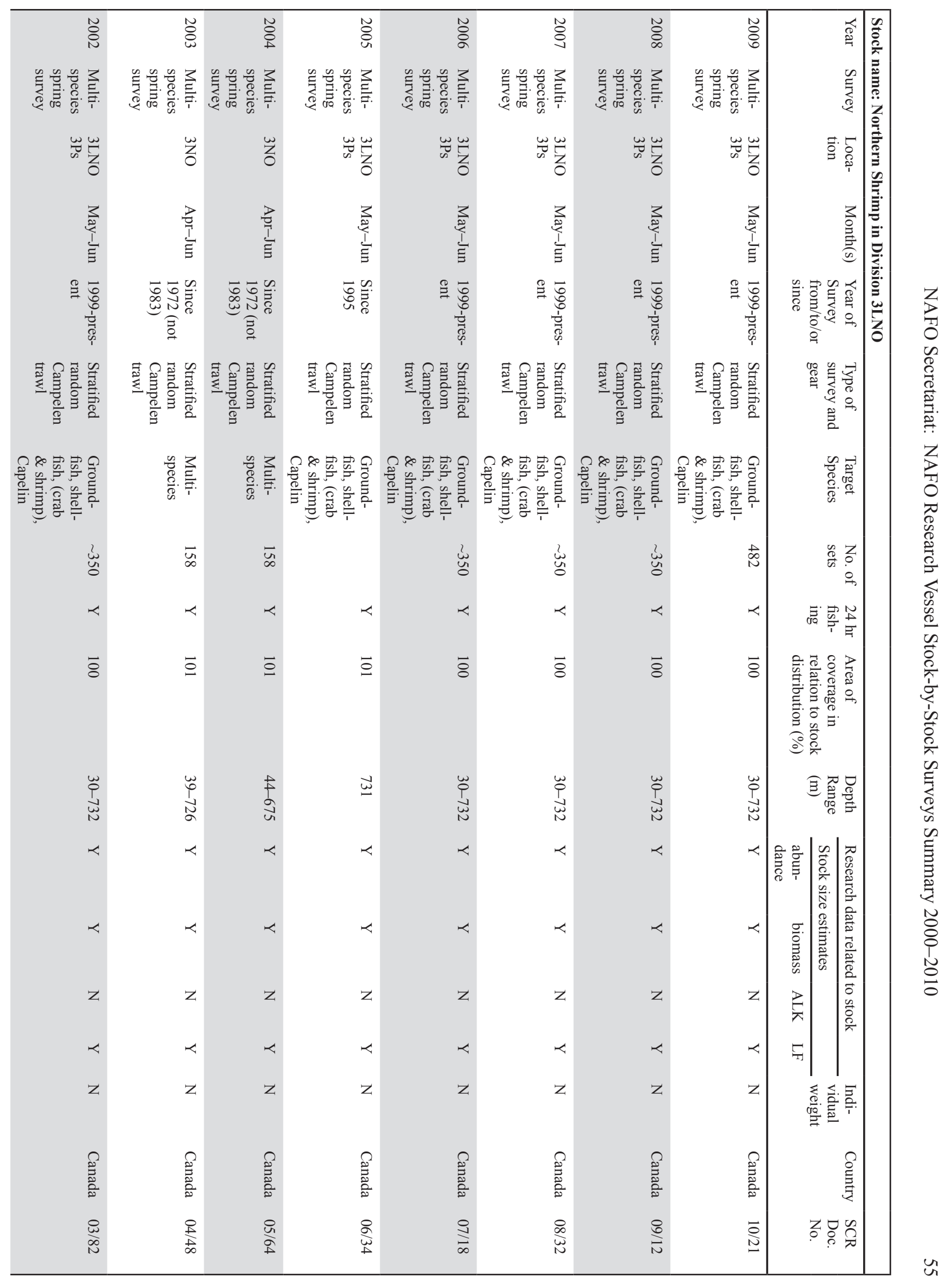




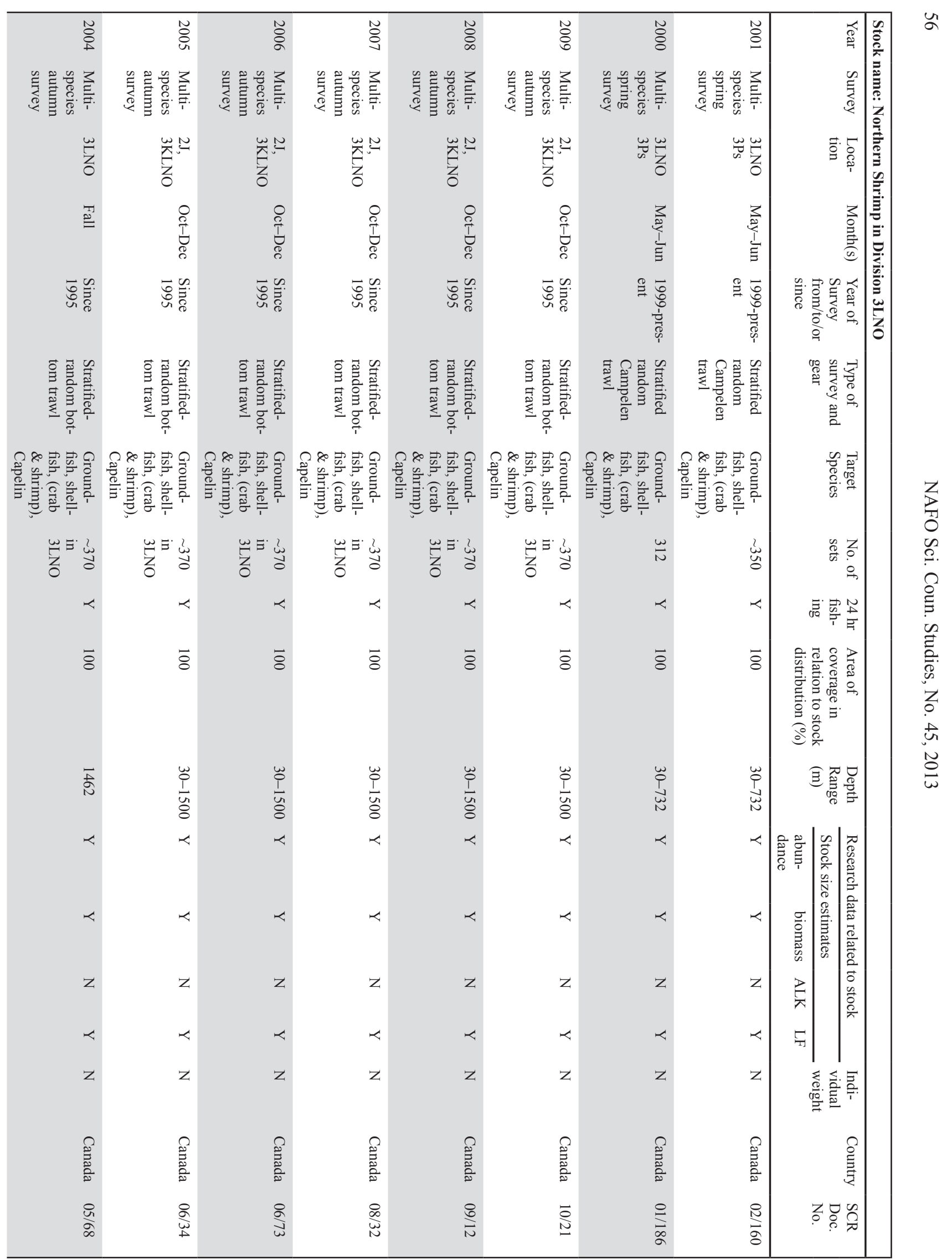




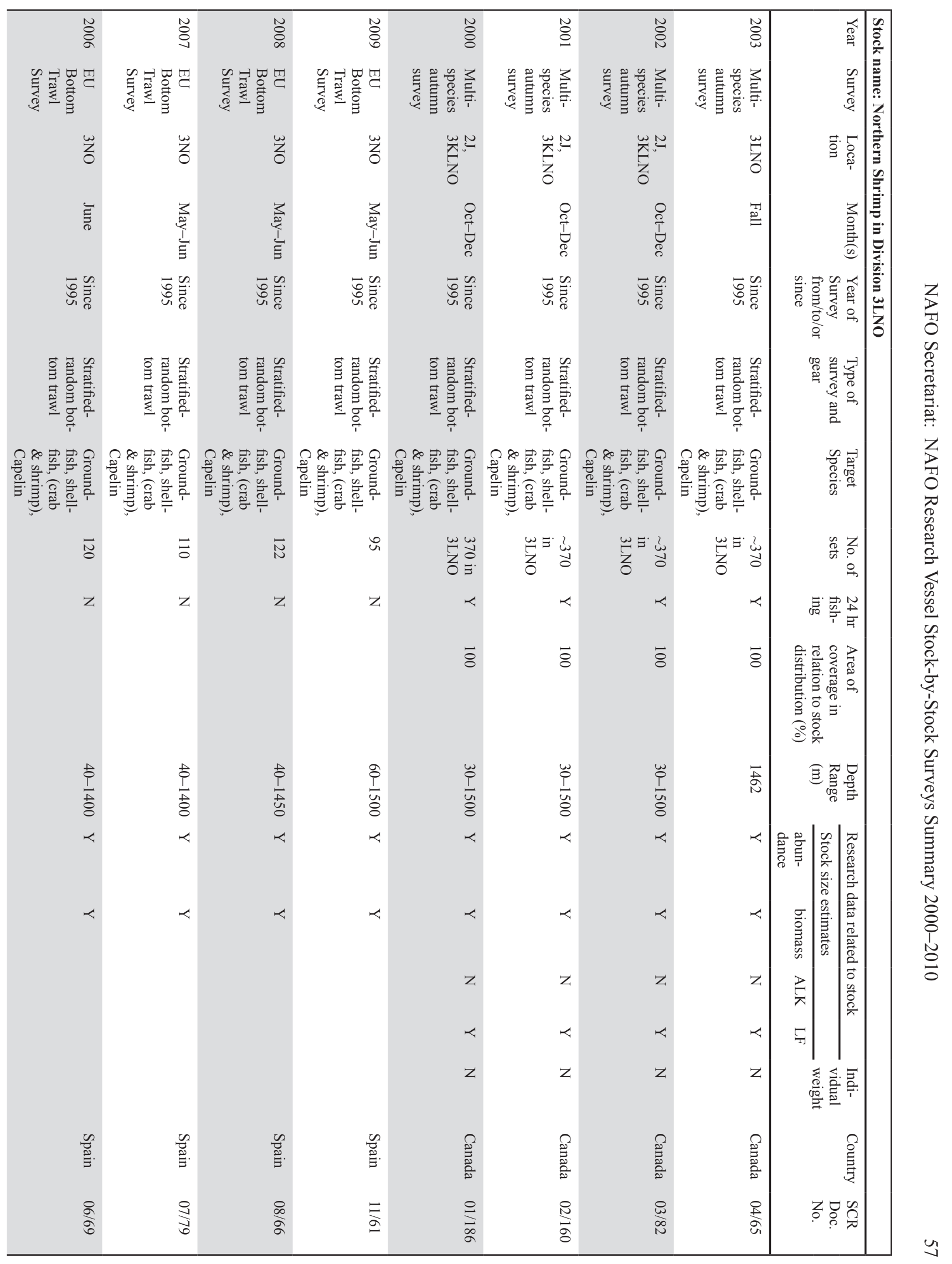




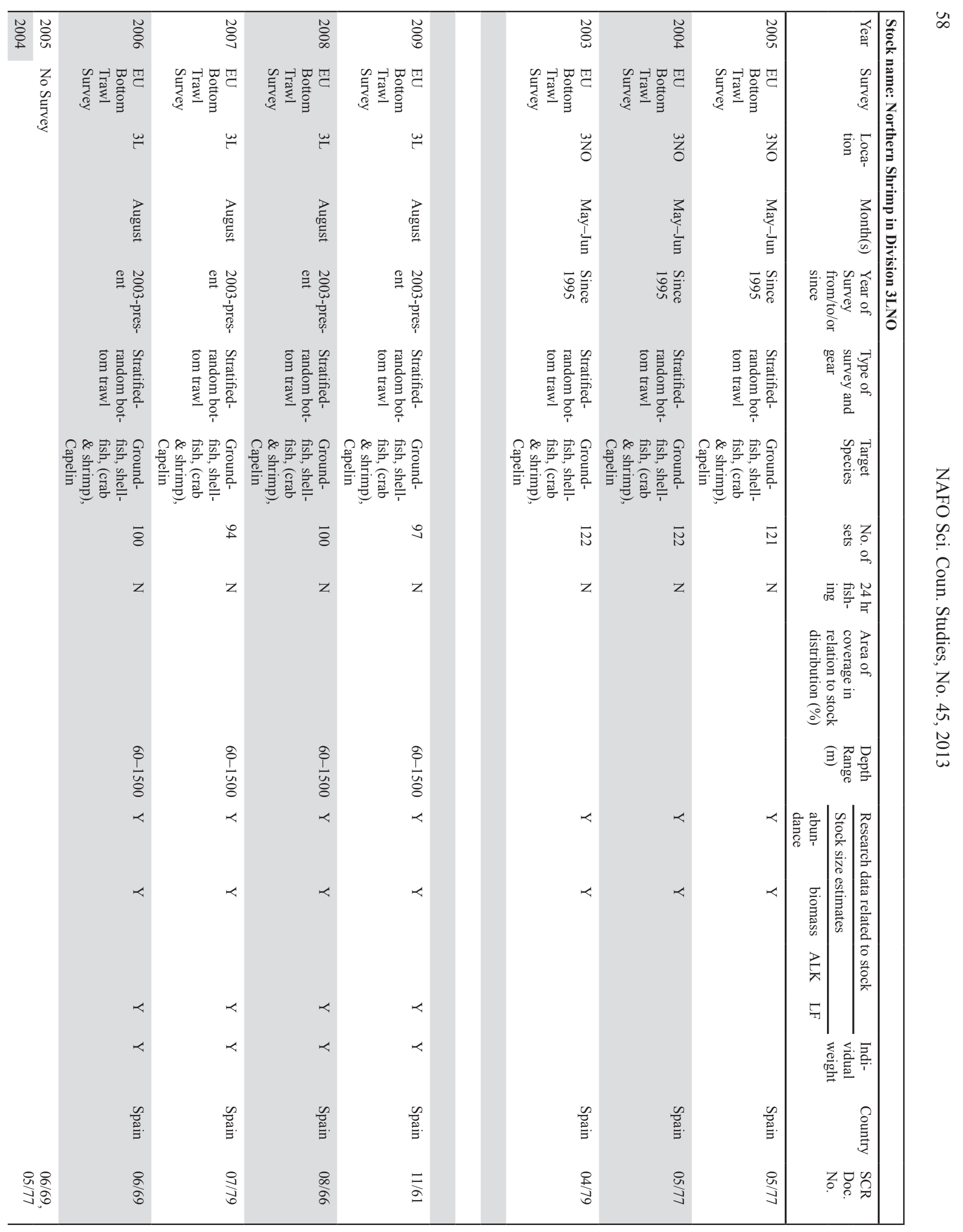




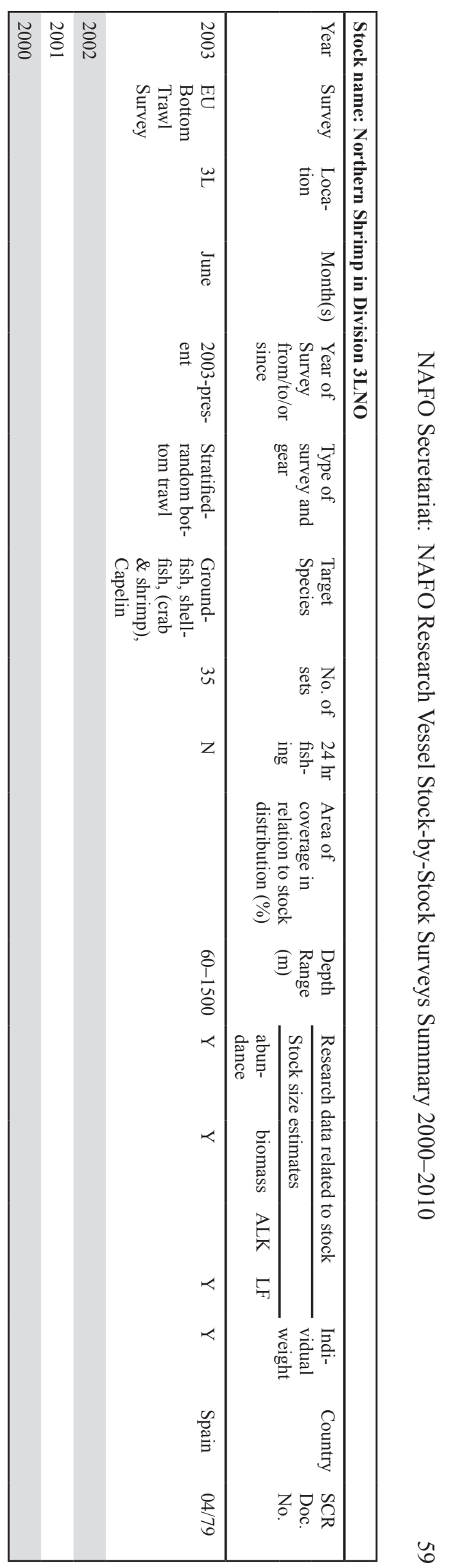




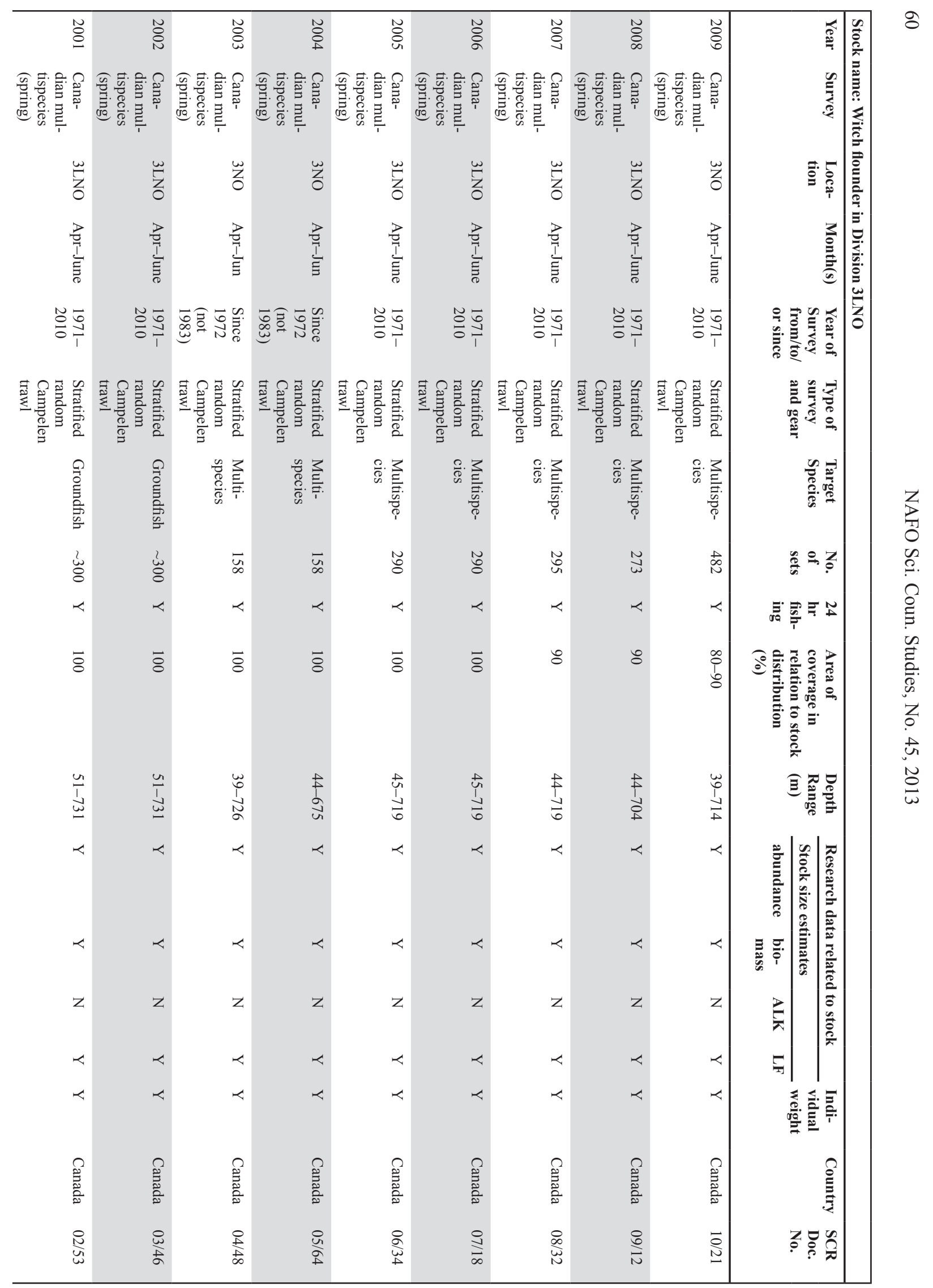




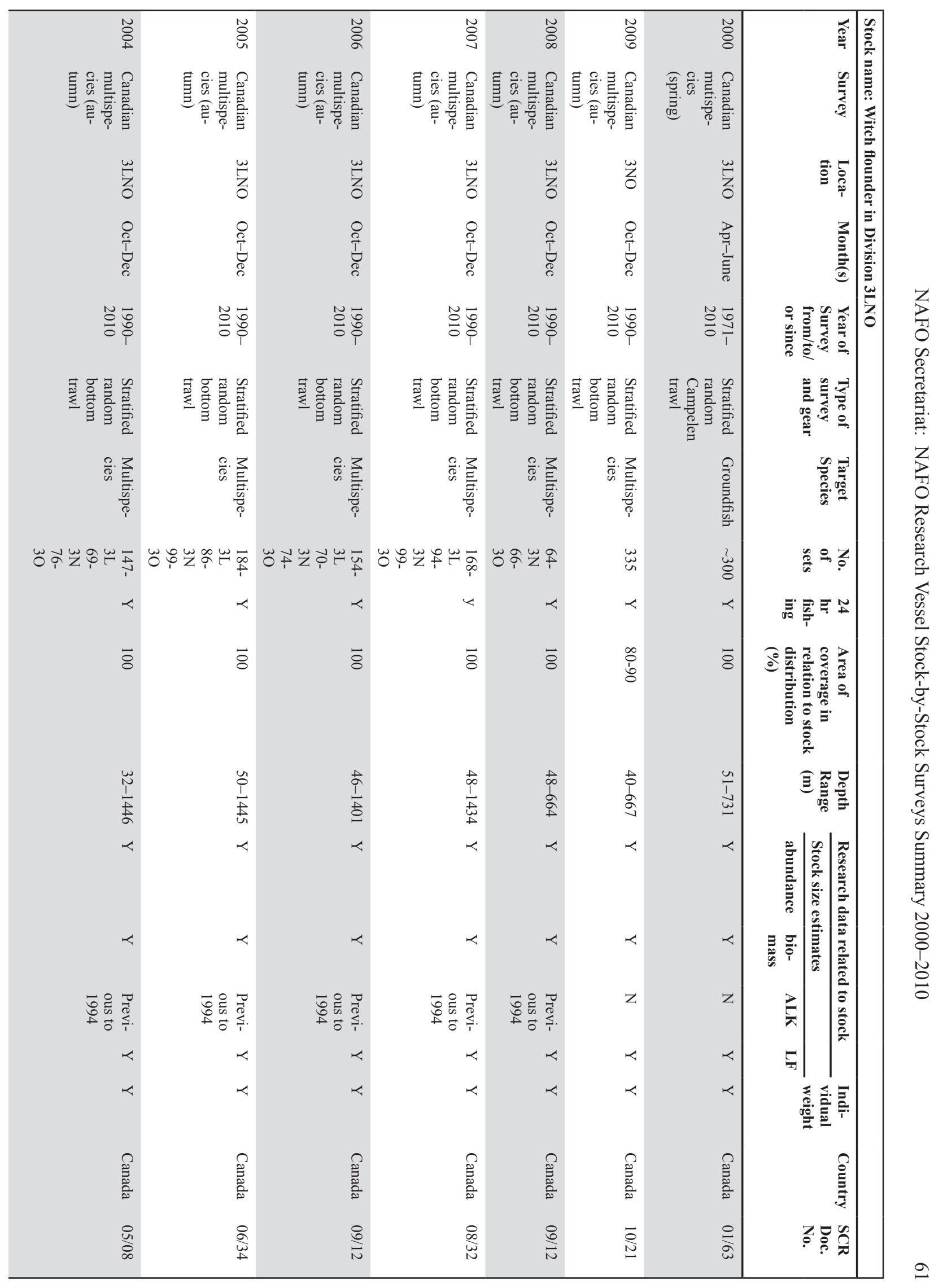




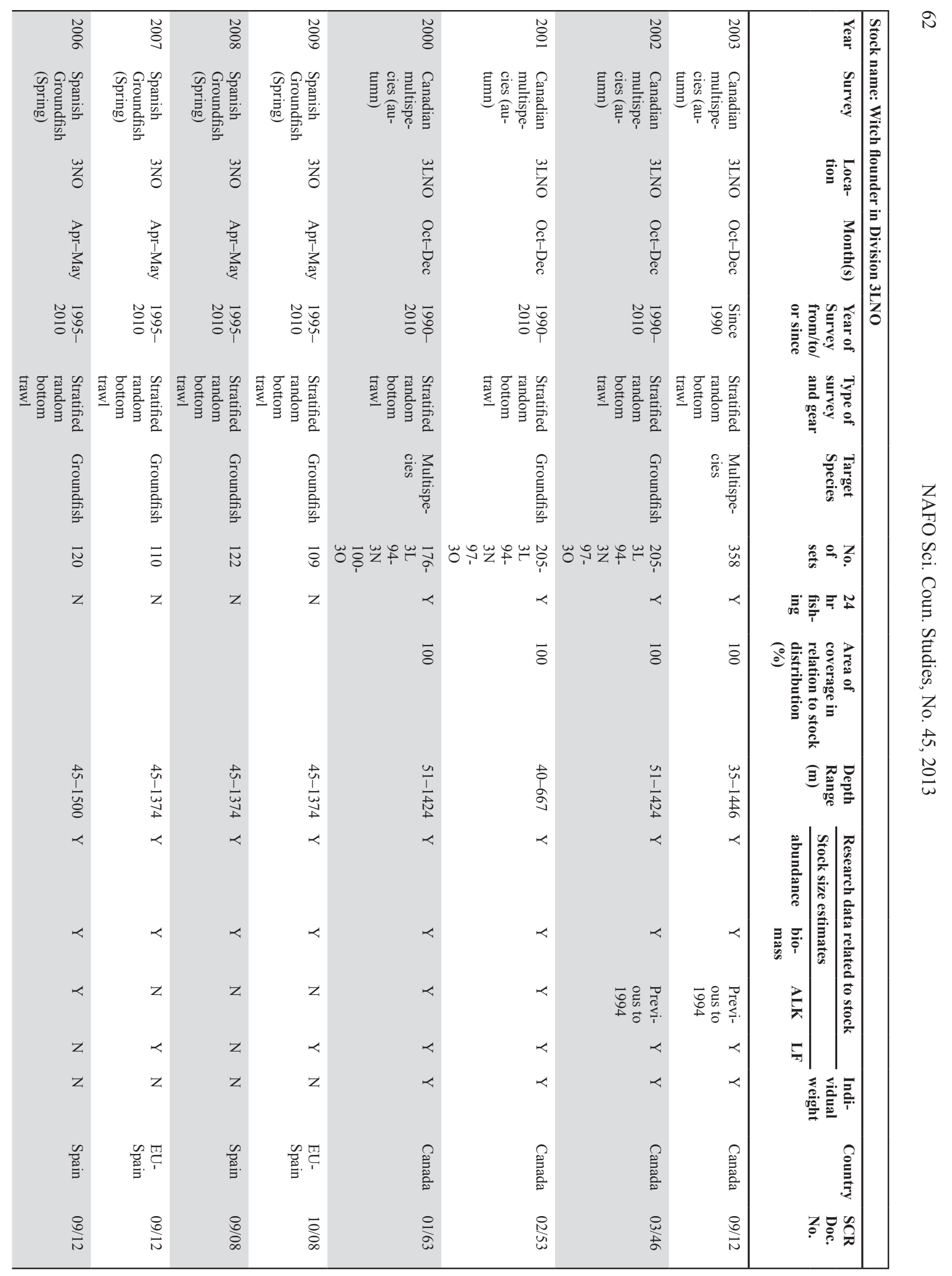




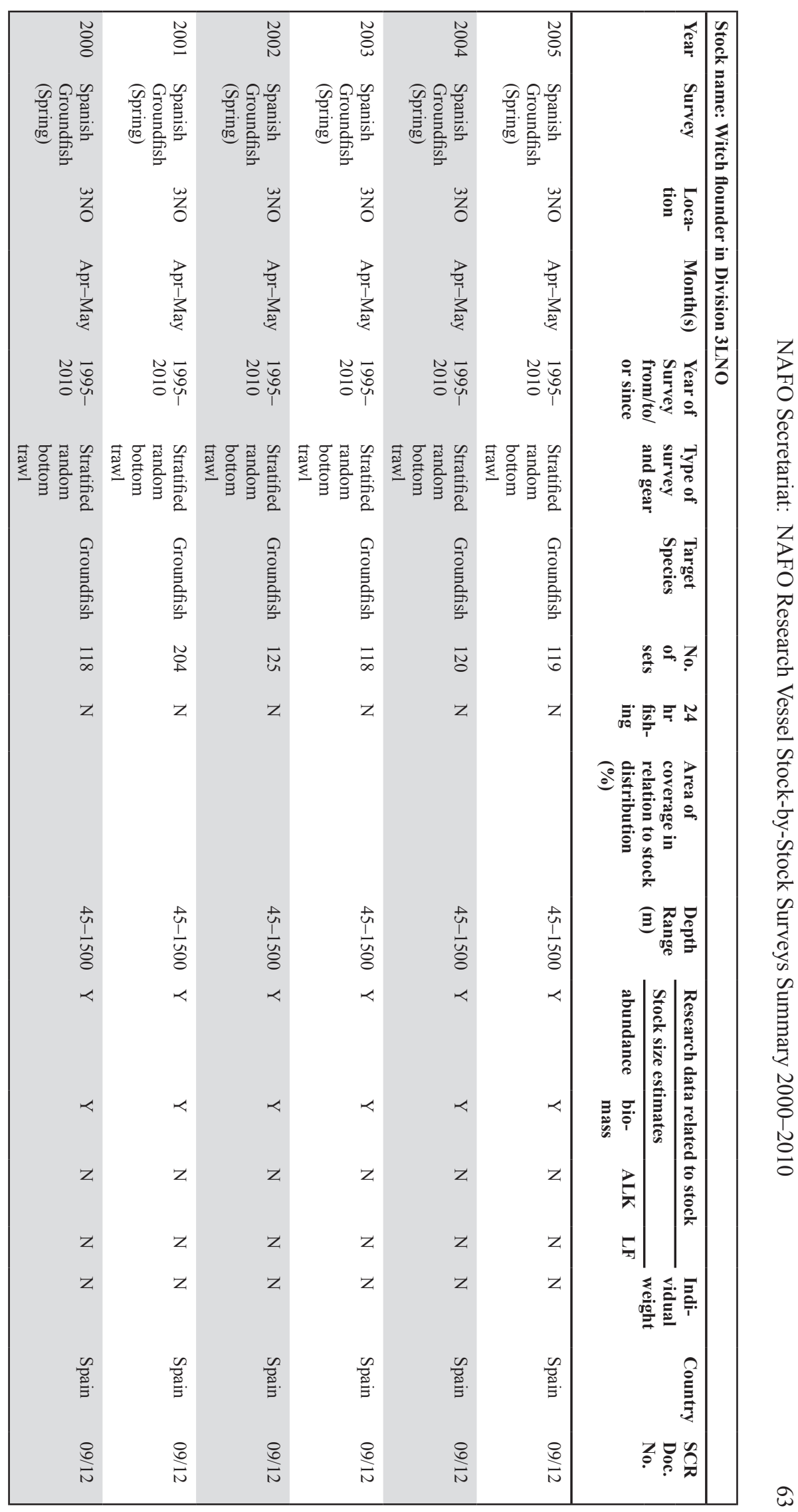




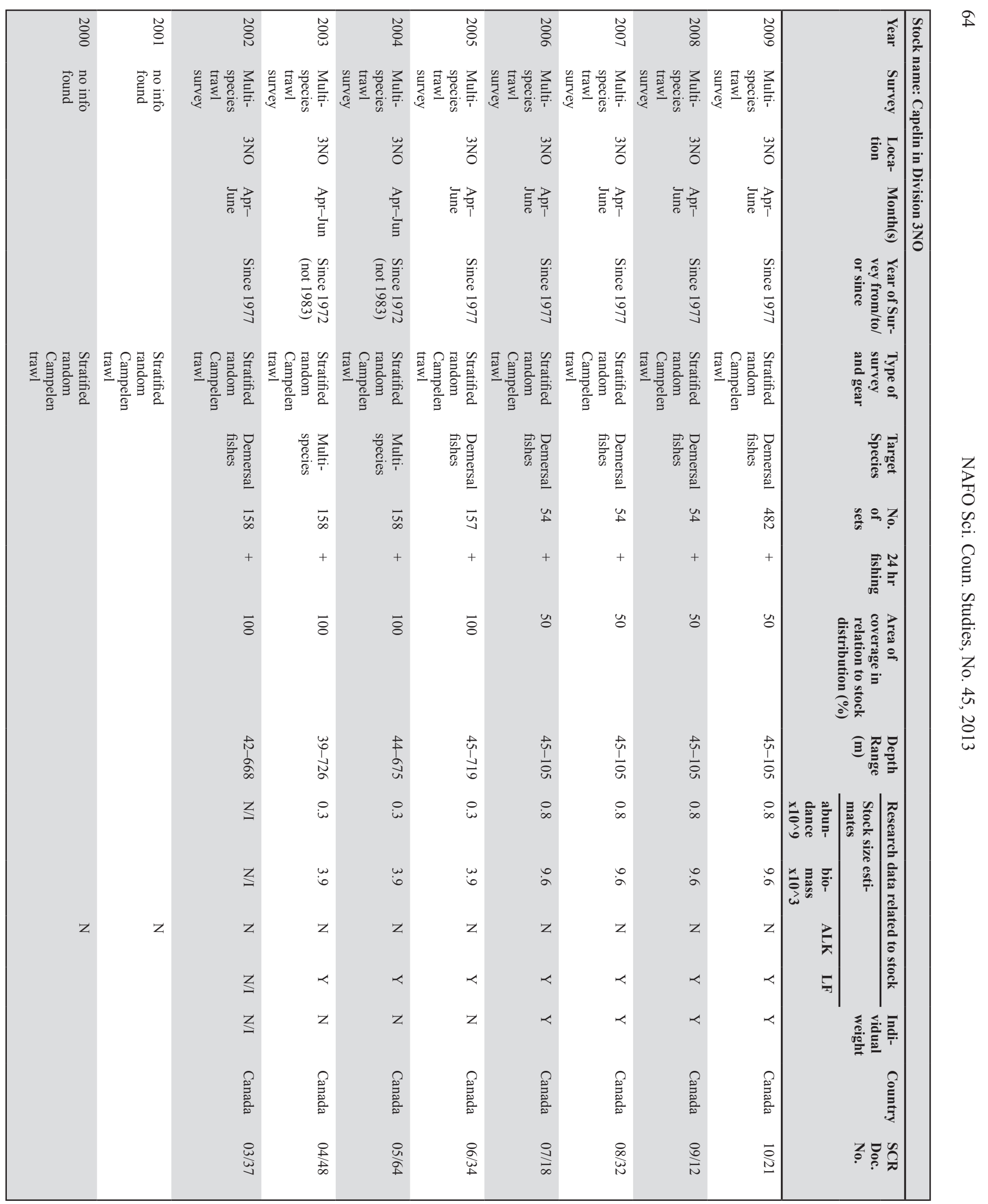




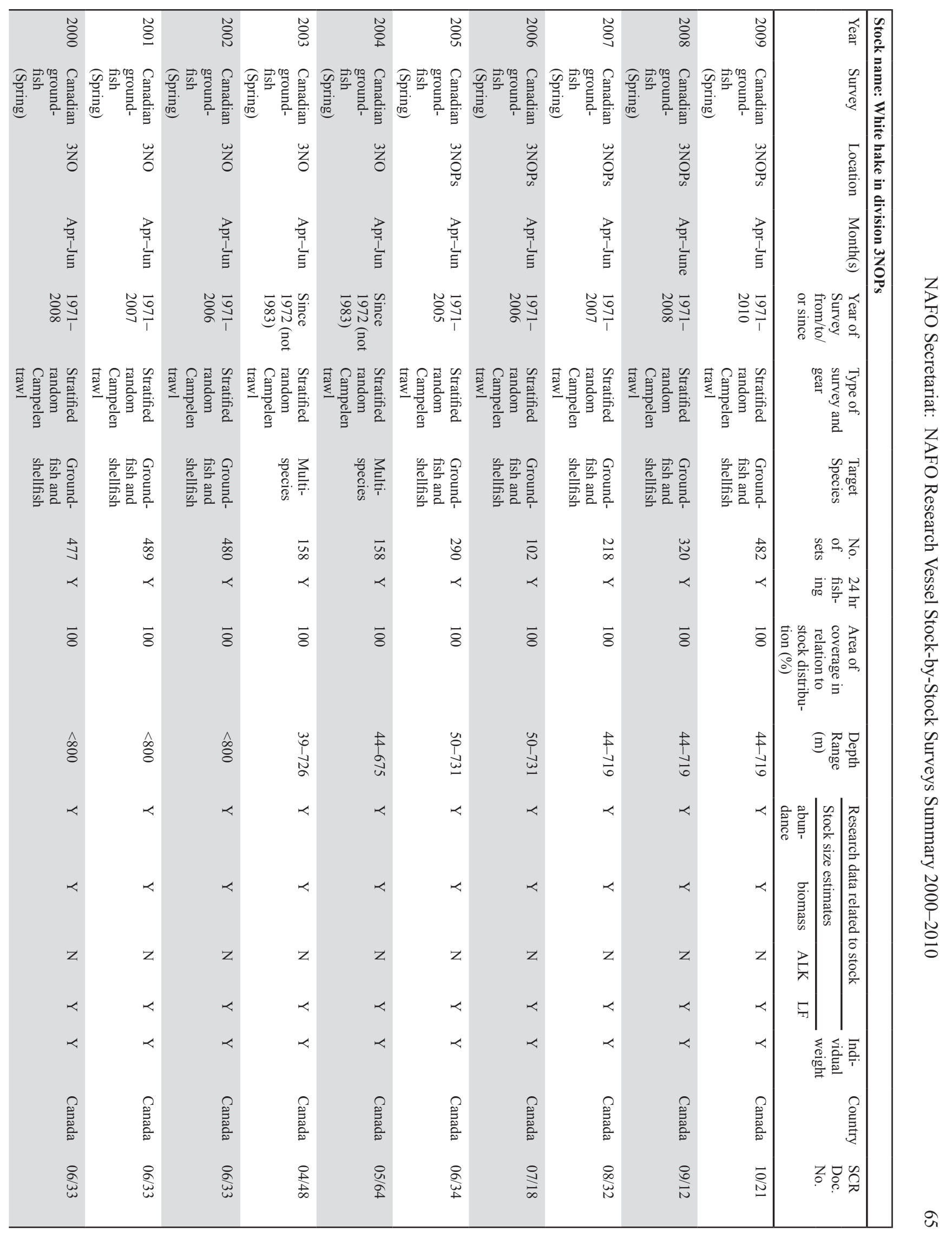




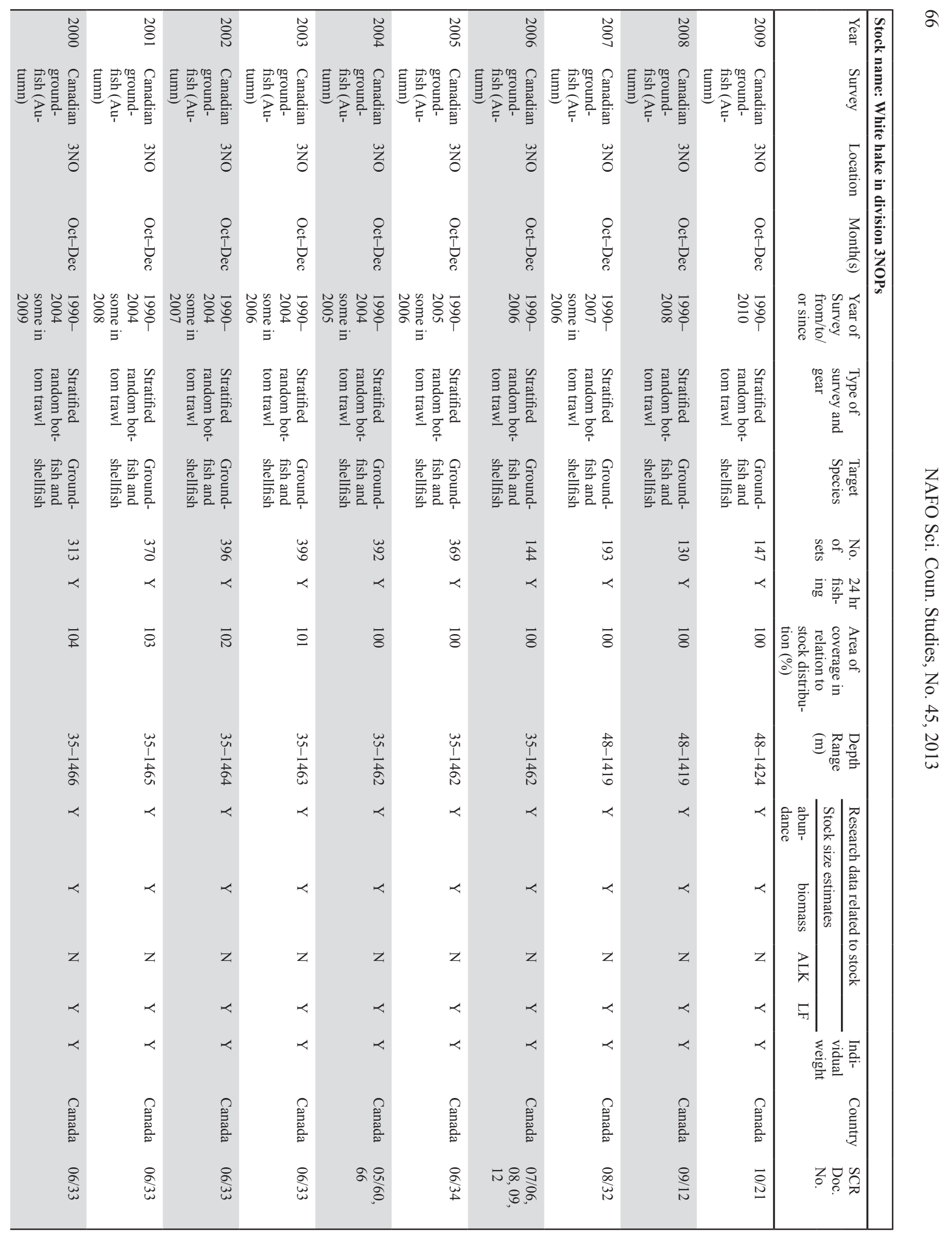




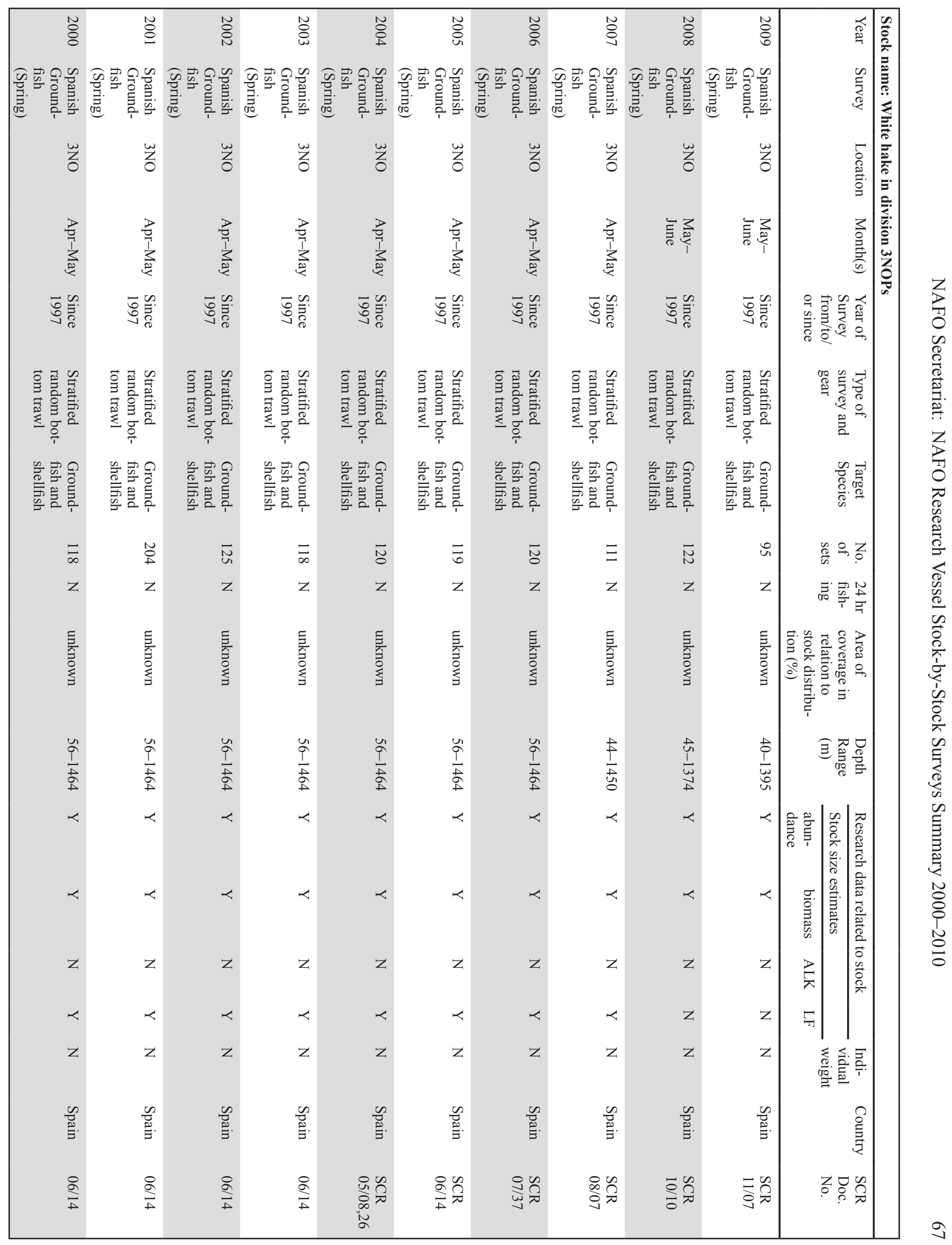




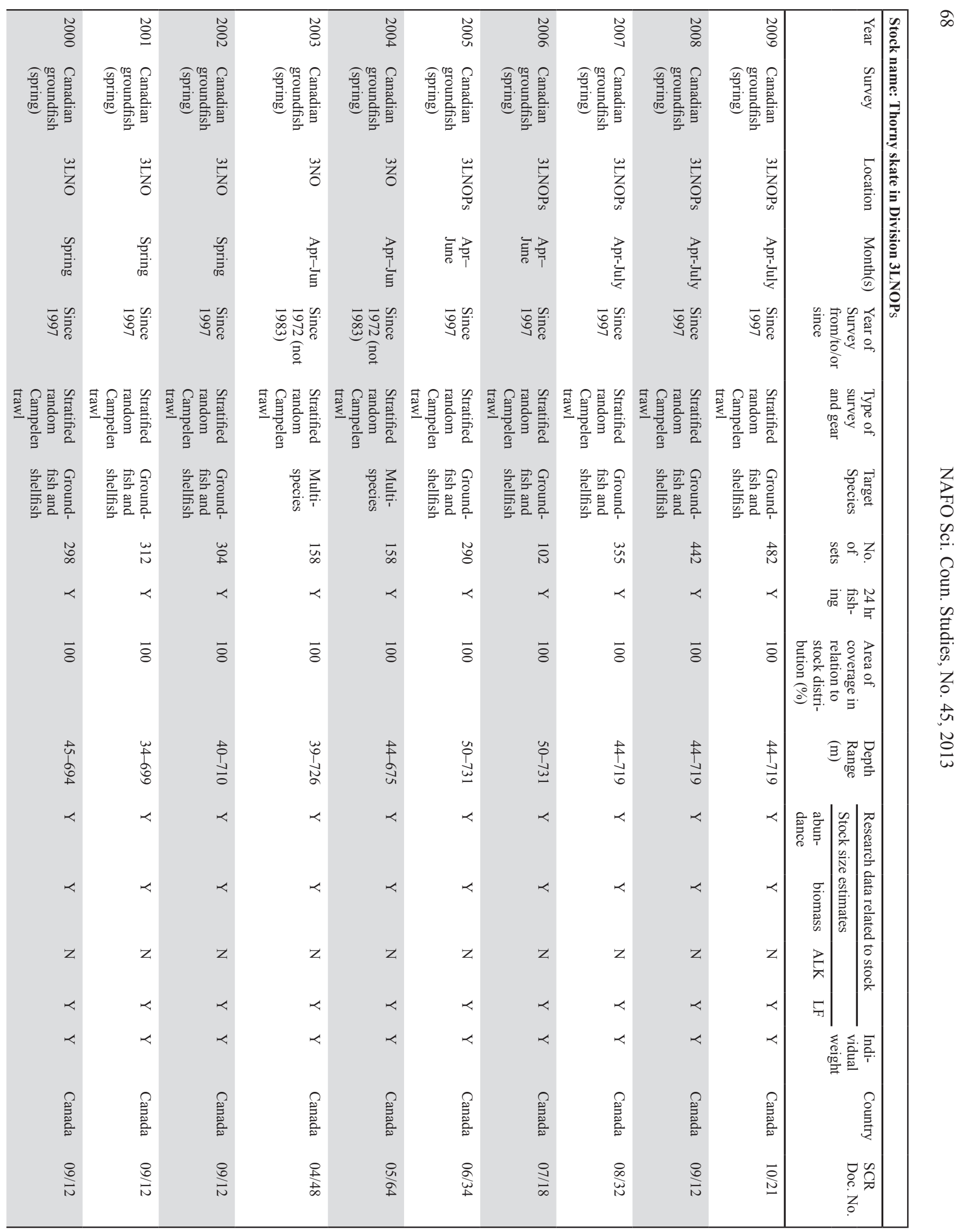




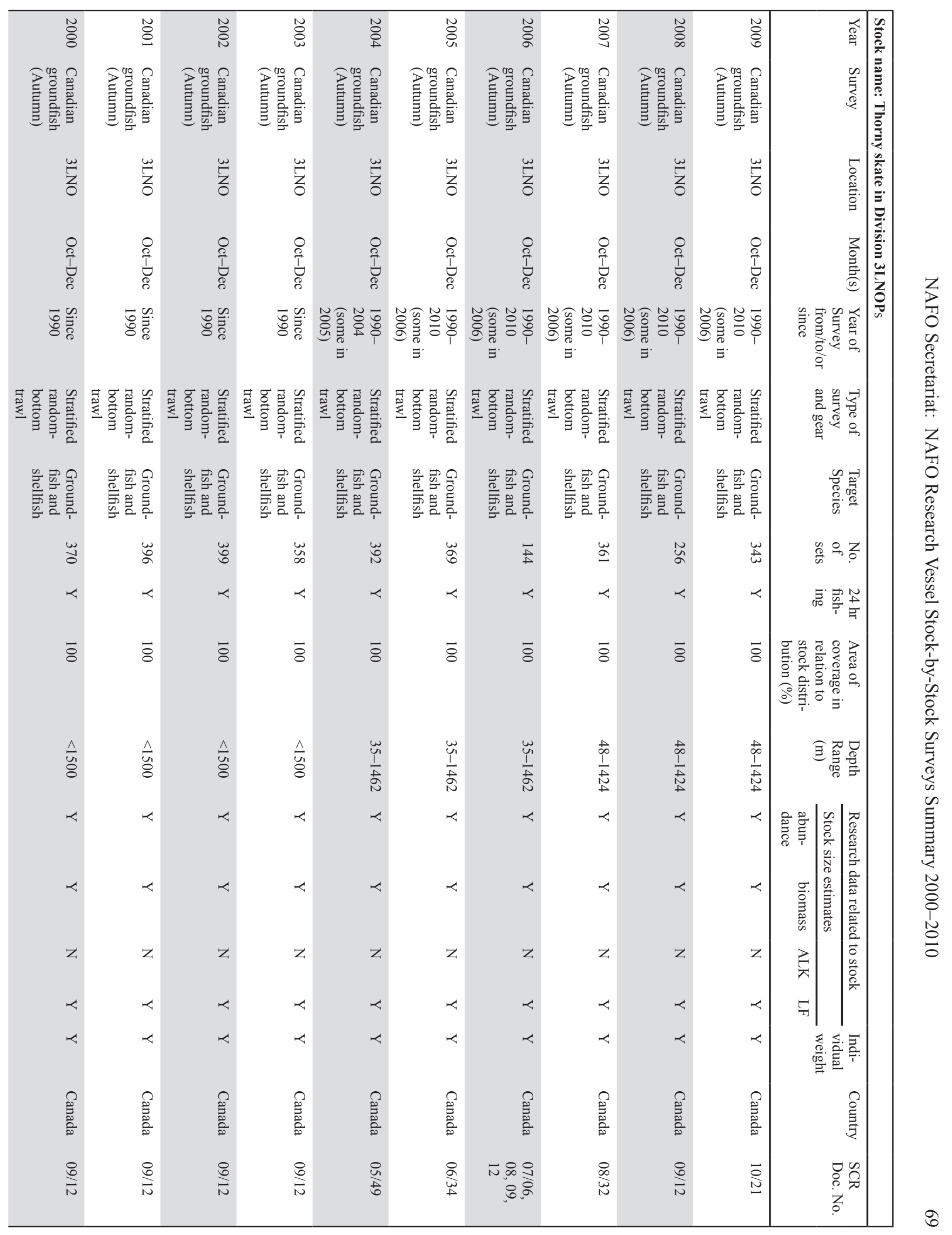




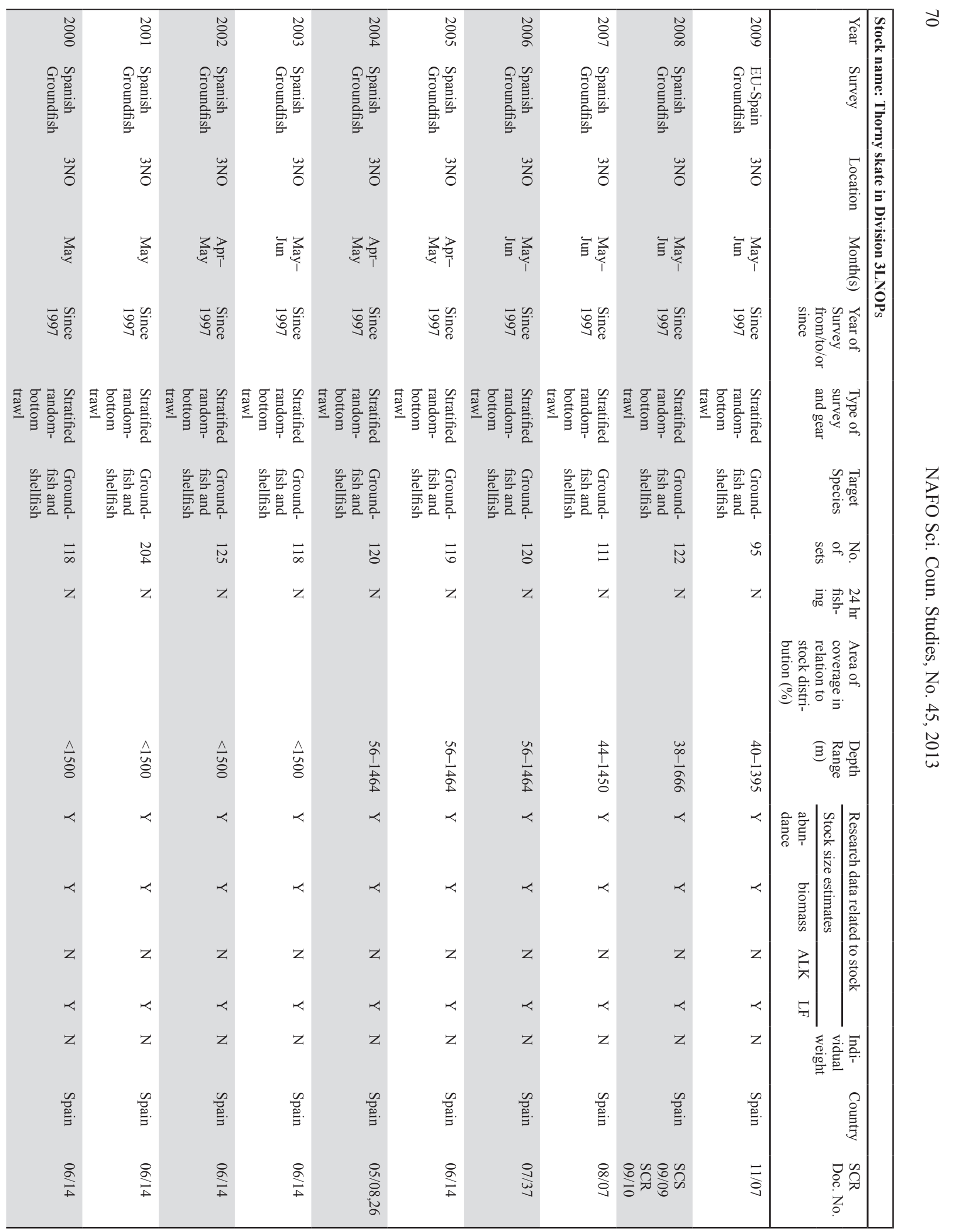




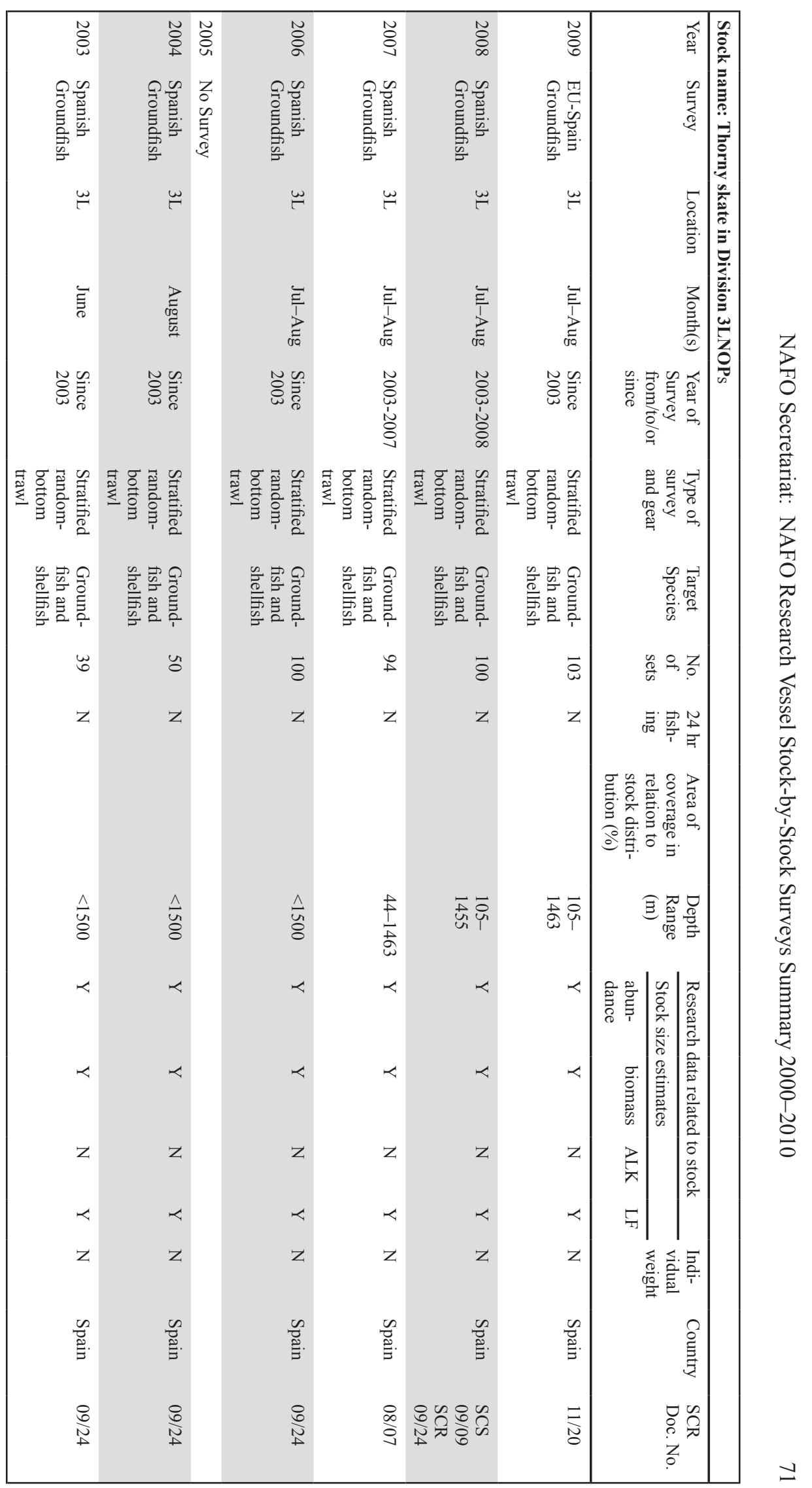




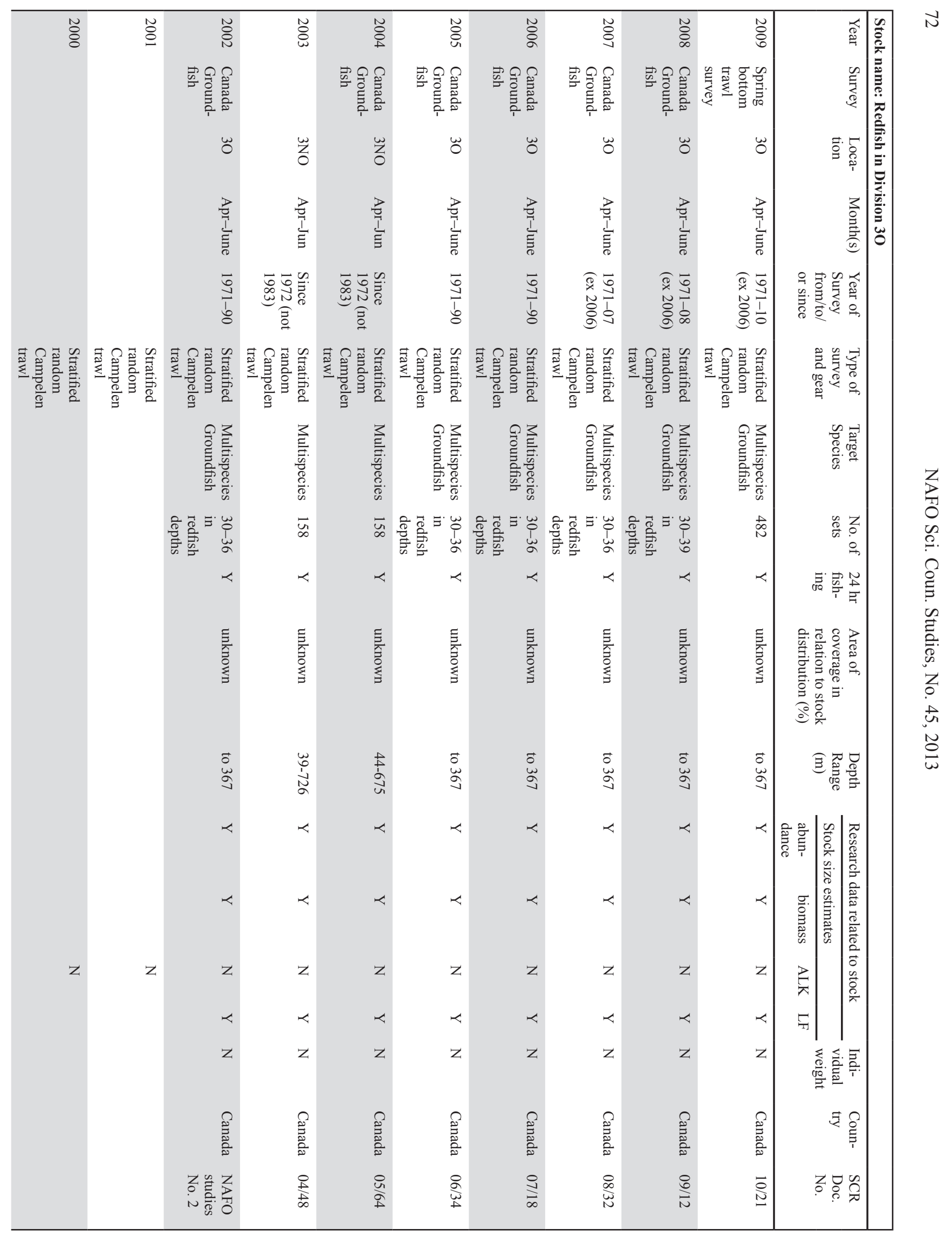




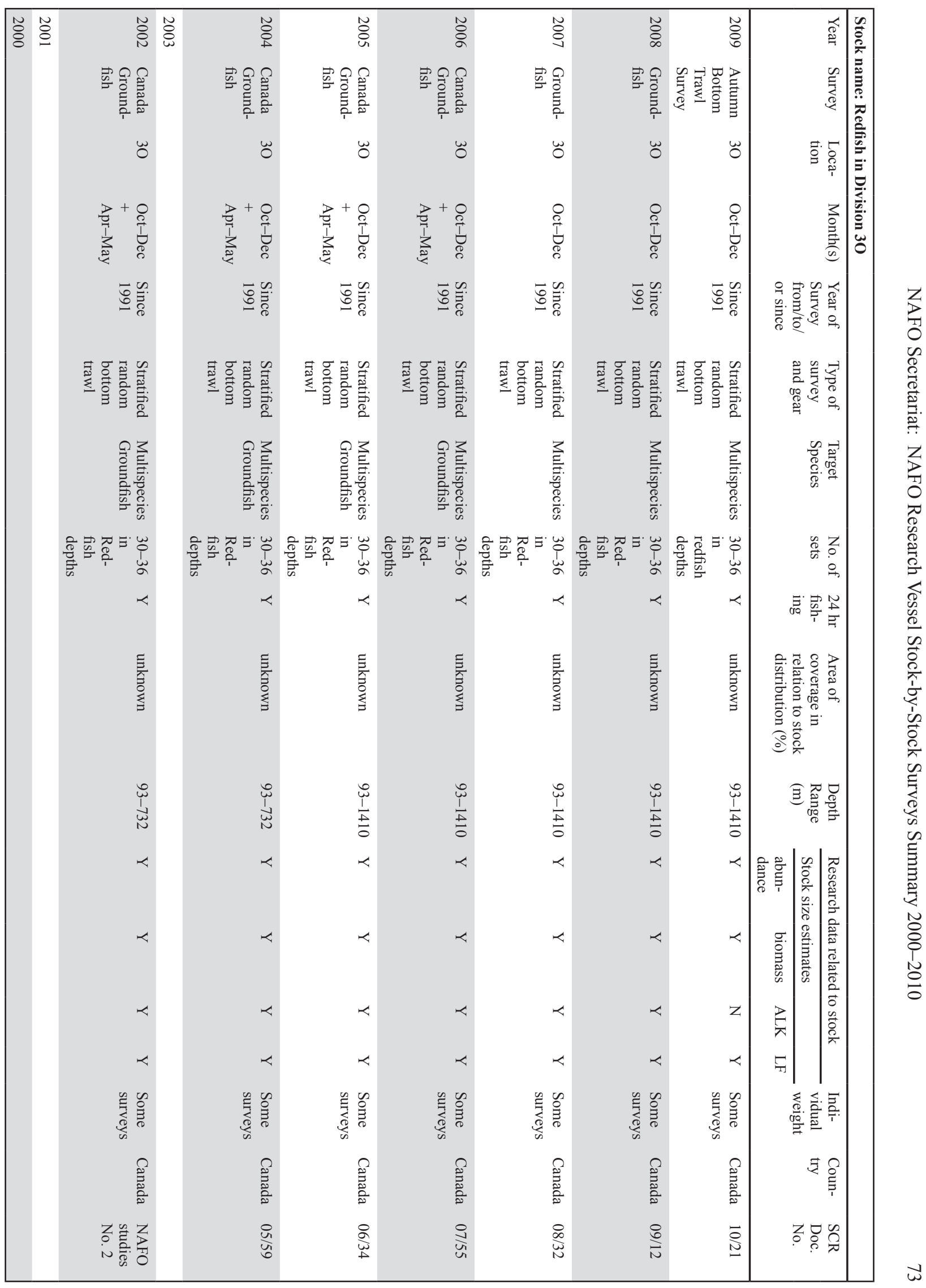




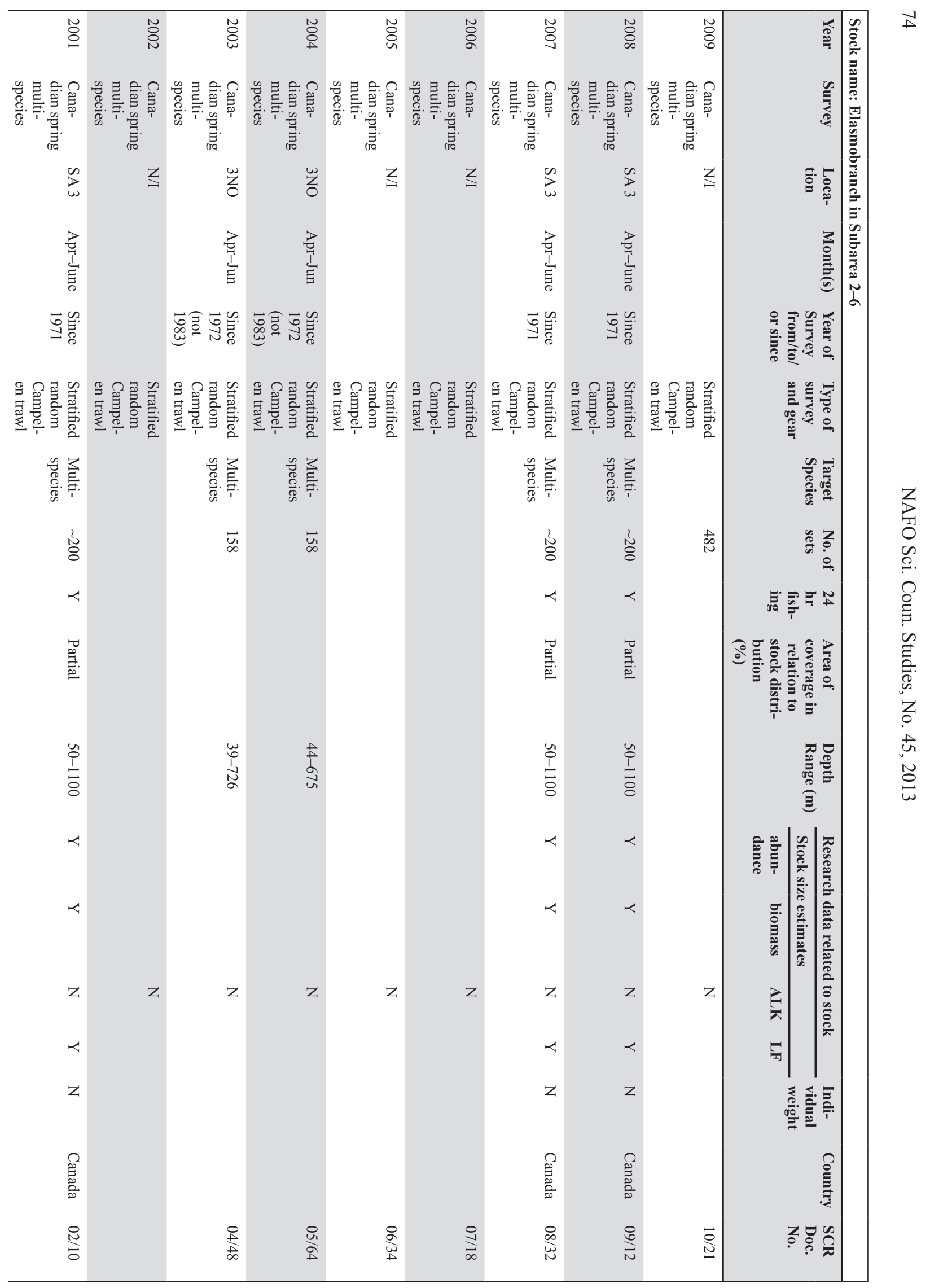




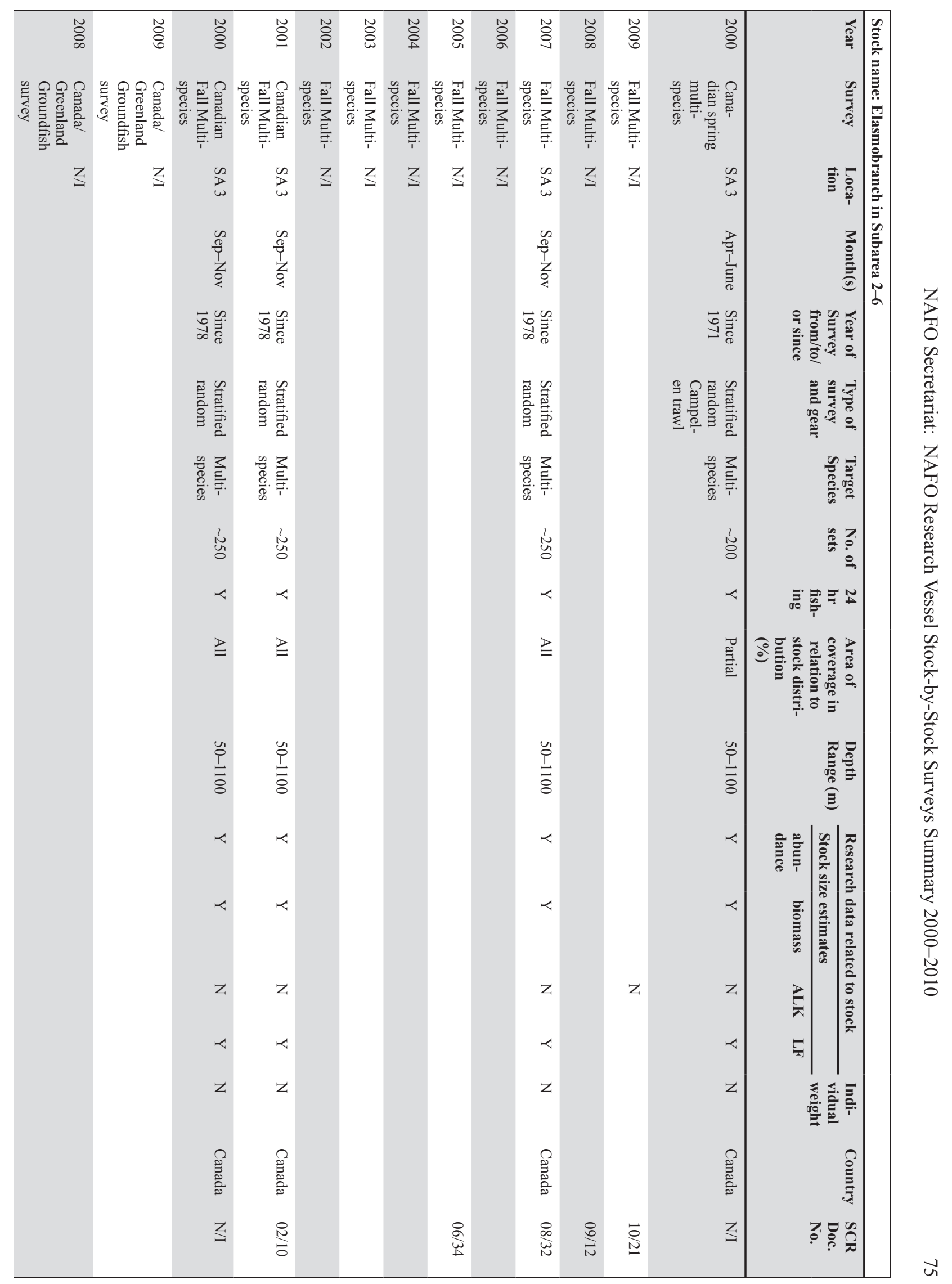




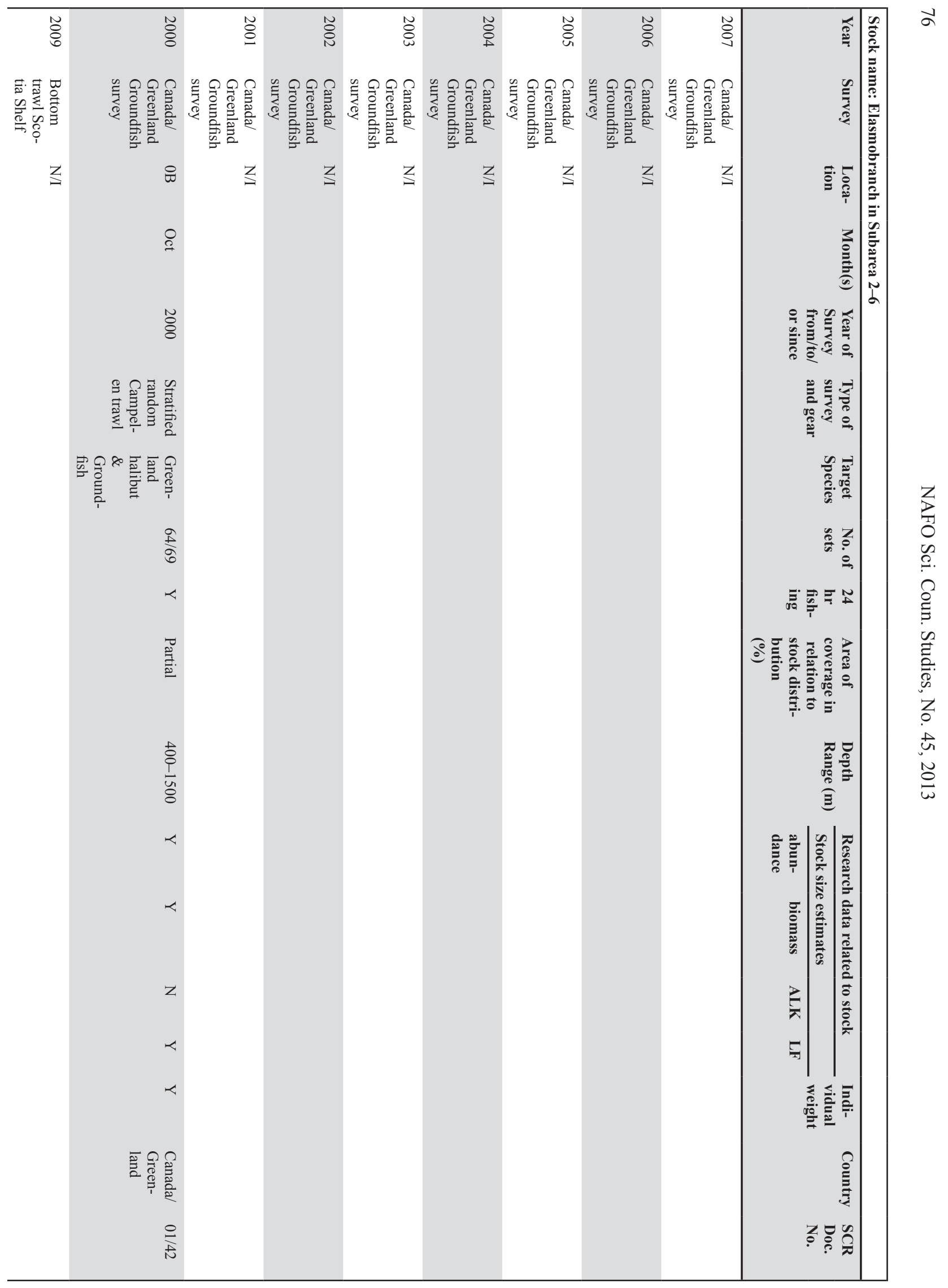




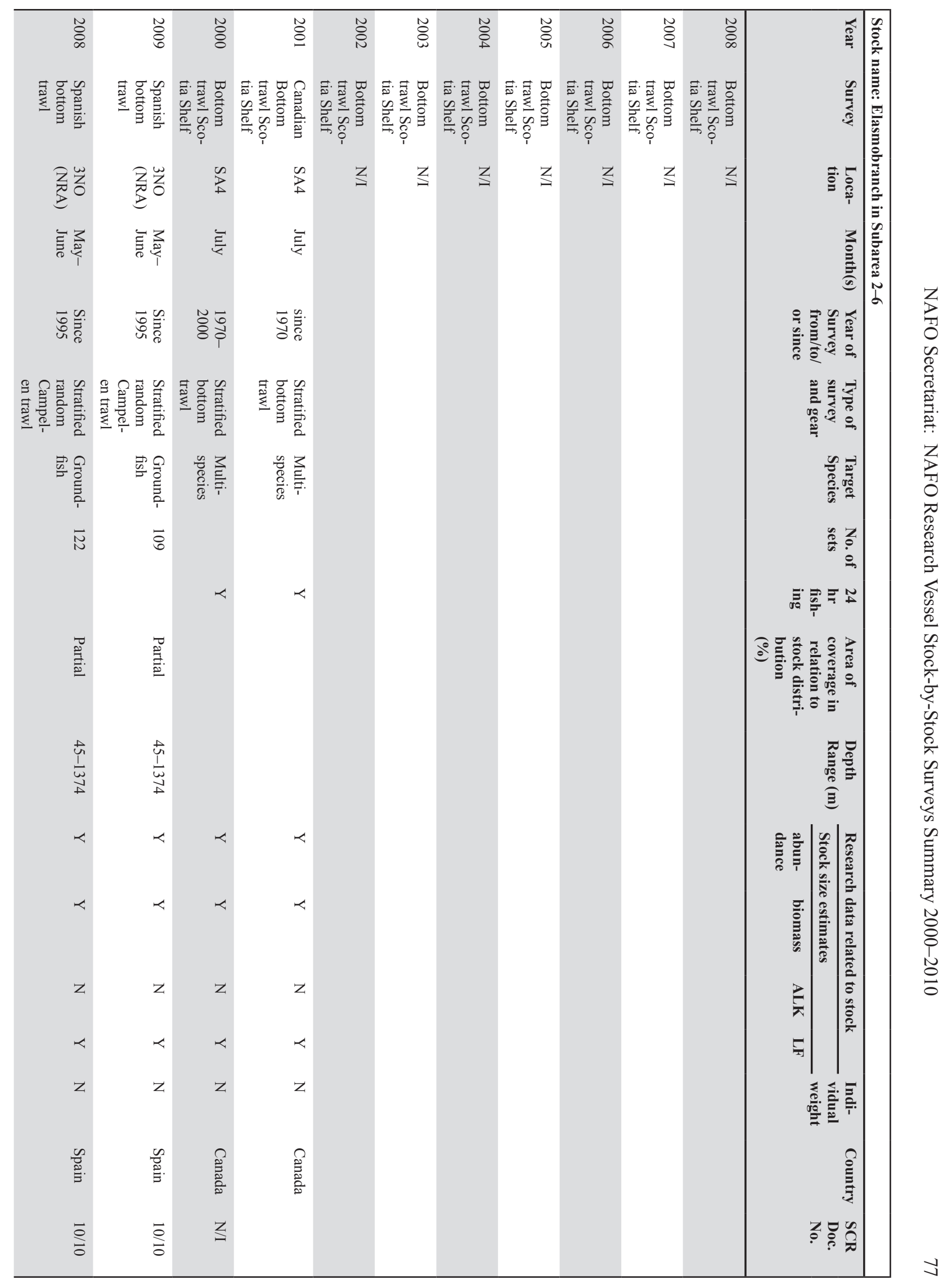




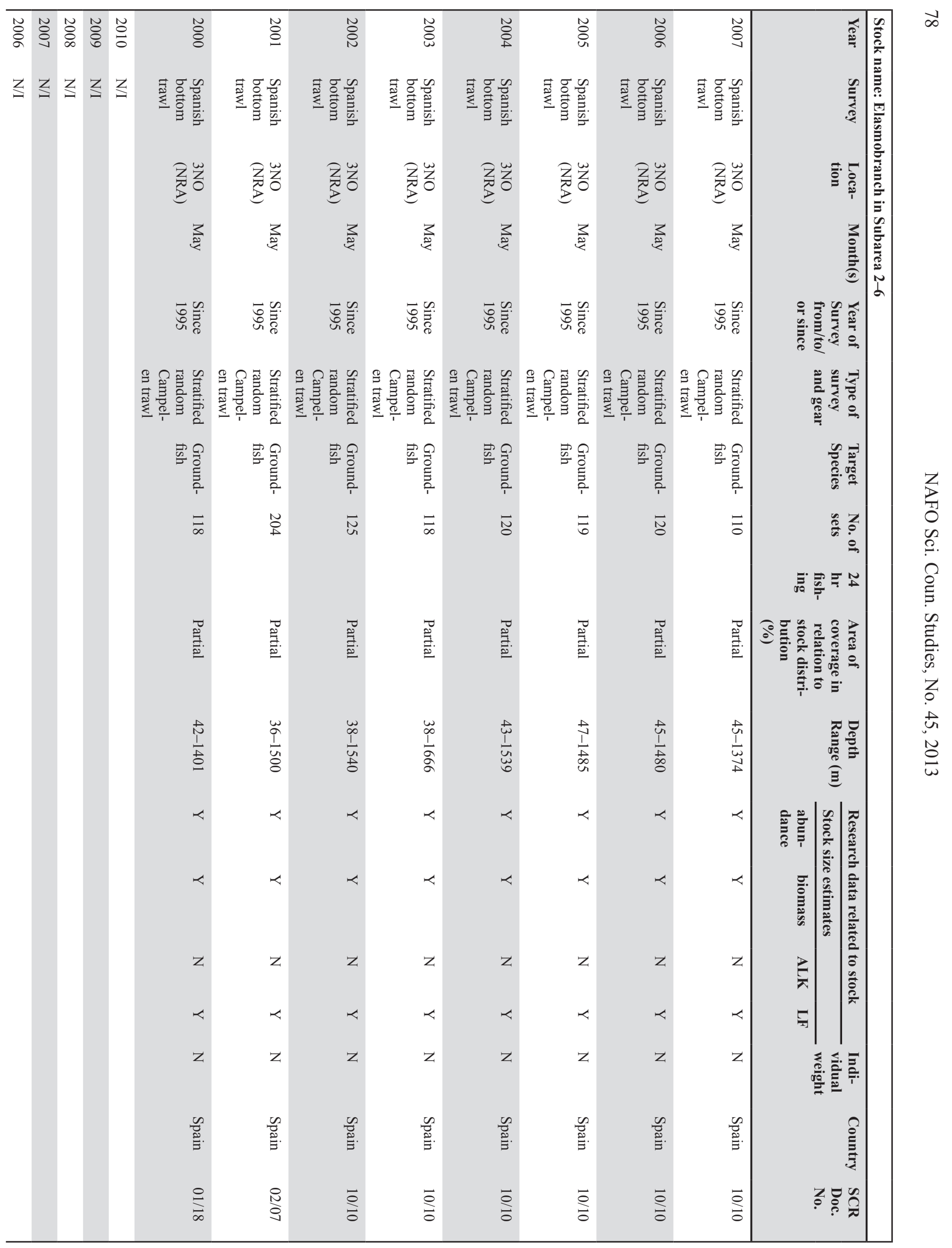




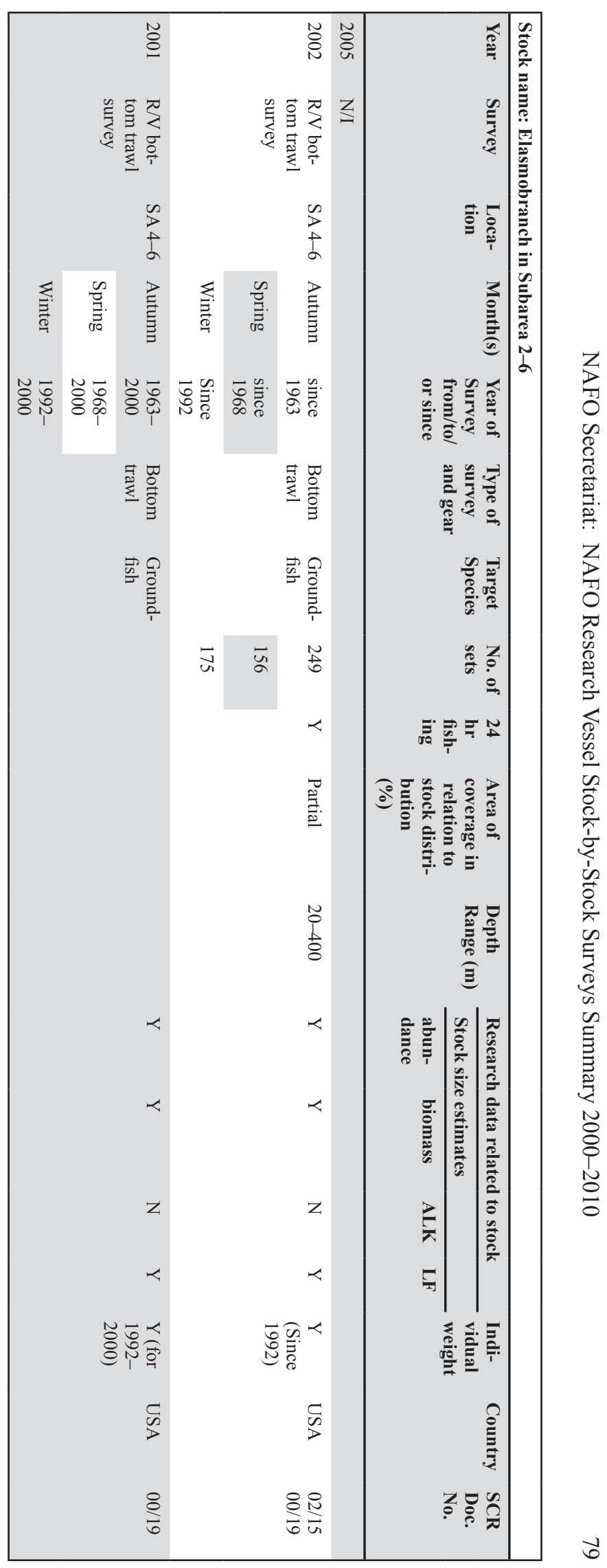




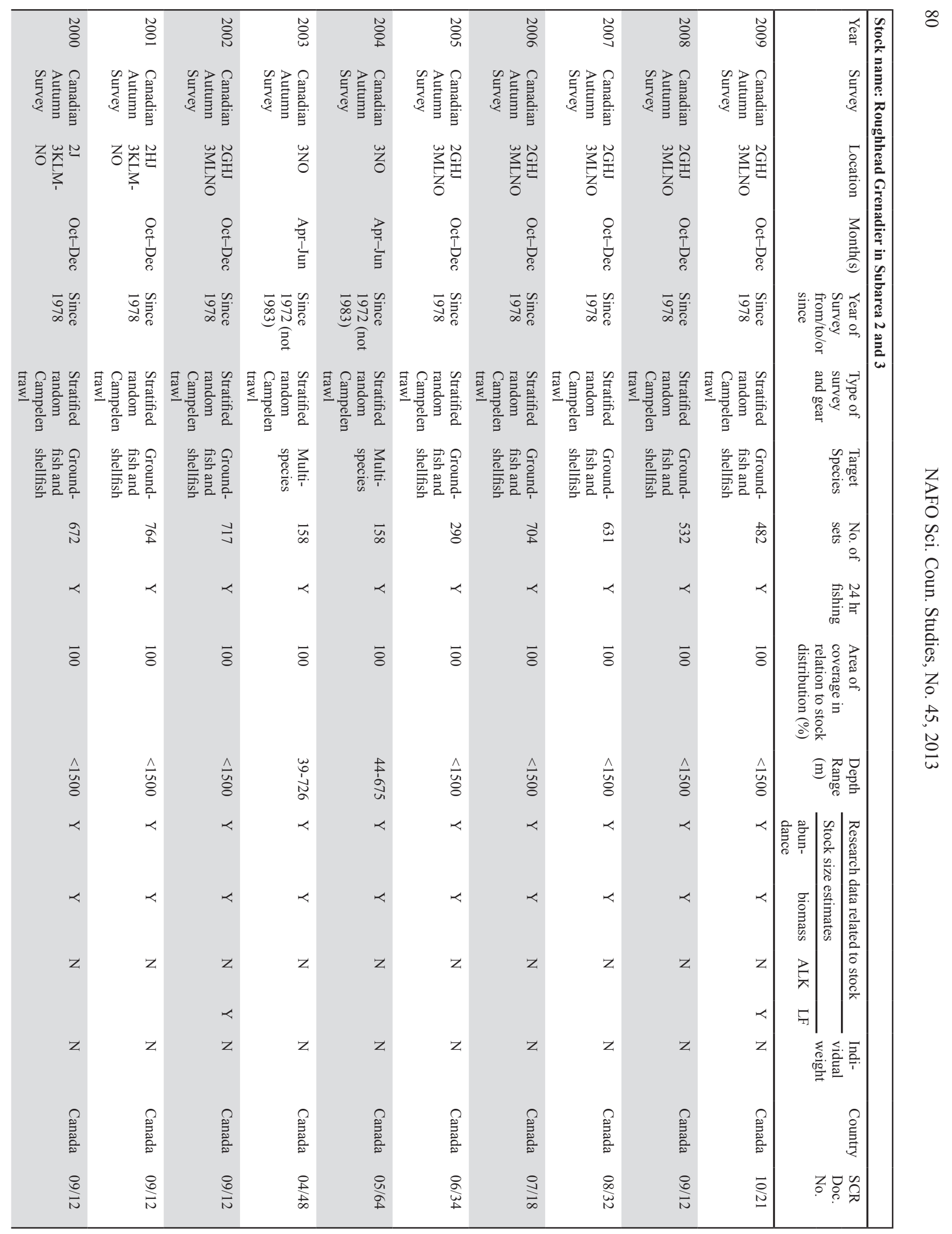




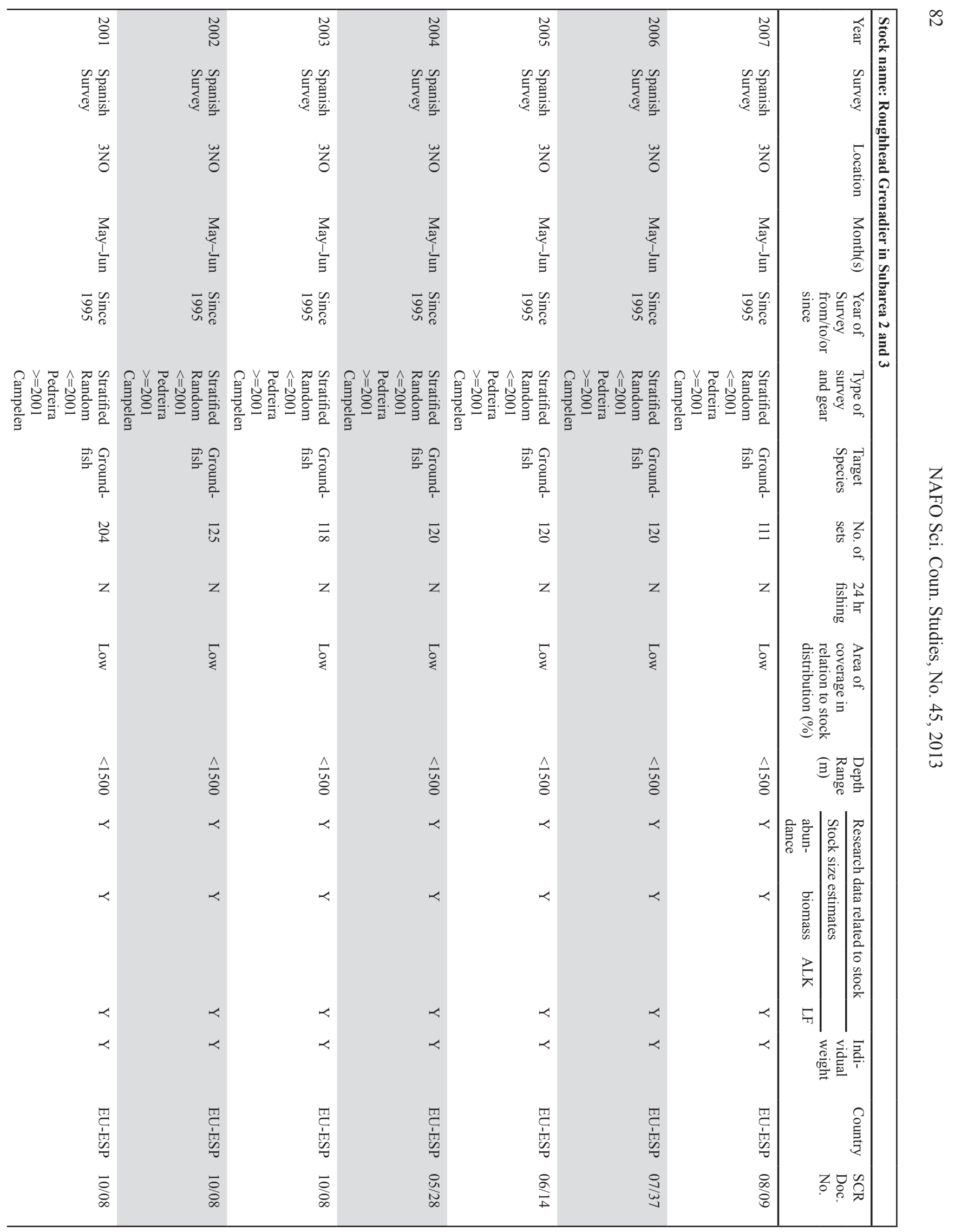




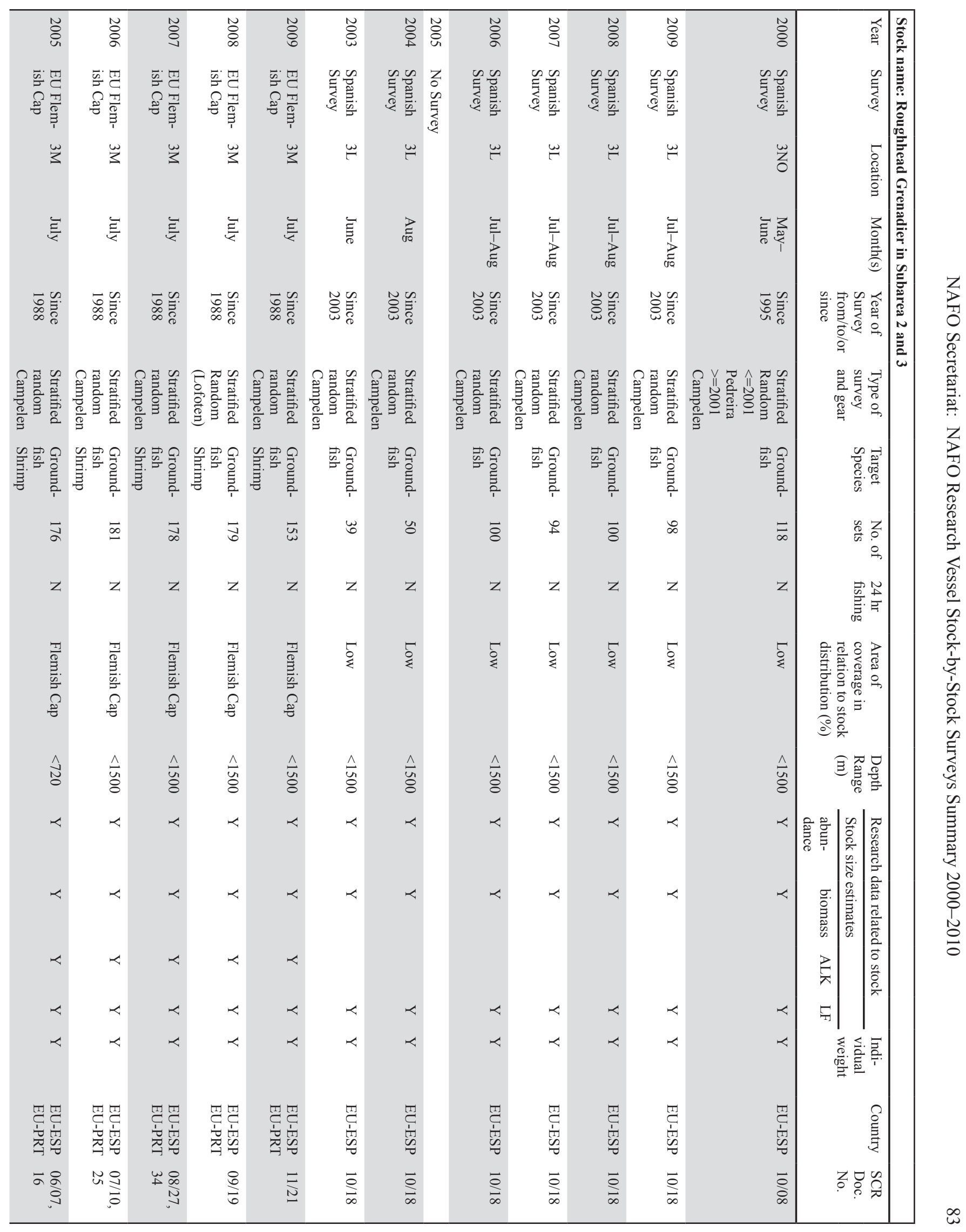




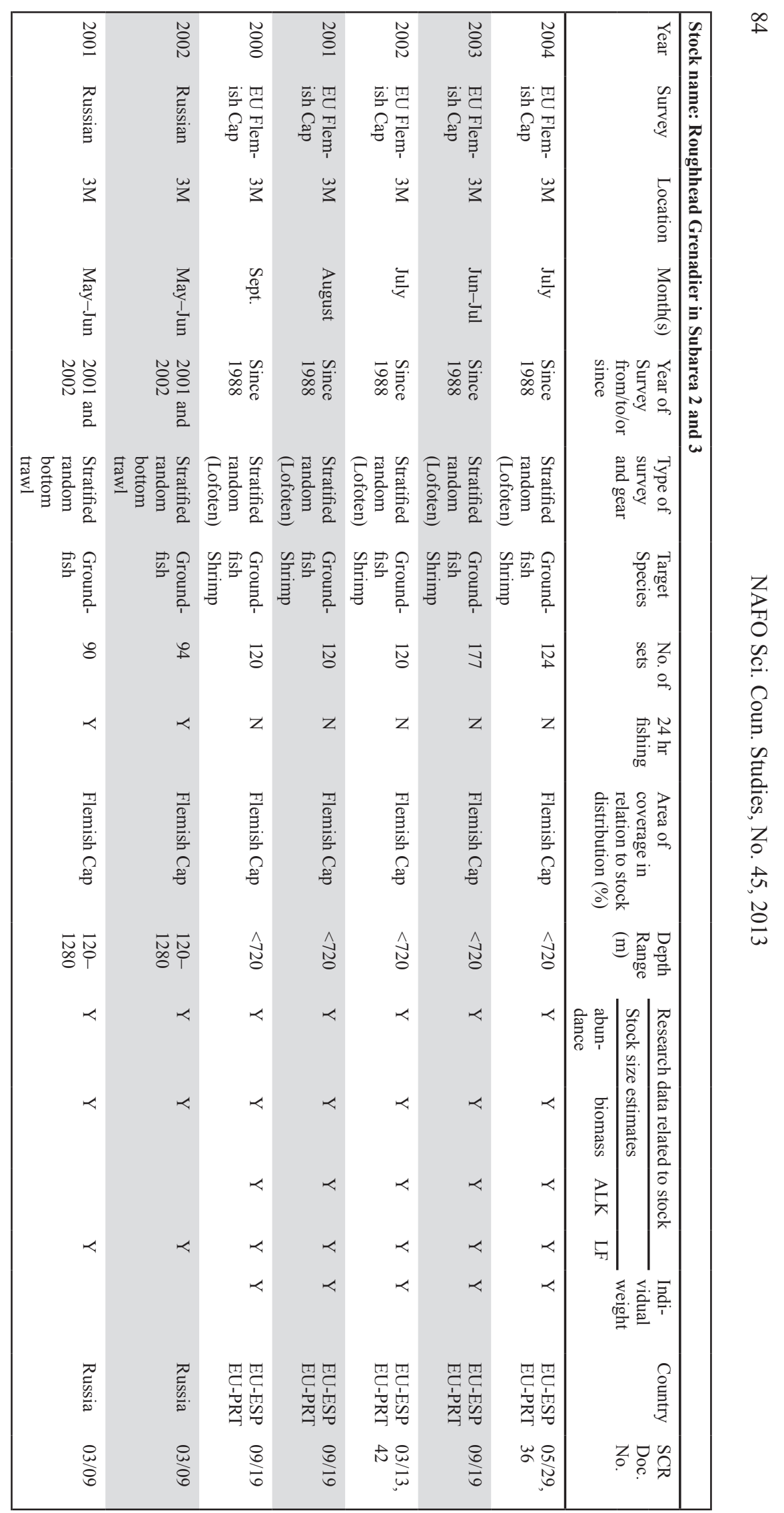




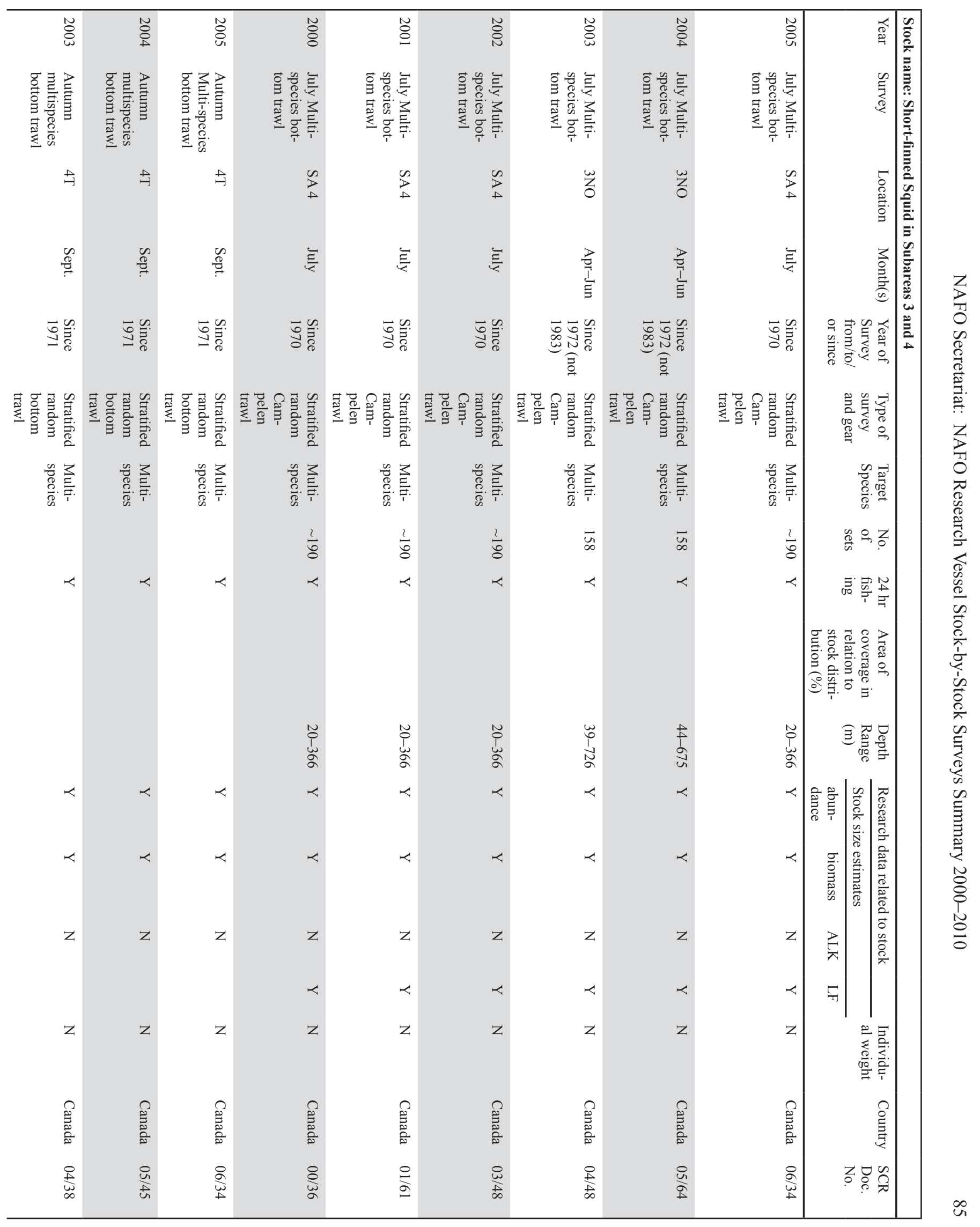




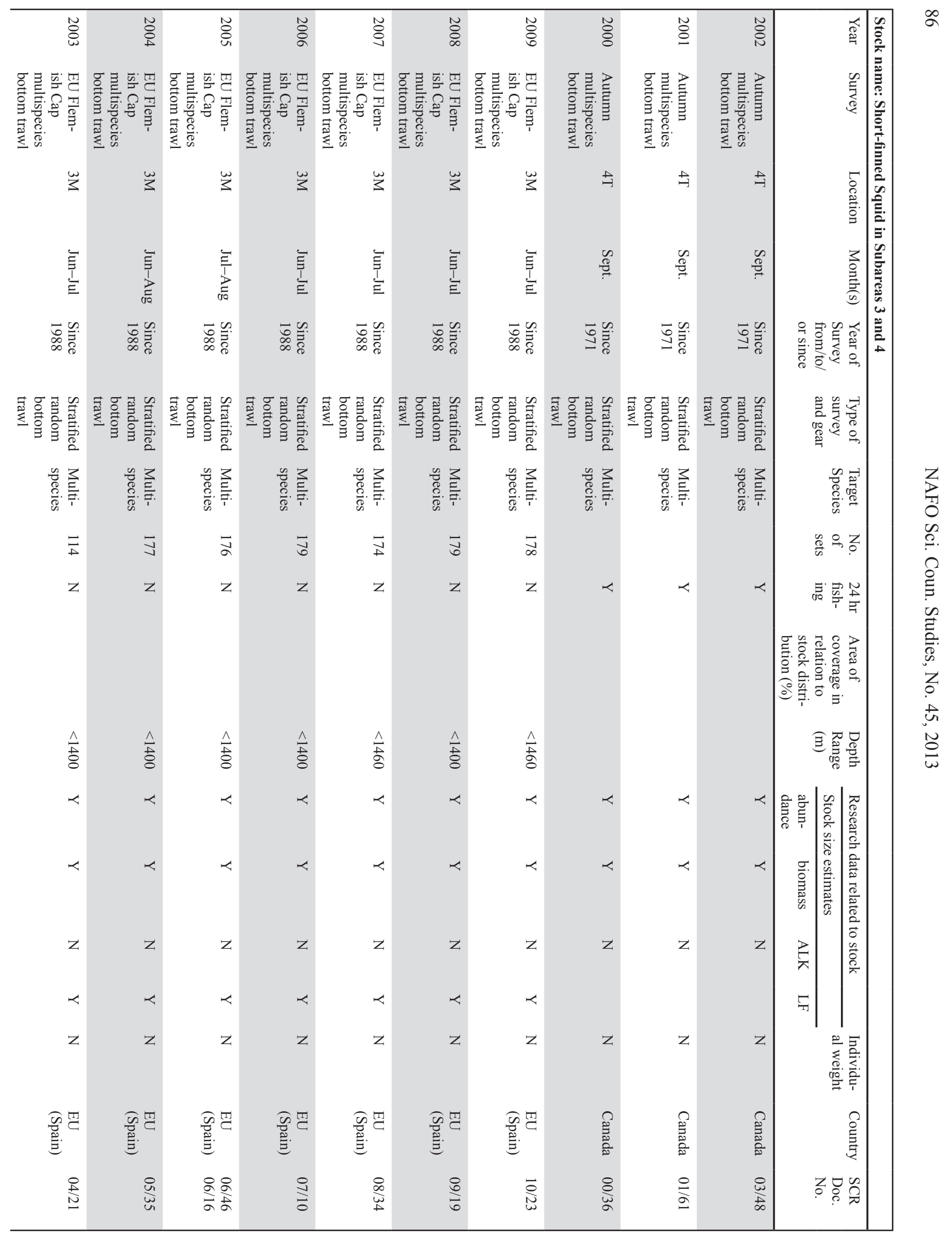




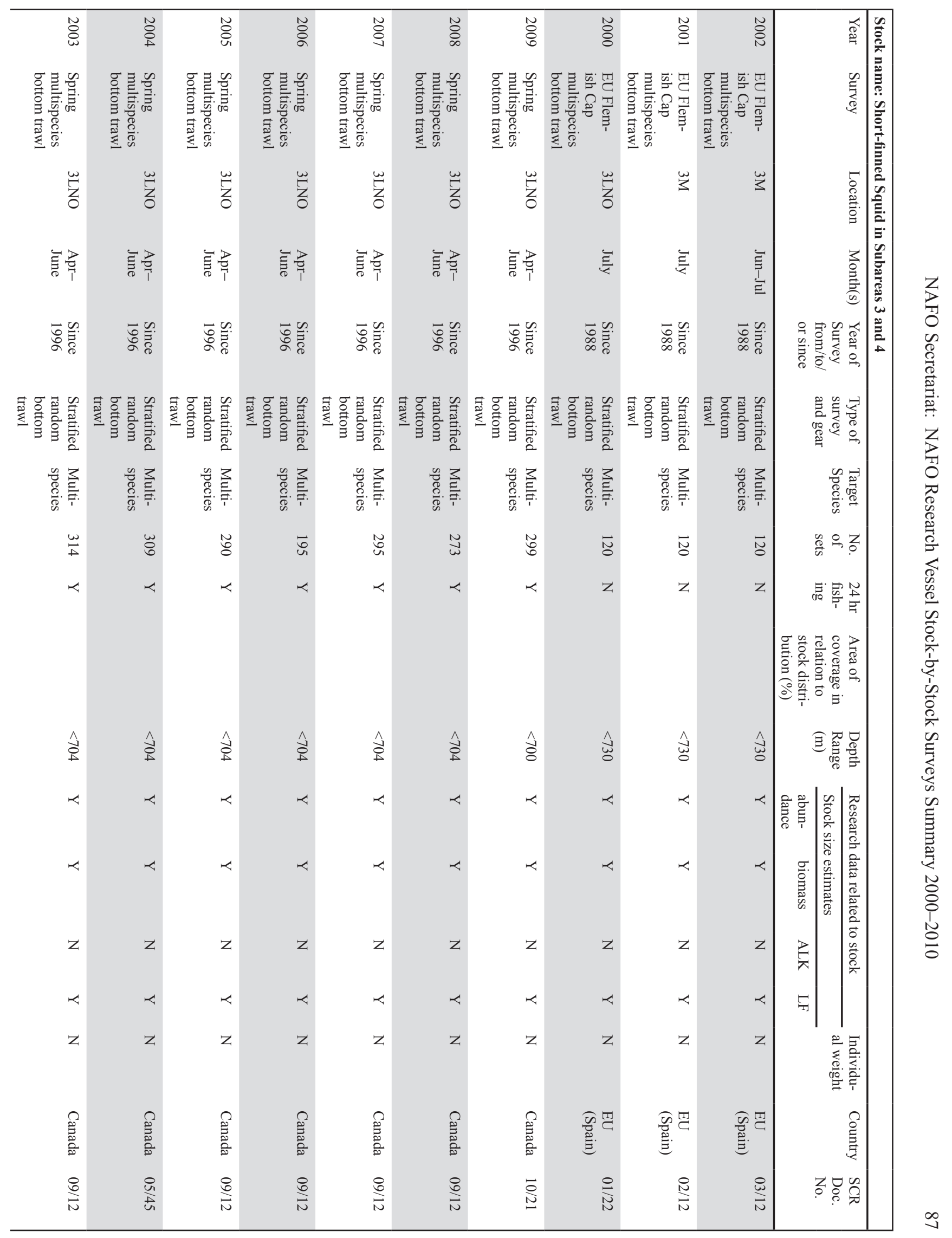




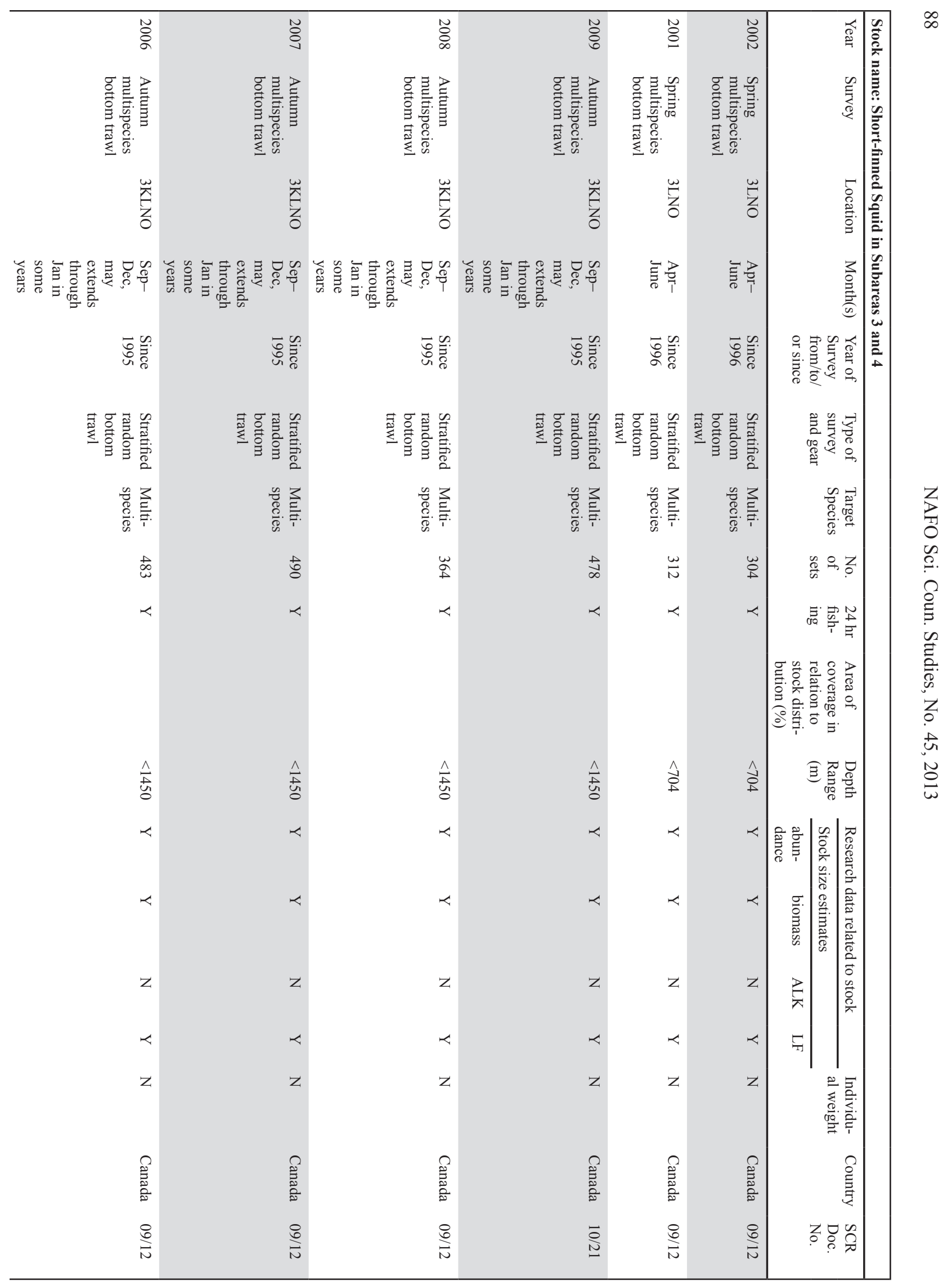




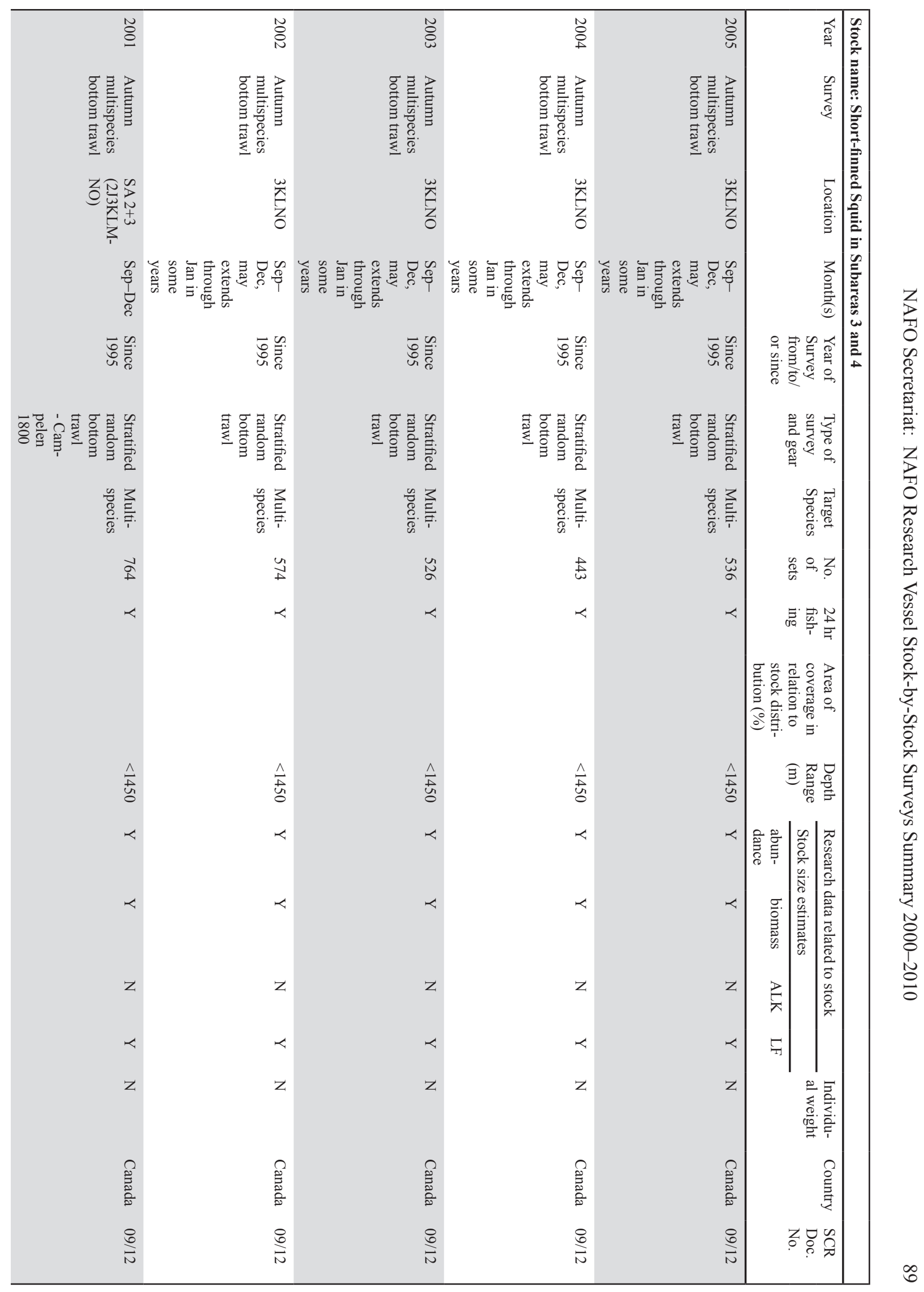




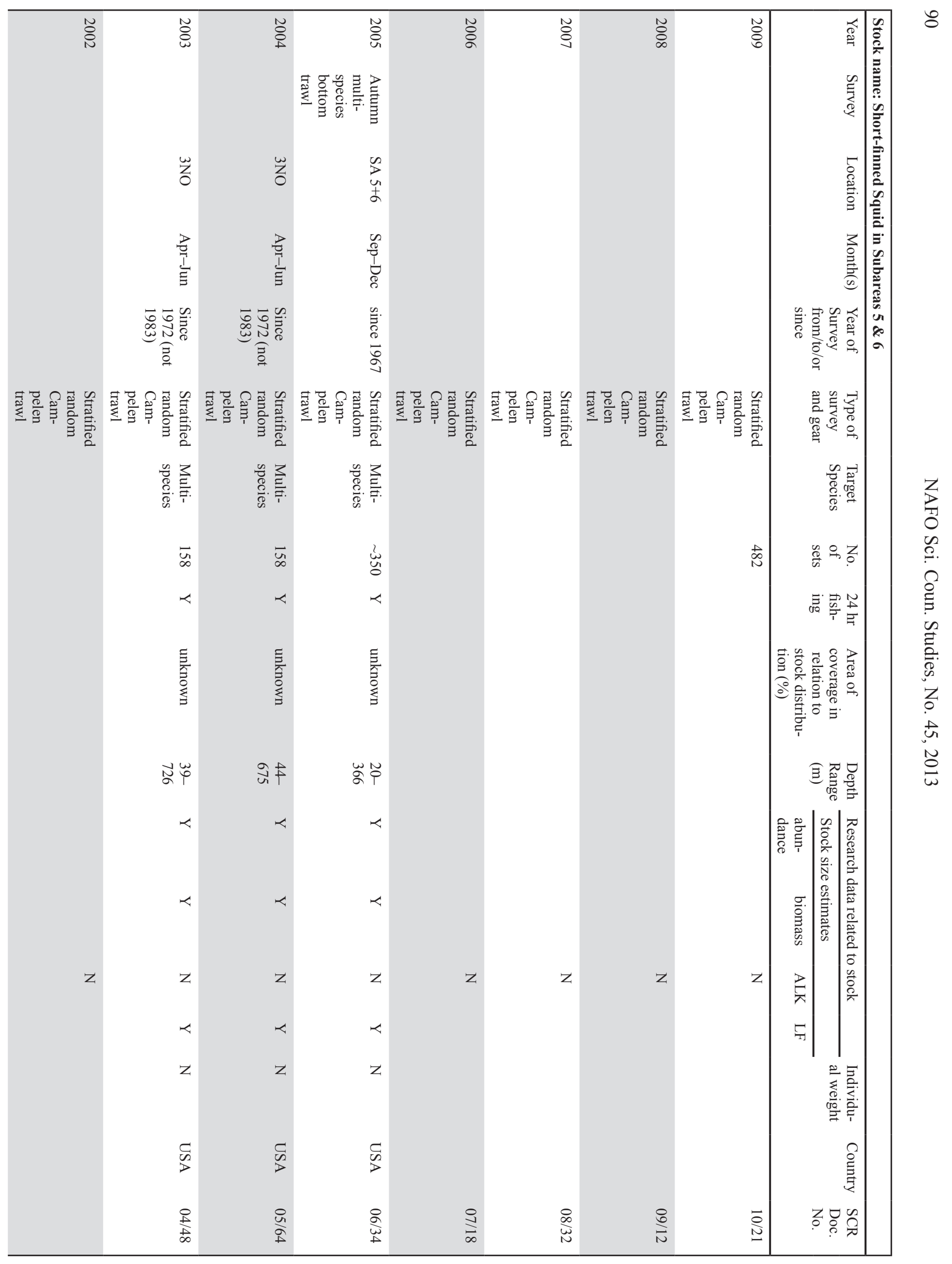




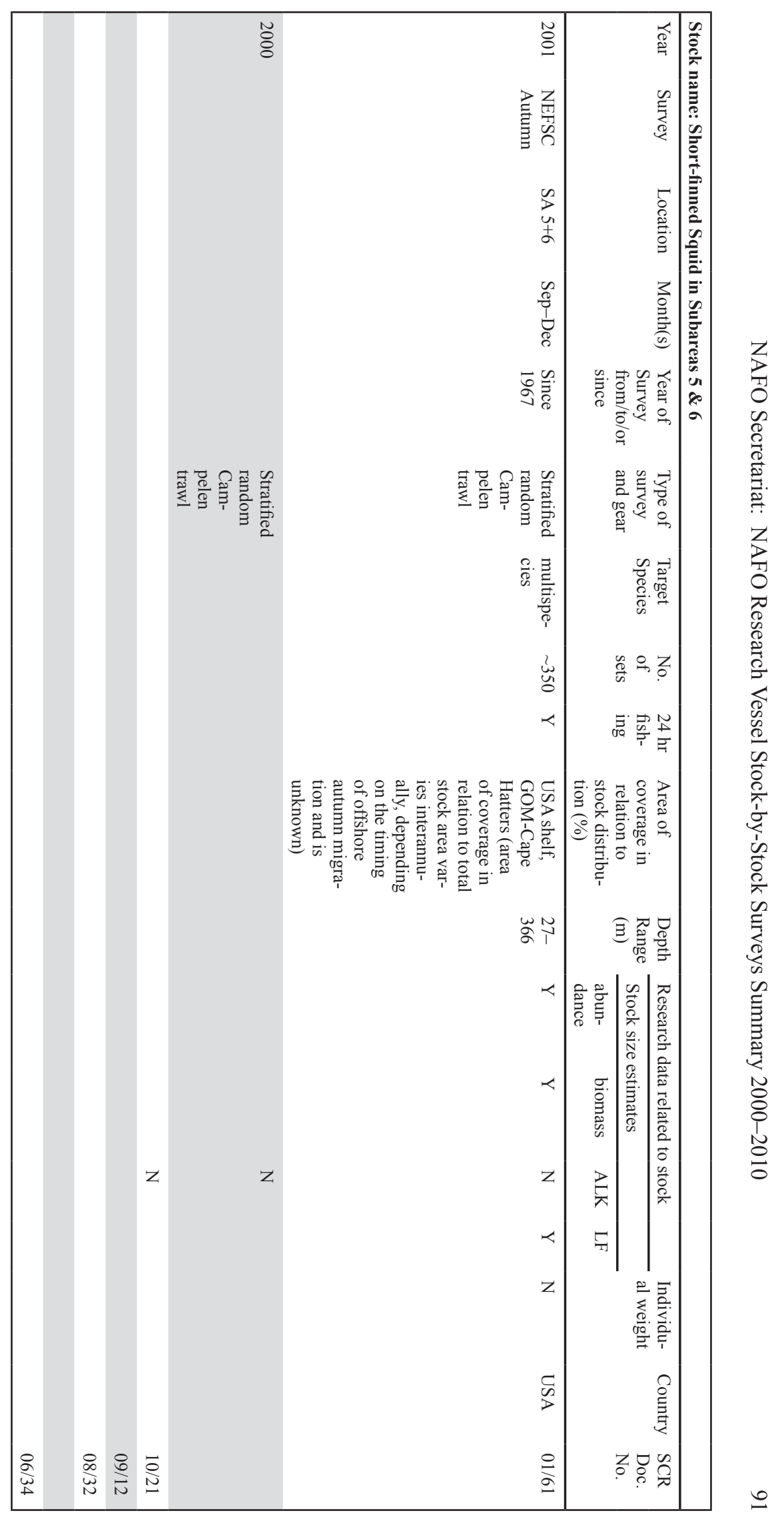

